\title{
SYNTHESIS OF HIGHER ALCOHOLS FROM CARBON MONOXIDE AND HYDROGEN \\ IN A SLURRY REACTOR
}

\author{
M. SHAWN McCUTCHEN
}

PRESENTED FOR PRELIMINARY QUALIFICATION

FOR THE DOCTORATE OF PHILOSOPHY IN

CHEMICAL ENGINEERING

AC22-90PC90043

AUGUST 28, 1992

\section{DISCLAIMER}

This report was prepared as an account of work sponsored by an agency of the United States Government. Neither the United States Government nor any agency thereof, nor any of their employees, makes any warranty, express or implied, or assumes any legal liability or responsibility for the accuracy, completeness, or usefulness of any information, apparatus, product, or process disclosed, or represents that its use would not infringe privately owned rights. Reference herein to any specific commercial product, process, or service by trade name, trademark, manufacturer, or otherwise does not necessarily constitute or imply its endorsement, recommendation, or favoring by the United States Government or any agency thereof. The views and opinions of authors expressed herein do not necessarily state or reflect those of the United States Government or any agency thereof. 


\section{TABLE OF CONTENTS}

\section{Introduction}

Current Need for Higher Alcohols 4

Incentives for Higher Alcohol Production Using Synthesis Gas 5

$\begin{array}{ll}\text { Economic Considerations } & 8\end{array}$

\section{Background and Literature Search}

Thermodynamics of Higher Alcohol Synthesis 9

Stoichiometric Impact of the Water-Gas-Shift Reaction 11

The Effect of Temperature on Reaction Behavior 12

Effect of Alcohol Recycle $\quad 20$

Phase Equilibrium with Ideal Fuids 22

Fluid Phase Non-Ideality $\quad 28$

Thermodynamic Calculations Summary $\quad 29$

Higher Alcohol Synthesis (HAS) Catalysts 31

Modified Methanol HAS Catalysts 32

Modified $\mathrm{Cu} / \mathrm{ZnO}$ Methanol Catalysts for HAS 33

Modified ZnCrO Methanol Catalysts for HAS $\quad 37$

HAS Catalysts Containing Molybdenum $\quad 60$

$\mathrm{SiO}_{2}$-Supported Mo HAS Catalysts $\quad 60$

MoS $_{2}$ HAS Catalysts

HAS Catalysts Containing Group VIII Metals 77

$\mathrm{Ru}, \mathrm{Co-Containing} \mathrm{HAS} \mathrm{Catalysts} \quad 77$

Rh-Containing HAS Catalysts $\quad 80$

HAS Catalyst Summary $\quad 86$

Novelty of Slurry Reactors $\quad 87$ 


\section{TABLE OF CONTENTS}

(continued)

\section{Research Proposal}

Overview $\quad 89$

Materials and Methods

Stirred Autoclave System 93

Autoclave Analytical System 95

Catalyst Characterization $\quad 97$

Blank Runs 98

$\begin{array}{ll}\text { Process Verification } & 98\end{array}$

High Temperature Autoclave Liquid 100

Determining Intrinsic Kinetic Conditions 101

Reactor Tracer Studies $\quad 102$

$\mathrm{ZnCrO}$ Methanol Catalyst Baseline $\quad 102$

Recycle Tests 103

$\mathrm{ZnMlo,} \mathrm{ZnW}$ and $\mathrm{MnCr}$ Catalysts 103

Altemate Research - Cs Promotion on ZnCrO Catalysts 104

$\begin{array}{ll}\text { Kinetic Model } & 104\end{array}$

$\begin{array}{ll}\text { Bibliography } & 105\end{array}$

$\begin{array}{ll}\text { Appendix A } & 110\end{array}$ 


\section{INTRODUCTION}

\section{Current Need for Higher Alcohn's}

Higher alcohols, i.e. $\mathrm{C}_{2}+$ alcohols, are of current interest as blending stocks for motor gasoline. The effect of adding oxygenated compounds, such as alcohols and e: ars, to gasoline, is to increase the octane rating of the gasoline and to decrease the emissions of carbon monoxide and unbumed hydrocarbons from the automobile. Many cities such as Los Angeles and Denver already have periods during the year when a minimum level of oxygenates is required in automobile gasoline. Even in Raleigh-Durham, the Environmental Protection Agency under the 1990 Clean Air Act is requiring certain levels of oxygenates, primarily ethanol or methyl-tertiarybutyl-ether (MTBE), in the gasoline from November to February to reduce carbon monoxide emissions. (Brooks, 1992) The push for cleaner burning fuels is evident, and alcohols are part of the solution.

Alcohols may be added directly to gasoline, as is currently being done with echanol. The use of methanol as a gasoline blending stock has been largely discontinued due to high volarility, tendency to cause phase separation and incompatibility with certain components in conventional automotive fuel systems. The addition of higher alcohols to methanol increases the water tolerance with respect to phase separation, reduces the fuel volatility and the vapor lock tendency, and increases the higher volumetric heating values. (Forzatti, 1991) Alcohols also may be reacted with olefins or other alcohols to form ethers, such as methyl-tertiary-butyl-ether (MTBE) and tertiaryamyl-methyl-ether (TAME), which are then blended into the gasoline. With modifications to the gasoline engine, higher alcohols can also be utilized as an alternate fuel, replacing gasoline. This would virtually eliminate carbon monoxide emissions from automobiles. 


\section{Incentives for Higher Alcohol Production Using Sunthesis Gas}

Efficient process technology is required to produce higher alcohols at costs that are compatible with gasoline selling prices. Current higher alcohol production processes almost exclusively use petroleum derivatives as feedstocks. Ethanol is the only higher oxygenate which currently can be produced from a non-petroleum source. Biomass or com fermentation is a main contributor to ethanol production, but this approach requires tax subsidies to deflate the apparent production costs, allowing ethanol generated from this process to be price competitive. The other method of ethanol production is the direct hydration of ethylene, a petroleum derivative, over an acidic catalyst. Iso-propanol is manufactured in a similar fashion, but the feedstock is propylene instead. The butanols are typically produced by the oxo process, i.e. the hydroformylation of an olefin. Propylene is reacted with $\mathrm{CO}$ and $\mathrm{H}_{2}$ over the appropriate catalyst to yield a mixture of normal and isobutyraldehydes, which are subsequently reduced to butanols. (Kirk-Othmer, 1981)

One al temate higher alcohol synthesis (HAS) route is the reaction of hydrogen and carbon monoxide, which takes place at about $325^{\circ} \mathrm{C}$ and 1000 psig, in the presence of catalysts containing elements such as copper, zinc, iron, molybdenum and cobalt. Mixtures of $\mathrm{H}_{2}$ and $\mathrm{CO}$, commonly referred to as synchesis gas or syngas, may be forned by reacting steam and/or oxygen at high temperatures with materials such as coal, coke, biomass, and natural gas. Herein lies a distinct advantage of the syngas HAS process. Using indigenous coal reserves, potentially even high sulfur coal, can lessen United State dependence on foreign oil. Also, syngas production can utilize what are currently considered wastes, such as petroleum coke, especially high sulfur, and agricultural wastes, sewage sludge, etc. This provides an outlet for waste streams that currently require costly and undesirable disposal.

One possible scenario for higher alcohol production involves Coal Gasification Combined Cycle (CGCC) power plants. This scenario has been specifically proposed for methanol production, but is applicable for higher alcohol synthesis as well. As shown in Figure 1A, CGCC plants consist of three major sections: coal gasification, heat recovery/impurity removal, and power generation via gas and steam turbines. A disadvantage of this configuration involves load 
Figure 1. Coal Gasification Combined Cycle (CGCC) power plant flowsheet, (A) original design, and (B) with alcohol synthesis process.
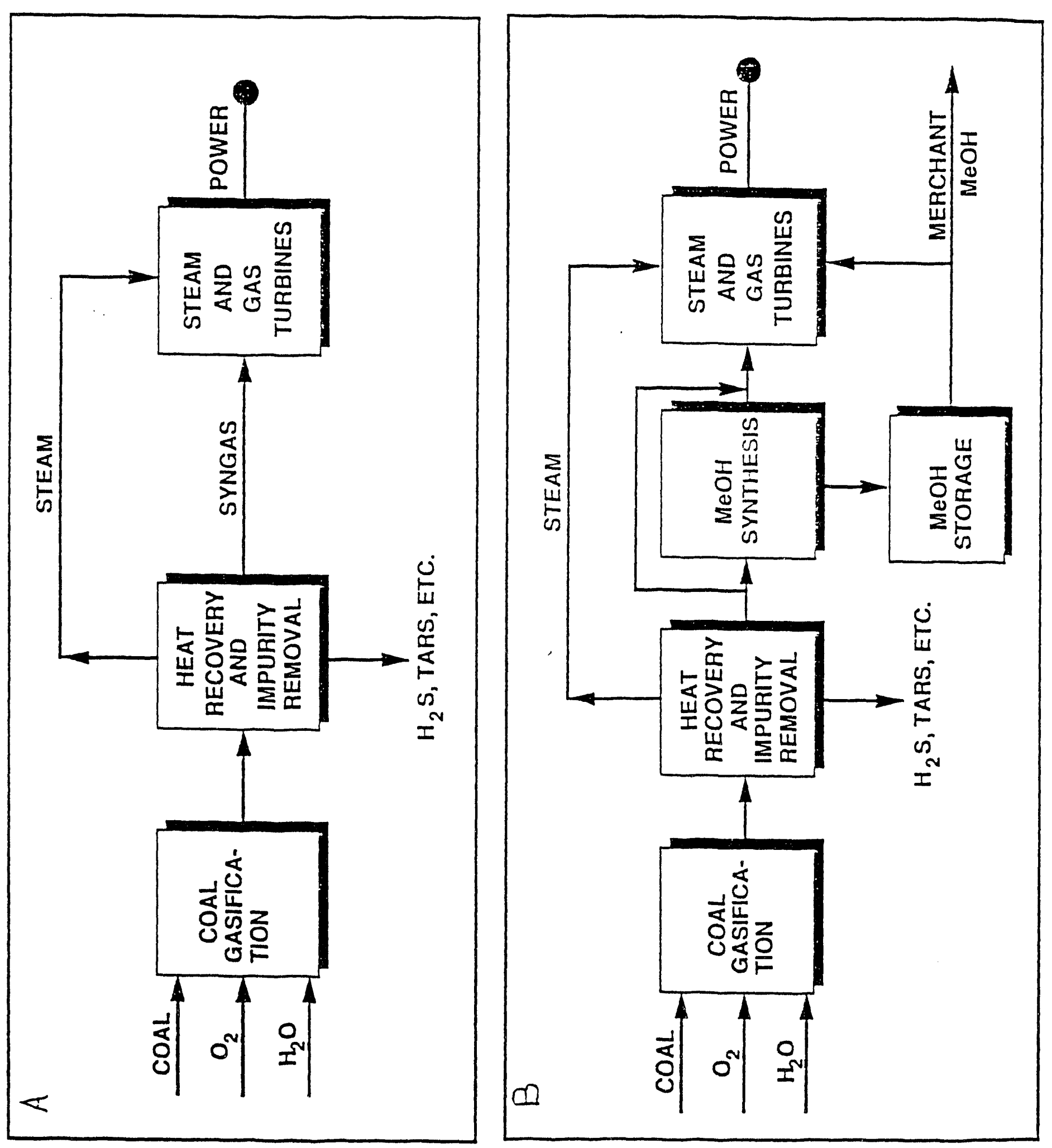
following, i.e. changing the output of the plant in response to variations in the demand for electricity. For the flowsheet of Figure 1A, load following can be done only by varying the feedrates of $\mathrm{O}_{2}, \mathrm{H}_{2} \mathrm{O}$ and coal to the coal gasifier. However, since the first two sections of the plant are very capital intensive, reducing their output results in poor utilization of capital, raising the unit cost of synthesis gas and electric power.

Figure $1 B$ shows a modification of the basic CGCC flowsheet. A methanol or higher alcohol synthesis section has been inserted between the heat recovery/gas cleanup and turbine sections, thus permitting the coproduction of alcohols and electric power. In the process of Figure 1B, the coal gasifier is always run at design capacity and the clean synthesis gas (syngas) is distributed between the alcohol synthesis section and the turbine section according to the power demand. (Brown, 1988; Moore, 1989) The alcohol produced goes to storage and the unconverted syngas is fed to the gas turbines. During periods of peak power demand, all of the synthesis gas is fed to the turbine section and the alcohols can be taken from storage and bumed as an auxiliary fuel, if necessary. At the design power load, the split of clean syngas between the alcohol synthesis and turbine sections is determined by the desired annual production rate of the alcohol products, which also determines the sizing of the gasifier, the heat recovery/gas cleanup and the alcohol synthesis sections.

The integration of methanol or higher alcohol synthesis into a CGCC plant imposes several important requirements on the alcohol process of Figure 1B. First, it should produce high conversions to the desired alcohol product on a "once-through" basis, i.e. without recycle of unconverted reactants. The extent to which power output can be reduced without reducing the output of the coal gasifier is largely determined by the fraction of the energy content in the syngas entering the alcohol synthesis section that can be converted to alcohols. Secondly, the process should be compatible with modem, thermally-efficient coal gasifiers of the entrained-flow, slagging type. Such gasifiers produce synthesis gas with $\mathrm{H}_{2} / \mathrm{CO}$ ratios in the range of 0.5 to 1 , far removed from the sioichiometric ratio of 2.0 for methanol and higher alcohol synthesis. The alcohol process of Figure $1 \mathrm{~B}$ should be able to accept a $\mathrm{CO}$-rich synthesis gas directly from the gas 
cleanup/heat recovery section without a water-gas shift step prior to the methanol or higher alcohol synthesis section.

\section{Economic Considerations}

If sufficient technical progess is made, the syngas HAS process could potentially be economically competitive with the existing HAS processes. The issues which will be considered during HAS research to enhance cost competiveness are:

- Catalyst activity. High catalyst activity will decrease the amount of catalyst required per unit of alcohol produced, thereby reducing the required reactor size for a set production rate. This will reduce equipment capital costs. Increased activity also increases feed gas conversion, reducing recycle of unconverted feed gas. This decreases recycle compressor capital and operating costs, which can be the most expensive costs in a chemical plant. Also, if the unconverted syngas is not recycled, but instead burned as fuel, increasing conversion will decrease the cost penalty associated with producing the unconverted syngas which is subsequently burned as a low grade fuel.

- Catalyst selectivity. High selectivity for alcohols, like activity, will decrease reactor costs for a set production rate. Also, the large cost penalty generated by the low value of the undesired byproducts (primarily mechane, other low-molecular-weight hydrocarbons, methanol, and $\mathrm{CO})$ would also decrease with increasing selectivity.

- Operating conditions. The less severe operating conditions (temperature, pressure, etc.) required, the cheaper the capital investment in a plant, and the lower the required plant main:enance. 


\section{BACKGROUND AND LITERATURE SEARCH}

\section{Thermodvnamics of Higher Alcohol Sunthesis}

Before investigating different higher alcohol synthesis catalysts, which have an impact only on kinetically controlled systems, a thermodynamic analysis is needed to determine: 1) the thermodynamically favored product distribution; 2) the maximum higher alcohol yield from synthesis gas; 3) the effects of operating variables (i.e., temperature , pressure, etc.) on the reaction equilibrium, and what conditions are most favorable thermodynamically for higher alcohol formation, and; 4) the effects of product recycle on the reaction equilibrium. Although in real HAS catalytic systems complete chemical and phase equilibrium is not obtained, a thermodynamic study helps clarify the boundaries and constraints that thermodynamics imposes on process and catalyst development.

Natta, et.al. (1957) illustrated that hydrocarbons are favored thermodynamically over oxygenates, including higher alcohols, at the temperatures $\left(225^{\circ} \mathrm{C}\right.$ to $\left.525^{\circ} \mathrm{C}\right)$ considered. Pressure effects were not examined. Therefore, a catalyst must be selective to oxygenate formation, and specifically to higher alcohols if higher alcohol synthesis is desired. Assuming such a catalyst exists, a recently completed study by the author and coworkers (Mawson, et.al. 1992) examined the thermodynamics of higher alcohol synthesis from synthesis gas. The thermodynamics were investigated by calculating the equilibrium composition of a system containing $\mathrm{CO}, \mathrm{H}_{2}, \mathrm{CO}_{2}, \mathrm{H}_{2} \mathrm{O}$ and all of the possible isomers of the $C_{1}$ through $C_{4}$ alcohols. $C_{5}+$ alcohols were not considered to decrease the complexity of the calculations. The reactions included in the study were:

Alcohol Synthesis:

$$
\begin{aligned}
& \mathrm{nCO}+2 \mathrm{n} \mathrm{H}_{2} \rightleftarrows \mathrm{C}_{\mathrm{n}} \mathrm{H}_{(2 \mathrm{n}+1)} \mathrm{OH}+(\mathrm{n}-1) \mathrm{H}_{2} \mathrm{O} \\
& \text { where } \mathrm{n}=1,2,3,4
\end{aligned}
$$


Water Gas Shift:

$$
\mathrm{CO}+\mathrm{H}_{2} \mathrm{O} \rightleftarrows \mathrm{CO}_{2}+\mathrm{H}_{2}
$$

Thermodynamic equilibrium calculations were performed using the Gibbs free energy minimization module in the ASPEN PLUS ${ }^{\text {TM }}$ process simulation package. Parametric studies were carried out to define the effects of temperature, total pressure, $\mathrm{H}_{2} / \mathrm{CO}$ ratio, the presence or absence of the water gas shift reaction and the recycle of certain alcohol species, based on the assumption that the final system is an ideal gas. Calculations were also done to determine the conditions under which the product can form two or more phases, and whether the formation of multiple phases has a significant effect on reactant conversion or product yield. The effect of fluid-phase non-idealities was also investigated. A discussion of the more relevant items follorvs.

Two definitions are essential for complete understanding of the material that follows. For the reactants, $\mathrm{CO}$ and $\mathrm{H}_{2}$, the results are expressed in terms of the percentage conversion, $X_{i}$, defined as:

$$
X_{i}=\frac{(\text { moles } i \text { in }- \text { moles } i \text { out })}{(\text { moles } i \text { in })} \times 100
$$

For the products, the results are expressed as the fractional yield of product $i$ based on moles of carbon converted, $\mathrm{Y}(\mathrm{i} / \mathrm{MCC})$, defined as:

$$
Y\left(\frac{i}{\mathrm{MCC}}\right)=\frac{(\text { atoms of } \mathrm{C})}{(\text { molecule of } i)} \times \frac{(\text { moles of } i \text { out }- \text { moles } i \text { in })}{(\mathrm{MCC})}
$$

where MCC is defined as the total moles of carbon actually converted to product. In the absence of alcohol recycle, all of the carbon converted comes from $\mathrm{CO}$. When alcohol is recycled and if there is a net consumption of the alcohol, then MCC is the surn of the moles of $\mathrm{CO}$ that reacts and the moles of the recycled alcohol that react times the carbon number of the recycled alcohol. The fractional yield of species $\mathrm{i}$ is equal to the fraction of the carbon atoms in the $\mathrm{CO}$ and recycled alcohol that actually react that are found in the " $\mathrm{i}$ " that leaves the system. 
Stoichiometric Impact of the Water-Gas Shift Reaction.

An examination of Reaction I, the alcohol synthesis reaction, shows that the number of atoms of oxygen in the carbon monoxide that reacts is greater than the number of atoms of oxygen in the alcohol that is formed, except for $n=1$, where the atoms of oxygen in the reacted CO exactly equal those in the product methanol. According to Reaction I, this excess oxygen is "rejected" via the formation of water. When alcohols are formed according to Reaction I, the stoichiometric $\mathrm{H}_{2} / \mathrm{CO}$ ratio is 2.0 for all values of $n$.

Reaction II, the water gas shift reaction, may be multiplied by (n-1) and added to Reaction I to give:

$$
(2 \mathrm{n}-1) \mathrm{CO}+(\mathrm{n}+1) \mathrm{H}_{2} \rightleftarrows \mathrm{C}_{n} \mathrm{H}_{(2 n+1)} \mathrm{OH}+(\mathrm{n}-1) \mathrm{CO}_{2}
$$

Reaction III describes a situation where oxygen is rejected via $\mathrm{CO}_{2}$ instead of $\mathrm{H}_{2} \mathrm{O}$. In this case, the stoichiometry of alcohol formation depends on the molecular weight of the alcohol, as shown in Table 1.

\section{Table 1}

Stoichiometry of Alcohol Formation From Sunthesis Gas When Oxvgen Is Rejected Via $\mathrm{CO}_{2}$

\begin{tabular}{ccc} 
I & \multicolumn{2}{c}{ Stoichiometric Ratio } \\
& $\underline{\mathrm{H}_{2} / \mathrm{CO}}$ & $\underline{\mathrm{CO}_{2} / \mathrm{CO}}$ \\
1 & 2.0 & 0 \\
2 & 1.0 & 0.33 \\
3 & 0.80 & 0.40 \\
4 & 0.71 & 0.43 \\
$\infty$ & 0.5 & 0.50
\end{tabular}

In some respects, alcohol formation from synthesis gas is similar to Fischer-Tropsch chemistry: oxygen can be rejected via either $\mathrm{CO}_{2}$ or $\mathrm{H}_{2} \mathrm{O}$, depending on the shift activity of the 
catalyst and the operating conditions of the process, and the apparent stoichiometry of the reaction depends on the molecular weight of the products, at least for low carbon numbers.

\section{The Effect of Temperature on Reaction Behavior}

A series of calculations was carried out to define the etfect of temperature on the conversion of reactants and product distribution. The total pressure, $\mathrm{P}$, was 70 atmospheres absolute and the feed consisted of a $2 / 1 \mathrm{H}_{2} / \mathrm{CO}$ molar ratio for all of the calculations in this series. The shift reaction was permitted to come to equilibrium.

The calculated conversions of $\mathrm{H}_{2}$ and $\mathrm{CO}$ are shown in Figure 2 as a function of temperature over the range from 300 to $800 \mathrm{~K}$. Most experimental research on the formation of higher alcohols has been conducted in the temperature range of 500 to $700 \mathrm{~K}$. Calculations were carried out at lower temperatures in order to understand the impact of using thermodynamic data at $298 \mathrm{~K}$. without any temperarure correction, to evaluate the behavior of the system at reaction conditions.

Figure 2 shows that the equilibrium conversion of $\mathrm{CO}$ is very high over the whole range of temperature considered. Below about $700 \mathrm{~K}$, the equilibrium $\mathrm{CO}$ conversion is essentially $100 \%$. Between 700 and $773 \mathrm{~K}$, it is still above $90 \%$. The calculated conversion of $\mathrm{H}_{2}$ is lower than the conversion of $\mathrm{CO}$ because these two species are affected differently by the shift reaction. Carbon monoxide is a reactant in both alcohol formation, Reaction I, and water gas shift, Reaction II. Hydrogen is a reactant in alcohol formation, but is produced by the shift reaction. The difference between the conversion curves for these two species is a measure of the importance of water gas shift. If this reaction did not take place, the $\mathrm{H}_{2}$ and $\mathrm{CO}$ conversion curves would be identical at a $\mathrm{H}_{2} / \mathrm{CO}$ ratio of 2.0. Figure 2 shows that the water gas shift reaction becomes significant at about $500 \mathrm{~K}$ and increases in importance as temperature is raised.

The fractional yield of $\mathrm{CO}_{2}$ is shown as a function of temperature in Figure 3. This figure illustrates the competition for $\mathrm{CO}$ between the alcohols and $\mathrm{CO}_{2}$. At low temperatures, very few of the carbon atoms in the $\mathrm{CO}$ that reacts appear in $\mathrm{CO}_{2}$. However, the yield of $\mathrm{CO}_{2}$ increases with temperature until it reaches a value of about 0.27 at about $800 \mathrm{~K}$. This value is only slightly below 
Figure 2. $\mathrm{CO}$ and $\mathrm{H}_{2}$ conversion as a function of temperature.

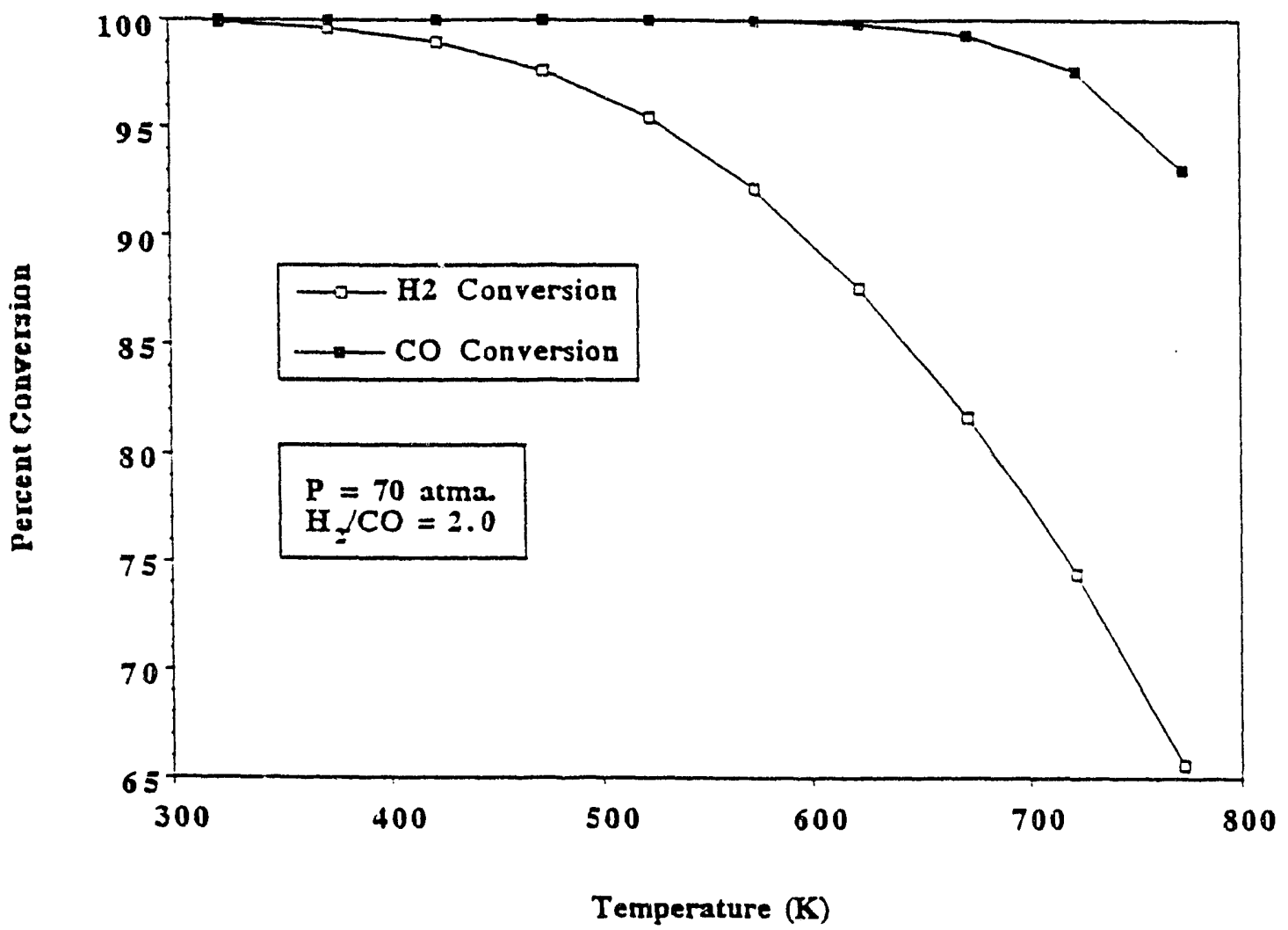


Figure 3. Carbon dioxide yield as a function of temperature.

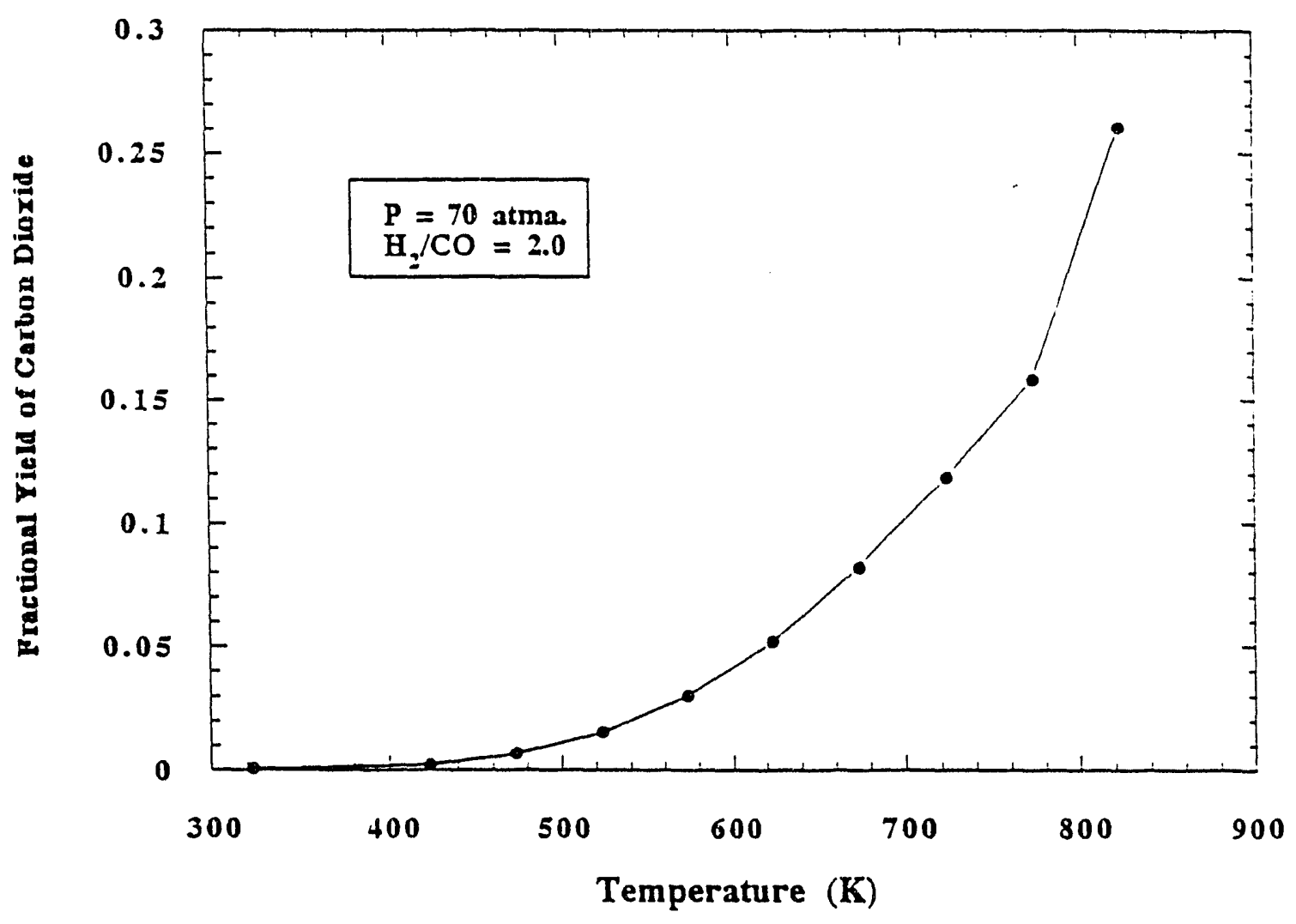


the range of stoichiometric yields shown in Table 1 for the case where oxygen rejection is exclusively by means of $\mathrm{CO}_{2}$. If the shift reaction occurs, it can play an important role in oxygen rejection at temperatures above about $500 \mathrm{~K}$.

Figure 4 shows the yield of methanol as a function of temperature. Two points are noteworthy. First, this yield is very small over the whole temperature range. Methanol is not favored thermodynamically in the competition for the available $\mathrm{CO}$ between the possible products. Second, the yield of methanol increases with temperature. This increase seems counter-intuitive, since the formation of methanol from synthesis gas is exothermic. However, methanol formation is less exothermic than the formation of the higher alcohols. Consequently, the equilibrium constant for methanol formation does not decrease as rapidly with temperature as the equilibrium constants for most of the competing reactions. This accounts for the increase in methanol yield with temperature.

The yields of the $C_{2}$ and $C_{3}$ alcohols are presented in Figure 5. For the conditions of this study, the individual yields of these three alcohols are not significant if thermodynamic equilibrium is attained. The complex behavior of these three alcohol yields with respect to temperature is attributable to relative changes in the equilibrium constants for their formation as discussed in the preceding paragraph.

Figure 6 shows that the $C_{4}$ alcohols are the dominant alcohol fraction at chemical equilibrium. At the low end of the temperature range, the yield of the four $\mathrm{C}_{4}$ alcohols taken as a group is close to unity, indicating that essentially all of the carbon atoms in the $\mathrm{CO}$ that is reacted are in the $\mathrm{C}_{4}$ alcohols. The total yield of the $\mathrm{C}_{4}$ alcohols decreases with temperature, largely due to the increasing importance of the shift reaction, as discussed in connection with Figure 3.

The distribution of $\mathrm{C}_{4}$ alcohol isomers is shown in Figure 7. At ambient temperature, tertiary butanol is the dominant species thermodynamically; the yields of the other three isomers are all negligible. As temperature increases, the equilibrium amount of tert-butanol declines rapidly and isobutanol becomes the predominant species at about 450K. Secondary butanol also increases with temperature; its equilibrium concentration becomes comparable to that of tert-butanol at about 
Figure 4. Methanol yield as a function of temperature.

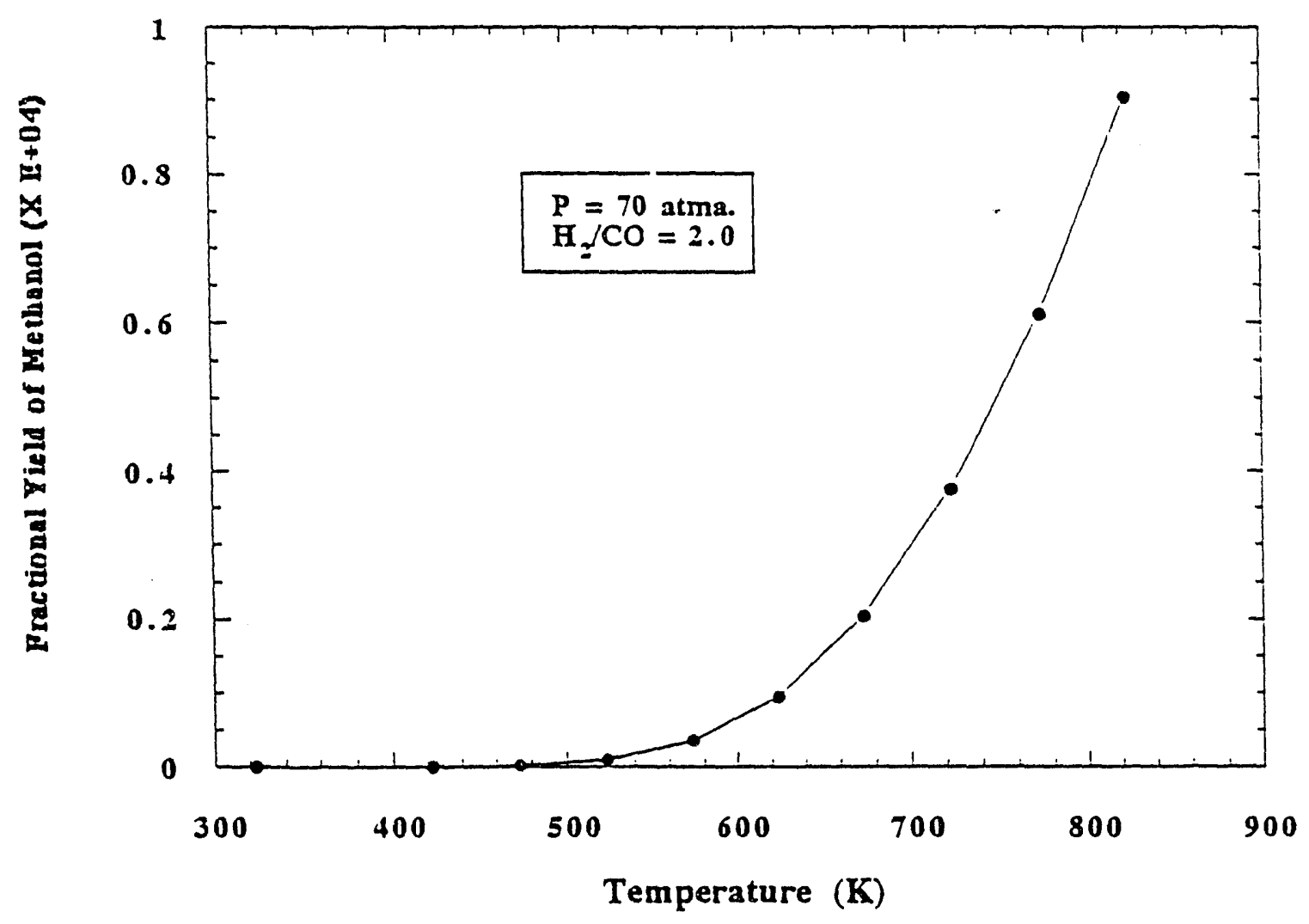


Figure 5. $C_{2}$ and $C_{3}$ alcohol yields as a function of temperature.

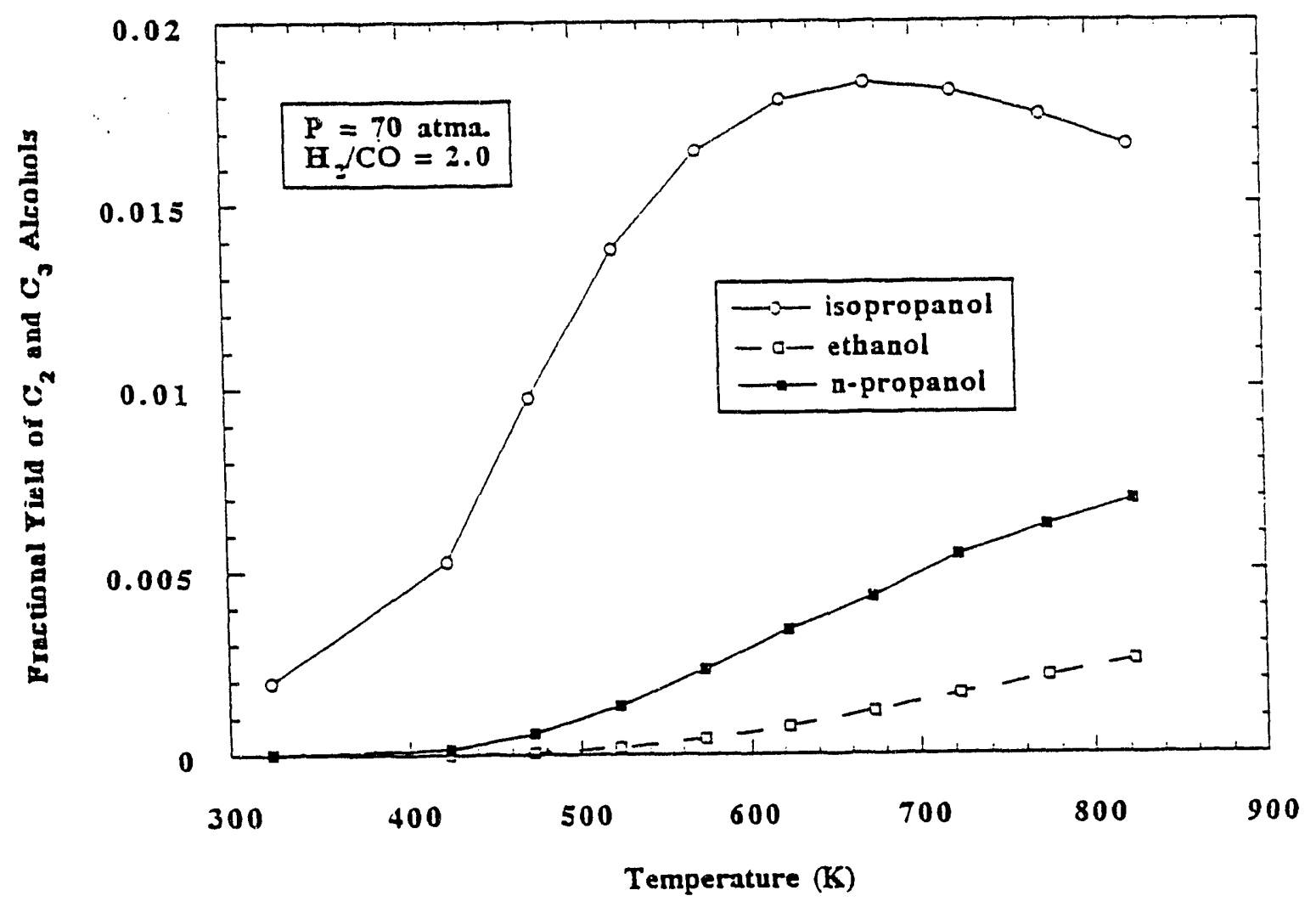


Figure 6. Total $C_{4}$ alcohol yield as a function of temperature.

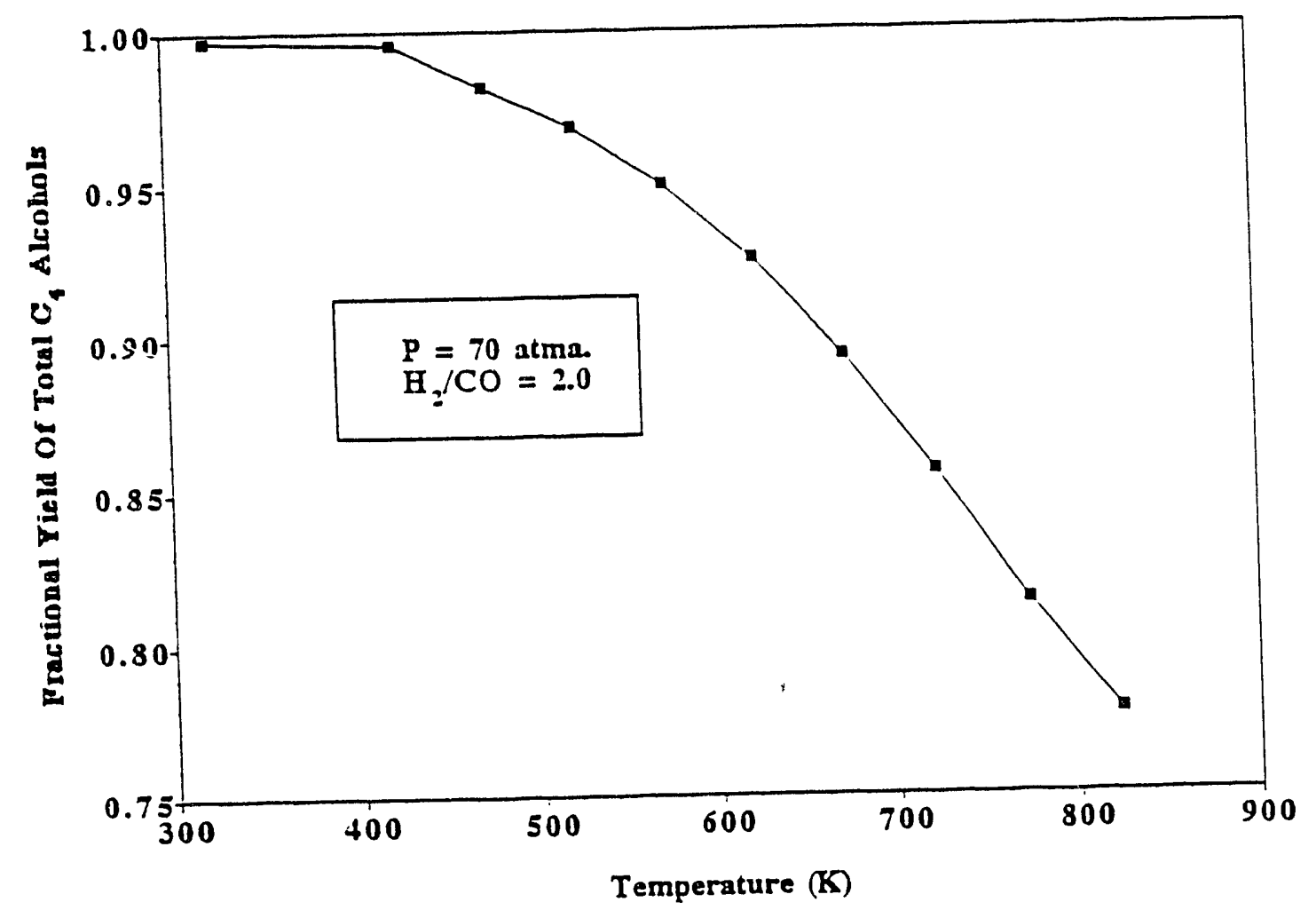


Figure 7. $\mathrm{C}_{4}$ alcohol isomer distribution as a function of ternperature.

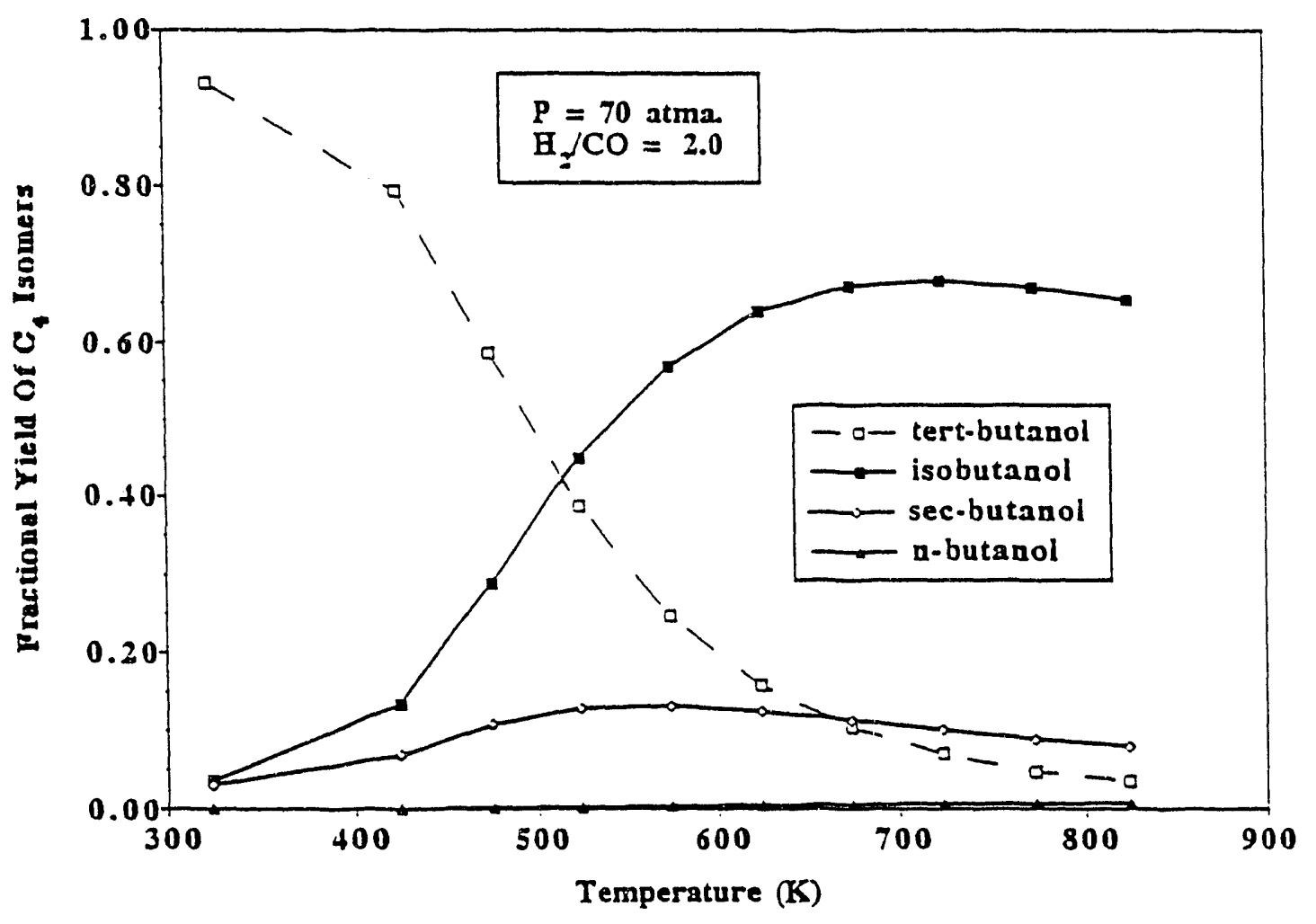


$600 \mathrm{~K}$. Figure 7 illustrates the error that could result from drawing conclusions based only on calculations at ambient temperature. Such a practice could lead to the erroneous conclusion that tert-butanol was thermodynamically preferred, whereas at representative reaction temperatures of 550 to $700 \mathrm{~K}$, the equilibrium yield of tert-butanol is quite low and isobutanol is the dominant species thermodynamically.

The issue of which butanol isomer is themodynamically favored is potentially important. Tertiary butanol could have value as a raw material for producing methyl tertiary butyl ether, a valuable gasoline additive. On the other hand, the utility of the methyl ether of isobutanol as a blending component for motor gasoline, or as a feedstock for ether formation, has not tsen established.

\section{Effect of Alcohol Recvcle}

Based upon the state of higher alcohol technology as it currently exists, alcohol recycle may be a useful device to promote higher alcohol formation from synthesis gas. For example, lower molecular weight alcohols, such as methanol and ethanol, might be recycled in order to shift the net product distribution towards the more valuable higher alcohols. In principle, the net formation of an undesired product, e.g., methanol, may be reduced to zero by recycling a sufficient amount of that product to satisfy the equilibrium relationship for its synthesis. Under that circumstance, all of the synthesis gas that was reacted would go into the other products.

As shown earlier, the butanols are the thermodynamically dominant alcohol product, with fairly small quantities of methanol, ethanol, and propanols formed. Therefore, the recycle of sec-butanol was chosen as a means to encourage formation of desirable branched butanols. Calculations were carried out at a temperature, $\mathrm{T}$, of $523 \mathrm{~K}$, a total pressure, $\mathrm{P}$, of 70 atma and a $\mathrm{H}_{2} / \mathrm{CO}$ ratio of 2.0 . Recycle was simulated in the ASPEN PLUSTM program by including varying amounts of secbutanol in the feedstream.

As shown in Figure 8, the yields of isobutanol and tert-butanol increased with increasing moles of sec-butanol fed until a "critical" point was reached, beyond which the yields remained relatively 
Figure 8. Effect of recycling secondary butanol on $\mathrm{C}_{4}$ alcohol isomers yield.

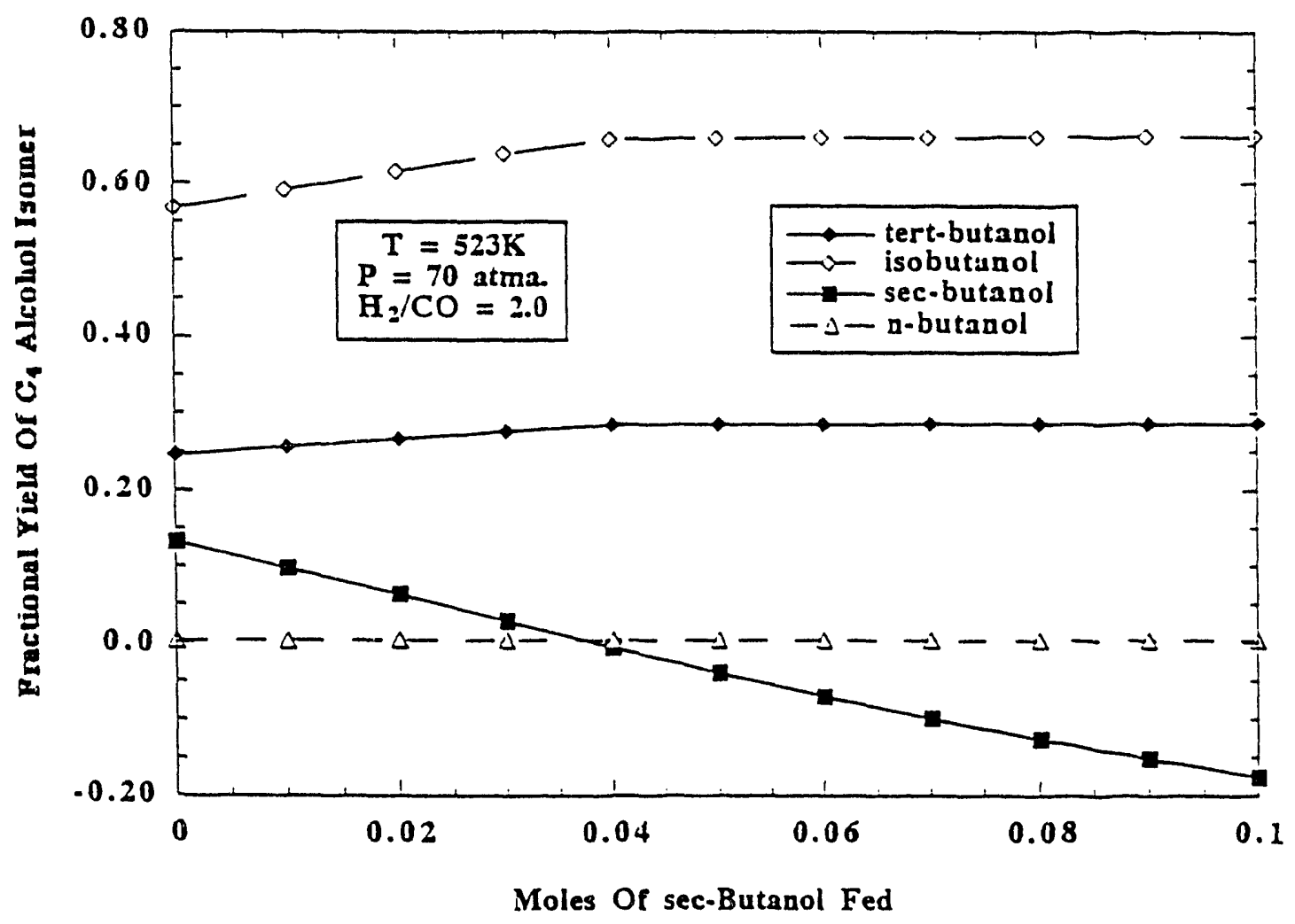


constant. The "critical" point occurs when the moles of sec-butanol fed are such that there is no net consumption or production of sec-butanol, i.e., the yield of sec-butanol is zero. When the amount of sec-butanol fed is above the "critical" point the excess sec-butanol is simply converted to other alcohols and the alcohol product distribution remains relatively constant. Note that the yield below the "critical" point is based upon moles of $\mathrm{CO}$ reacted, while the vield above the critical point is based upon moles of $\mathrm{CO}$ reacted plus moles of carbon converted from the excess sec-butanol fed. These results suggest that alcohol recycle maybe an effective way to retard the production of less valuable species and promote the formation of more desirable species.

\section{Phase Equilibrium With Ideal Fluids}

All results presented to this point are based on the assumption that the products were ideal gases. However, in some of these calculations, the vapor pressures of some species at chemical equilibrium were greater than the equilibrium vapor pressure of the pure component liquid. This suggests that at least part of the product will be present in a liquid phase or phases. Therefore, a series of calculations was carried out in which phase equilibrium as well as reaction equilibrium was considered. It was assumed that all phases, both gas and liquid, behaved as ideal fluids, i.e., the vapor was an ideal gas and the liquid obeyed Raoult's law. As a result of the latter assumption, only one liquid phase can exist at fquilibrium.

Figure 9 summarizes the information derived from these calculations conceming the existence of various product phases. This "phase diagram" shows what phase or phases are thermodynamically preferred when the set of nine reactions, including water gas shift, comes to chemical equilibrium at a total pressure of 70 atma and at various temperatures and $\mathrm{H}_{2} / \mathrm{CO}$ ratios. At a $\mathrm{H}_{2} / \mathrm{CO}$ ratio of exactly 2.0 and temperatures below about $550 \mathrm{~K}$, a single liquid product phase is formed. For these conditions, the sum of the partial pressures of the system components is less than the total pressure at chemical equilibrium, largely due to the essentially complete conversion of $\mathrm{H}_{2}$ and $\mathrm{CO}$ to alcohol products.

Surrounding the single liquid phase line is a two phase region with a gas and single liquid 
Figure 9. Product phase diagram.

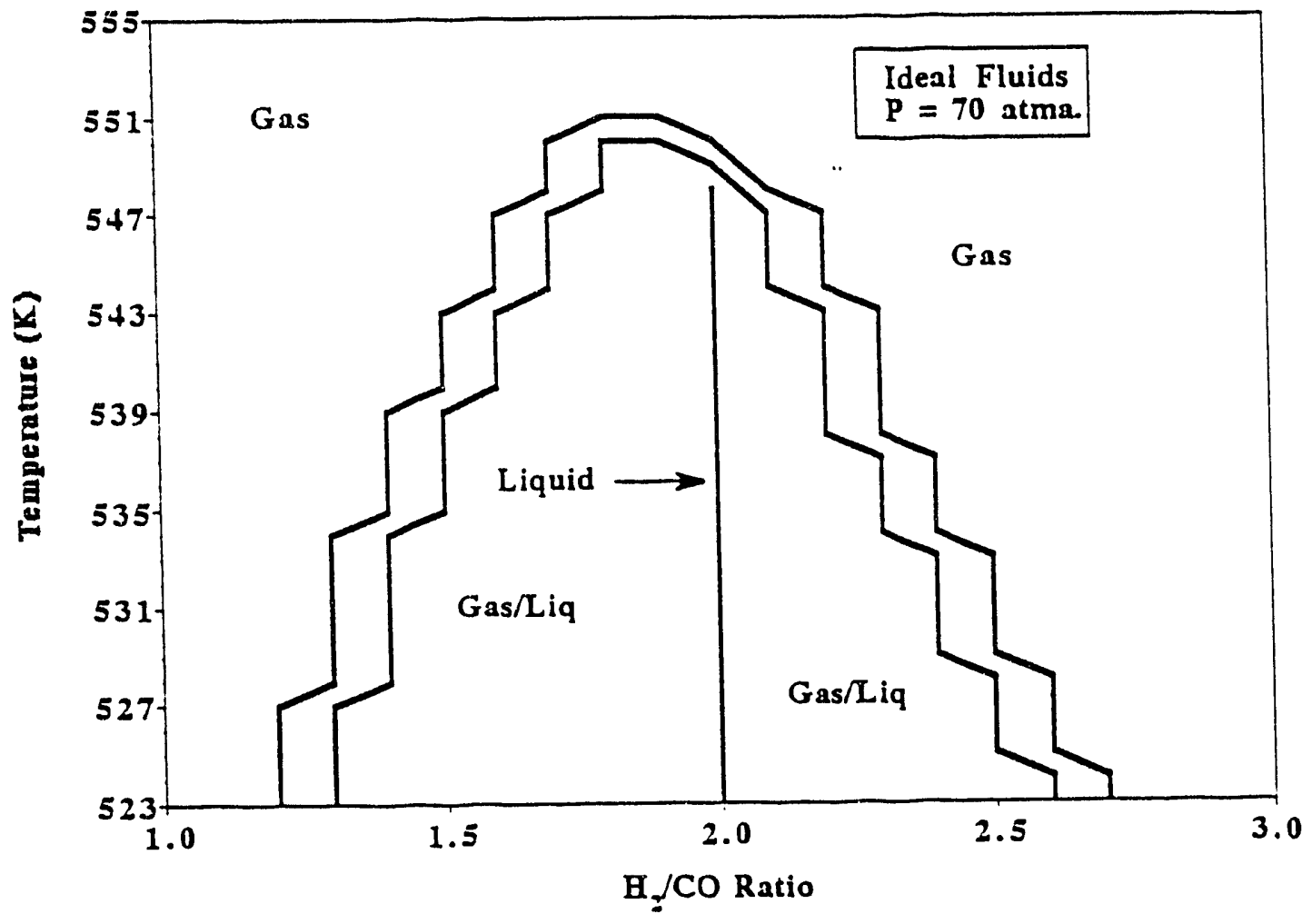


phase in equilibrium with each other. The liquid phase consists primarily of water and the butanols, while the gas phase contains primarily $\mathrm{H}_{2}$ or $\mathrm{CO}$ depending upon which is in stoichiometric excess. Outside the dome, a single gas phase exists since the conversion of either $\mathrm{H}_{2}$ or $\mathrm{CO}$ is very low, or the temperature is sufficiently high to keep the products in the vapor phase. The exact boundary between the two phase region and the gas phase region lies sometvhere inside the thin strip that separates these two regions on Figure 9. Additional calculations with smaller increments of temperature and $\mathrm{H}_{2} / \mathrm{CO}$ ratio would be required to define this boundary more precisely.

The reactant conversions and product distributions are somewhat different when phase equilibrium is considered than they are when the products are assumed to be ideal gases. Table 2 shows a comparison of the $\mathrm{CO}$ and $\mathrm{H}_{2}$ conversions at a temperature of $523 \mathrm{~K}$ and various $\mathrm{H}_{2} / \mathrm{CO}$ ratios.

Table 2

Effect of Phase Equilibrium on Reactant Conversion

( $\mathrm{T}=523^{\circ} \mathrm{K}, \mathrm{P}=70$ atma, with WGS)

Ideal Gas Onlv Ideal Fluids

\begin{tabular}{|c|c|c|c|c|c|}
\hline $\mathrm{H} / \mathrm{CO}$ Ratio & $\mathrm{H}_{2}$ Conversion & CO Conversion & $\mathrm{H}_{2}$ Conversion & CO Conversion & Phase(s) \\
\hline 4 & 50 & 100 & 50 & 100 & $\mathrm{~V}$ \\
\hline 3 & 66.7 & 100 & 66.7 & 100 & V \\
\hline 2.2 & 90.4 & 100 & 90.9 & 100 & $\mathrm{~V} / \mathrm{L}$ \\
\hline 2.0 & 95.5 & 100 & 100 & 100 & L \\
\hline 1.8 & 96.9 & 100 & 100 & 100 & $\mathrm{~V} / \mathrm{L}$ \\
\hline 1.0 & 100 & 99 & 100 & 99 & V \\
\hline 0.5 & 100 & 70 & 100 & 70 & $\mathrm{~V}$ \\
\hline
\end{tabular}

The product distribution can also change when simultaneous phase and chemical equilibria are considered. The most pronounced effects are on tert-butanol (Figure 10) and isobutanol (Figure 11), where the mixed-phase system encourages isobutanol formation while suppressing tertbutanol formation. As seen in Figure 12, the equilibrium vapor pressure of the pure component liquid, $p_{i}^{*}$, is a function of temperature. At phase equilibrium, the fugacity of the gas phase is 
Figure 10. Effect of product state on the yield of tert-butanol.

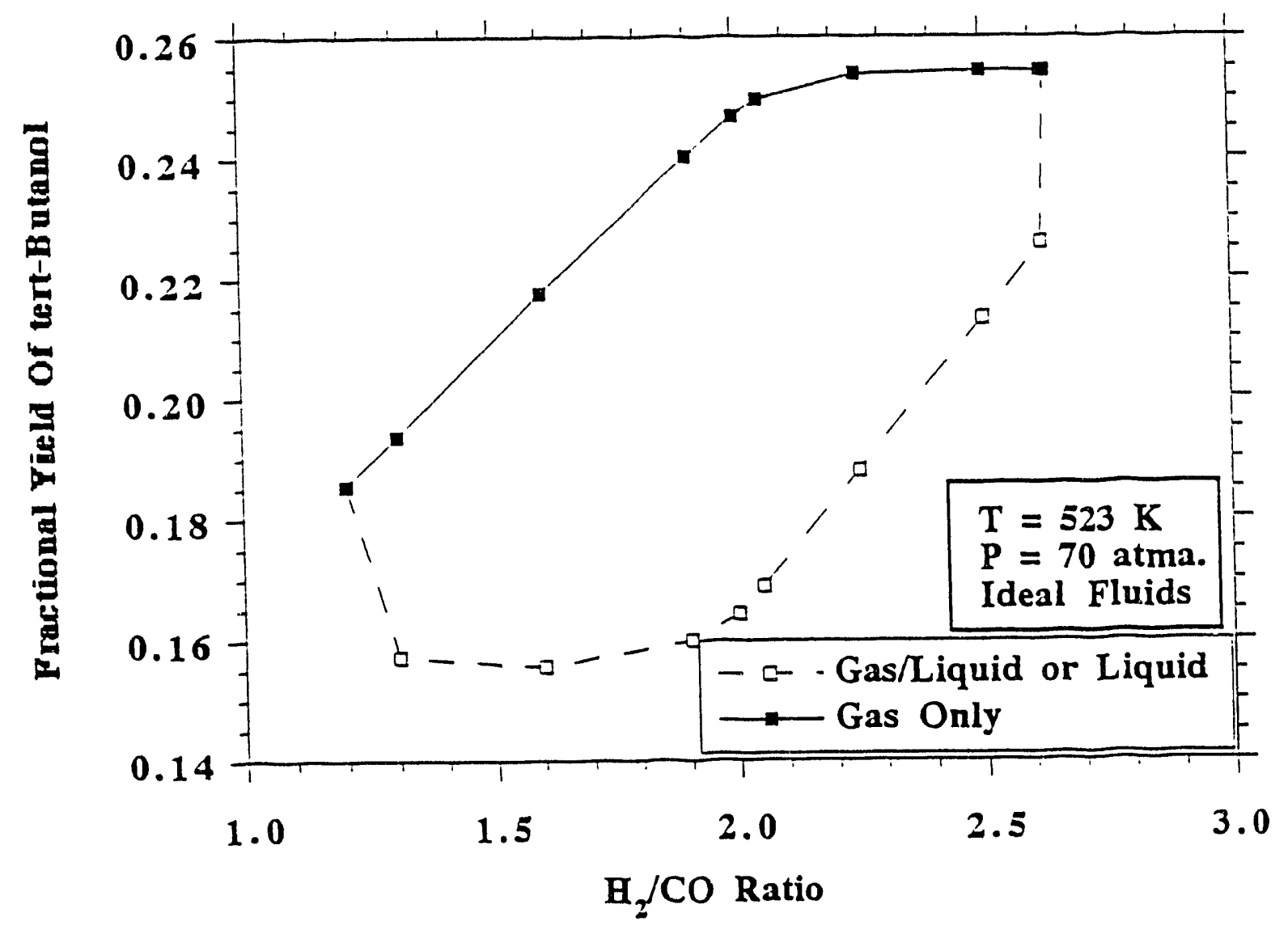


Figure 11. Effect of product state on the yield of isobutanol.

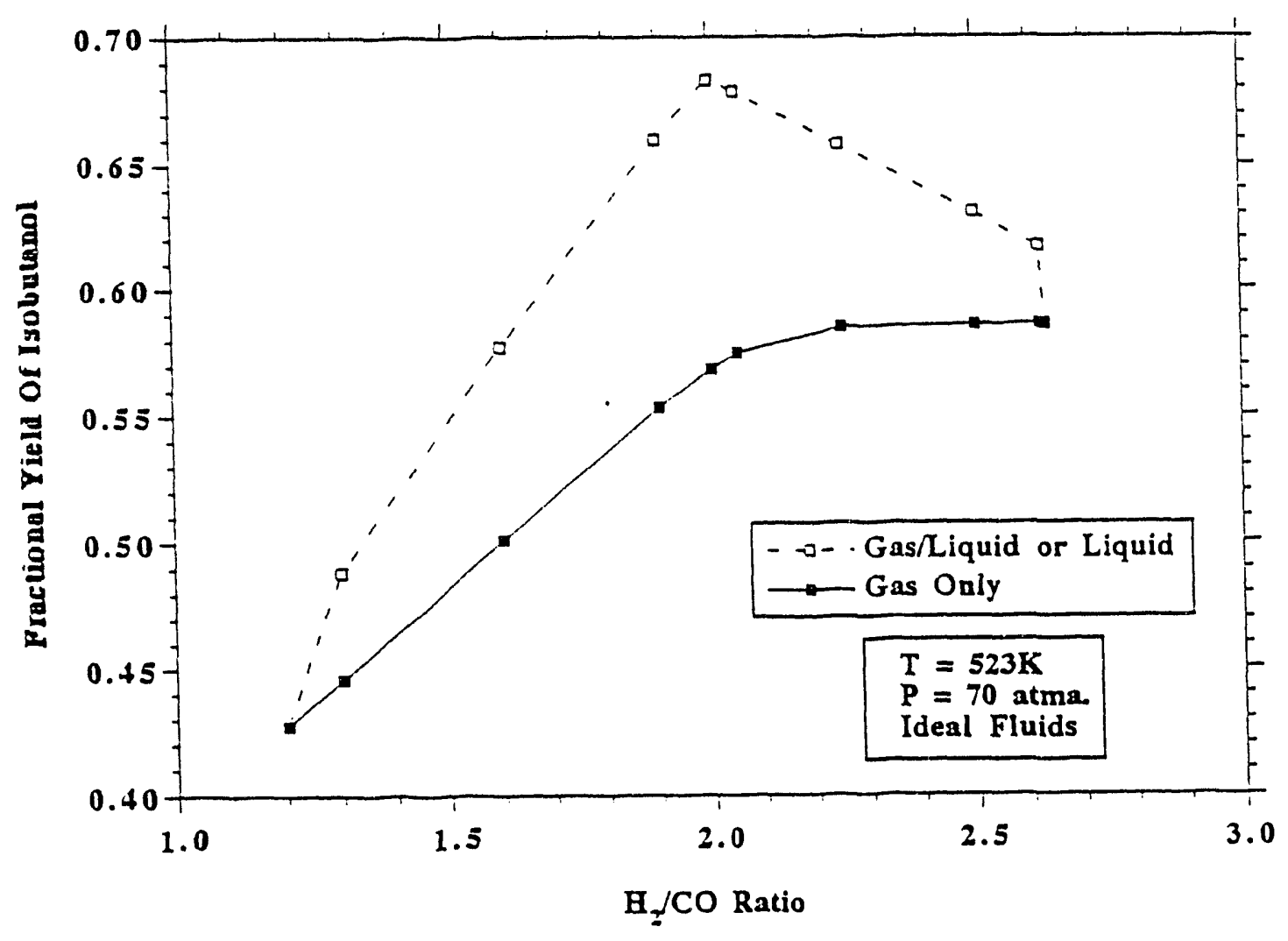


Figure 12. Pure component liquid vapor pressures of $\mathrm{C}_{4}$ alcohols generated by ASPEN-PLUS ${ }^{\mathrm{TM}}$.

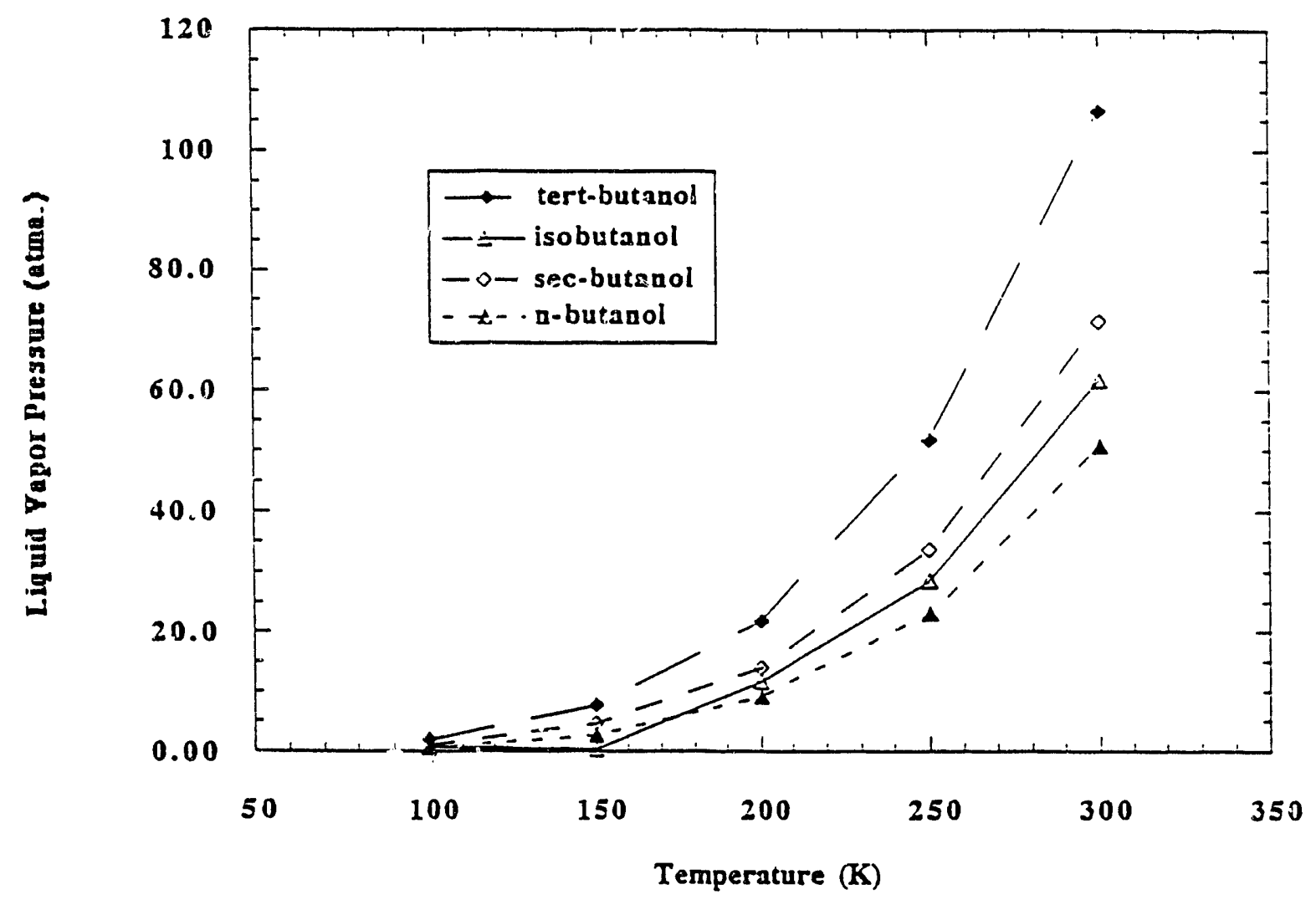


equal to the fugacity of the liquid phase, i.e, $p_{i}^{*} x_{i}=P y_{i}$. For given values of $y_{i}$ and total system pressure, $\mathrm{P}, x_{i}$ varies inversely with $p_{i}^{*}$. In other words, the higher the vapor pressure of the pure component liquid, the less product can be "stored" in the liquid phase. This explanation is consistent with the results of Figures 10-12, where the yield of isobutanol, which has the lower $\vec{p}_{i}^{*}$, is enhanced at the expense of tert-butanol, which has the higher $\vec{p}_{i}^{*}$, when simultaneous phase and reaction equilibria are considered.

The effect of multiple phases is important if the product distributions predicted by these thermodynamic calculations are approached in real catalytic reactors. If a liquid phase forms in the reactor, either in a fixed bed or in a stirred autoclave, the results could be disastrous for continued production unless the liquid is removed. For the stirred autoclave, a liquid purge stream could be continuosiy removed from the reactor, but a fresh mineral oil stream addition would be required to maintain liquid level in the reactor. Also, the exiting liquid would have to be separated from the catalyst so that the catalyst could be recycled, or the liquid would have to be removed from the reactor so as to prevent unwanted removal of the suspended catalyst.

\section{Fuid Phase Non-Idealitv}

All previous results were based upon the assumption of ideal gas and liquid behavior. However, alcohols and water can deviate significantly from ideality due to their high polarity. Therefore, simulations of the higher alcohol synthesis were executed using the Peng-Robinson equation of state to describe the fugacities of the vapor and liquid phases. This equation of state accurately models the behavior of polar compounds and mixtures, especially at high temperatures and pressures. (Aspen, 1988) The binary interartion parameters of the Peng-Robinson equation of state, $\delta_{i, k}$, were set equal to zero for the present calculations. Values of these parameters can be estimated by the ASPEN PLUS'M Pure Component Data Base; however, the parameter values are not automatically calculated unless specified in the program input. The results of several calculations showed no significant difference in product distribution when the ASPEN PLUSTM binary interaction parameter estimates were used. 
Two sets of cases were computed at $\mathrm{T}=523 \mathrm{~K}, \mathrm{P}=70$ atma and $\mathrm{H}_{2} / \mathrm{CO}$ ratio of 2.0; Case A allowed only a single, non-ideal vapor product phase upon reaction equilibrium; Case B allowed simultaneous phase and reaction equilibrium, with up to three phases present. The results, as shown in Table 3, illusirate little change in CO conversion and yield of alcohols between the ideal and the non-ideal models in both cases. Note that two liquid phases are predicted by the PengRobinson model: a water-rich phase and an alcohol-water phase. This seems plausible since the dominant liquid product is water, and the higher alcohols are finitely soluble in water, so their solubility limit can he reached. (Perry, 1973) The results also emphasize that allowing multiple phases to occur, i.e., simultaneous thermodynamic and phase equilibrium, appears to have a more significant impact on the product distribution than the specific model that is used to describe the behavior of the fluid phases.

Table 3

Effect of Fluid-Phase Model

( $\mathrm{T}=523^{\circ} \mathrm{K}, \mathrm{P}=70$ atma, $\mathrm{H}_{2} / \mathrm{CO}=2.0$ )

Conversion

Yield

$\underline{\text { Model Phases(s) } \quad \underline{\mathrm{CO}} \quad \underline{\mathrm{H}_{2}} \text { isobutanol tert-butanol }}$

A) Single Gas Phase Only

\begin{tabular}{|c|c|c|c|c|c|}
\hline Ideal & G & 100 & 95.5 & 0.57 & 0.25 \\
\hline Peng-Robinson & $\mathrm{G}$ & 100 & 97 & 0.60 & 0.23 \\
\hline \multicolumn{6}{|c|}{ I No Phase Restrictions } \\
\hline Ideal & $\mathrm{L}$ & 100 & 100 & 0.68 & 0.16 \\
\hline Peng-Robins $n$ & LL & 100 & 100 & 0.67 & 0.17 \\
\hline
\end{tabular}

Thermodvnamic Calculations Summary

The most important conclusions resulting from the higher alcohol synthesis thermodynamic study were:

- The apparent reaction stoichiometry depends on the extent of the shift reaction, i.e., on the extent to which oxygen molecules in the $\mathrm{CO}$ are rejected by either $\mathrm{H}_{2} \mathrm{O}$ or $\mathrm{CO}_{2}$. When oxygen rejection is largely via $\mathrm{CO}_{2}$, the apparent stoichiometry also depends on the relative 
amounts of the various alcohols that are formed;

- The equilibrium conversion of the limiting reactant is above $90 \%$ at all temperatures up to T73K;

- The $\mathrm{C}_{4}$ alcohols are the predominant product at all temperatures up to $773 \mathrm{~K}$;

- Tertiary butanol is the predominant $\mathrm{C}_{4}$ alcohol isomer at temperatures below about $473 \mathrm{~K}$; at higher temperatures up to $773 \mathrm{~K}$, isobutanol is the thermodynamically-preferred species;

- Oxygen rejection is largely via $\mathrm{CO}_{2}$ at higher temperatures and $\mathrm{H}_{2} / \mathrm{CO}$ ratios;

- Alcohol recycle increases higher alcohol yield until a "critical" point is reached, i.e., no net production or consumption of the recycled component. After that, no significant changes in product vield are observed;

- Multiple phases can form under cerain conditions of temperature, pressure and $\mathrm{H}_{2} / \mathrm{CO}$ ratio. Some of the product yields are changed significantly by considering simultaneous chemical and phase equilibrium;

- Allowing simultaneous chemical and phase equilibrium to occur changed the product distribution by favoning isobutanol at the expense of tert-butanol;

- Utilizing equation of state models to predict thermodynamic properties does not significantly change the alcohol product distribution or the yield as compared to the ideal gas results. 


\section{Higher Alcohol Sunthesis (HAS) Catalvsts}

Methanol synthesis from the hydrogenat on of carbon monoxide was first developed in the 1920's using catalysts composed of $\mathrm{ZnO}, \mathrm{MnO}$, and $\mathrm{Cr}_{2} \mathrm{O}_{3}$ and operating under high temperatures (300 to $400^{\circ} \mathrm{C}$ ) and pressures (1500 to $7000 \mathrm{psig}$ ). (Anderson, 1952) At the time, higher alcohols were a significant, but undesired, byproduct of this process. This technology developed rapidly, and commercial processes were built to produce methanol. Several years later, a low pressure (< $1000 \mathrm{psig})$ and temperature $\left(250^{\circ} \mathrm{C}\right)$ methanol manufacturing process was developed using a $\mathrm{Cu} / \mathrm{ZnO}$ catalyst. This catalyst is more selective toward methanol with essentially no higher alcohol byproducts. By about 1980, the low-pressure process had displaced essentially all of the high-pressure capacity in the United States. The CwZnO methanol catalyst is currently used for methanol production from synthesis gas which is produced by various methods.

Higher alcohol synthesis from $\mathrm{CO} / \mathrm{H}_{2}$ mixtures did not gain interest until the oil embargos of the mid and late 1970's. At that time, there was renewed interest in altemative automotive fuels, such as methanol and higher alcohols, that could be produced from domestic resources such as coal. As mentioned earlier, the problems with methanol as a fuel in existing engines quickly diminished its value as an altemate fuel, higher alcohols were a better choice. However, due to the oil shortage, production of higher alcohols from petroleum derivatives was not acceptable. Alcohol synthesis from $\mathrm{CO}$ and $\mathrm{H}_{2}$ gas, which could be produced from domestic coal and other resources, was considered a strong option and renewed research efforts began. Since that time, exisiting methanol synthesis catalysts have been promoted with alkali metals to improve selectivity toward higher alcohols and new catalysts for $\mathrm{HAS}$ from $\mathrm{CO}$ and $\mathrm{H}_{2}$ have been developed. However, none of these catalysts have been used commercially for higher alcohol synthesis due to relatively low selectivity for higher alcohols and low catalyst activity.

Higher alcohol synthesis catalysts developed to date can generally be divided into three broad categories: modified methanol catalysts, modified Group VIII metal-based catalysts, which include the modified Fischer-Tropsch catalysts, and the molybdenum-based catalysts. These are not definite divisions; some overlapping occurs as evidenced by HAS catalysts containing both Rh and 
Mo. However these general groups do serve to categorize the many different HAS catalysts.

The modified methanol catalysts yield primarily methanol and primary branched alcohols with 2-methyl-1-propanol as the major $C_{2+}$ alcohol. (Smith, 1991; Forzatti, 1991) The latter two catalyst groups generally form linear primary alcohols which typically obey a Schulz-Flory (S-F) distribution due to the Fischer-Tropsch activity of the catalysts. The S-F distribution is a correlation for the probability of carbon chain growth and chain termination in a reaction system. A plot of the natural log of the mole fraction of carbon product versus the carbon number of the product yields a straight line with a negative slope if the S-F distribution is obeyed. Hence, methanol would have a higher mole fraction than ethanol, which is higher than the propanols, which is higher than the butanols, etc. for a S-F alcohol product distribution. Therefore, if an S-F distribution is followed, methanol will always be the predominant alcohol product, and high selectivity to a particular desired higher alcohol could never be achieved.

All HAS catalysts generally suffer from relatively low activity for higher alcohol production as well as typically $<50 \%$ selectivity for $\mathrm{C}_{2+}$ alcohols. A detailed discussion of each catalyst group follows.

\section{Modified Methanol HAS Catalvsts}

Methanol catalysts can be divided into two groups, the low temperature/low pressure $\mathrm{Cu} / \mathrm{ZnO}$ catalysts and the high temperature/high pressure $\mathrm{ZnCrO}$ and $\mathrm{MnCrO}$ catalysts. As mentioned earlier, these unpromoted catalysts are good methanol catalysts. Because of their excellent methanol activity, these catalysts must be modified to increase selectivity to higher alcohols. The primary modification is promotion with an alkali hydroxide, carbonate or oxide. Although these promoters do enhance higher alcohol selectivity, typically more severe operating conditions are required for significant higher alcohol quantities and methanol remains the predominant alcohol product. 
Modified $\mathrm{Cu} / \mathrm{ZnO}$ methanol catalysts have received substantial attention for the past decade, with several different promoters being investigated. Elliott and Pennella (1986) examined the effect of transition metal addition to a commercial $\mathrm{Cu} / \mathrm{ZnO}$ catalyst. They deposited the metal by impregnation with an aqueous solution of a metal salt, using the incipient wetness technique. The metal to $\mathrm{Cu}$ atom ratio ranged from 0.008 to 0.02 . Each catalyst was screened in a fixed-bed tubular reactor with a $7.2 \mathrm{~L} / \mathrm{cm}^{3}$ catalyst/hr flow of $\mathrm{H}_{2} / \mathrm{CO} / \mathrm{CO}_{2}$ ratio of $2 / 0.94 / 0.06$ at $523 \mathrm{~K}$ and $65 \mathrm{~atm}$. Their results indicate that none of the transition metals significantly affected product selectivity, with methanol remaining $>99 \%$ of the alcohol product. The metal additives $\mathrm{Ti}, \mathrm{Zr}, \mathrm{V}$, $\mathrm{W}, \mathrm{Rh}$, and Pd also did not affect the methanol synthesis activity. Though $\mathrm{Mo}, \mathrm{Ru}, \mathrm{Co}$, and $\mathrm{Pt}$ were moderate inhibitors, Re inhibited catalyst activity so strongly that it should be considered a poison. None of the metals appreciably changed the catalyst bulk or surface properties. Transition metals, although considered HAS catalysts themselves as discussed later, do not serve well as promoters on $\mathrm{Cu} / \mathrm{ZnO}$.

Alkali promoters on the $\mathrm{Cu} / \mathrm{ZnO}$ methanol have been shown to increase selectivity to $\mathrm{C}_{2}+$ alcohols, but methanol remained the predominant product. Vedage, et.al. (1983) promoted 30/70 molar ratio $\mathrm{Cu} / \mathrm{ZnO}$ catalysts with alkali hydroxides. They achieved fairly uniform surface distributions and concentrations for each of the promoters to ensure comparability between catalyst samples. Their results indicate, as shown in Figure 13, that the $\mathrm{Li}, \mathrm{Na}, \mathrm{Rb}$, and $\mathrm{Cs}$ promoters actually enhance overall alcohol yield, but only $C s$ appears to increase $C_{2}+$ alcohol selectivity with ethanol as the major higher alcohol product. Vedage, et.al. also found that lowering the $\mathrm{H}_{2} / \mathrm{CO}$ ratio also increased the selectivity to higher alcohols, but decreased the overall catalyst activity.

Further work by Nunan, et.al. (1988) has shown that product yield passes through a maximum for nominal Cs concentrations of $0.3-0.5 \%$, which translates to optimum surface concentrations of $15-25 \%$. This promoter maximum suggests that higher alcohol synthesis probably requires an alkali-copper interface. Confirming earlier results, selectivity to higher alcohols was encouraged by lowering the $\mathrm{H}_{2} / \mathrm{CO}$ ratio and by increasing temperature. The typical product distribution was $46 \%$ (by mass) methanol, $6 \%$ ethanol, 11\% 1-propanol, and 13\% 2-methyl-1-propanol under 
Figure 13. A comparison of the alcohol yields over impregnated $\mathrm{Cu} / \mathrm{ZnO}=30 / 70 \mathrm{~mol} \%$ catalysts. Operating conditions were $288^{\circ} \mathrm{C}, 75 \mathrm{~atm}$, and a total gas flow of $10.4 \mathrm{~L}$ (STP)/hr. $\mathrm{M}=$ methanol, $\mathrm{E}=$ ethanol, 1-P = 1-propanol, 2-M1-P = 2-methyl-1-propanol, and $1-B=1$-butanol. (Vedage, 1983)

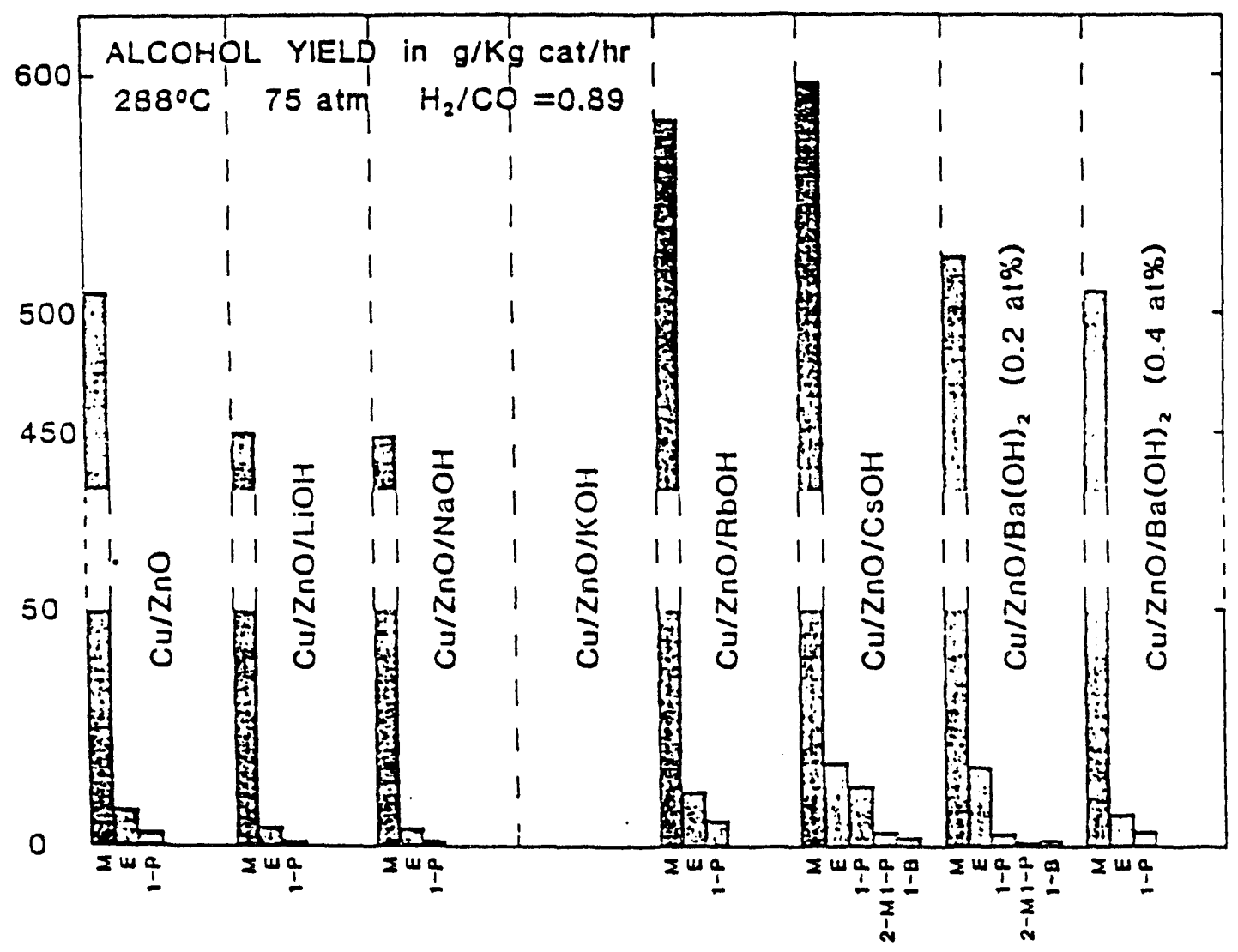


operating conditions of $310^{\circ} \mathrm{C}, 75 \mathrm{~atm}, \mathrm{H}_{2} / \mathrm{CO}$ feed ratio of 0.45 and a gas hourly space velocity (GHSV) of $3265 \mathrm{~L}(\mathrm{STP}) /[\mathrm{kg}$ catalyst $\cdot \mathrm{hr}]$.

Smith and Anderson (1983) investigated promotion effects of $\mathrm{K}_{2} \mathrm{CO}_{3}$ on $\mathrm{Cu} / \mathrm{ZnO}$ catalysts and determined optimum promoter concentration of 0.5 weight \% for higher alcohol selectivity, but 1 wt \% for overall CO conversiun. The predominant higher alcohol product was 2-methyl-1propanol, and they also determined that increasing reaction temperature increased higher alcohol selectivity. Later work by Calverley and Smith (1991) determined effects of carbon dioxide, methanol, temperature, and alkali promoter $\left(\mathrm{K}_{2} \mathrm{CO}_{3}\right)$ over a $\mathrm{Cu} / \mathrm{ZnO} / \mathrm{Cr}_{2} \mathrm{O}_{3}$ catalyst. Their results, shown in Figures 14 and 15, confirm earlier reported effects of temperature on higher alcohol selectivity and an optimum promoter concentration for highest alcohol yields (both methanol and higher alcohols). This evidence suggests that a common intermediate for methanol and higher alcohols formed from $\mathrm{CO}$, possibly on common alkali/copper interfacial sites. Adding methanol and/or $\mathrm{CO}_{2}$ to the reactor feed gave mixed results, indicating an interaction between $\mathrm{CO}_{2}$ and the higher alcohol synthesis which has not been previously reported.

Since the higher alcohol synthesis over promoted $\mathrm{Cu} Z \mathrm{ZnO}$ catalysts apparently is encouraged by increasing reaction temperature, thermal stability of the catalysts is a legitimate concem. Roberts, et.al. (1991) have shown in a slurry reactor that $\mathrm{Cu} / \mathrm{ZnO} / \mathrm{Al}_{2} \mathrm{O}_{3}$ methanol catalysts deactivate due to sintering of the overall surface of the catalyst over time and this deactivation rate increases substantially with increasing reactor temperaure. Calverley and Anderson (1987) also have shown that $\mathrm{Cu} / \mathrm{ZnO} / \mathrm{Al}_{2} \mathrm{O}_{3}$ surface areas dectease with time and increasing reactor temperature. They also found that a $0.5 \% \mathrm{~K}_{2} \mathrm{CO}_{3}$ promoted $30 / 60 / 10$ mole $\% \mathrm{CuO} / \mathrm{ZnO} / \mathrm{Cr}_{2} \mathrm{O}_{3}$ catalyst remained thermally stable at $325^{\circ} \mathrm{C}$ for $60 \mathrm{~h}$, and the catalyst demonstrated comparable alcohol synthesis activity and selectivity to the promoted $\mathrm{Cu} / \mathrm{ZnO} / \mathrm{Al}_{2} \mathrm{O}_{3}$ catalyst. Although a $60 \mathrm{~h}$ test is very short relative to the 1000 to $2000 \mathrm{~h}$ tests of Roberts, et.al., this result shows promise for the $\mathrm{CuO} / \mathrm{ZnO} / \mathrm{Cr}_{2} \mathrm{O}_{3}$ mixture as a HAS catalyst.

Under HAS conditions, Vedage, et.al. (1985) and Nunan, et.al. (1988) found that the methanol and water-gas shift reactions approach thermodynamic equilibrium. This equilibrium is 
Figure 14. Space-time yields of methanol at conditions of interest in the present study (yields in $\mathrm{mmol} / \mathrm{h} / \mathrm{gram}$ of catalyst, $\left(\mathrm{CO}+\mathrm{CO}_{2}\right) / \mathrm{H}_{2}=2 / 1$, space velocity $=20000 \mathrm{~h}^{-1}, \mathrm{P}=10$ $\mathrm{MPa}$ ). (A) $0.5 \% \mathrm{~K}_{2} \mathrm{CO}_{3}$ promoted catalyst. (B) $4.0 \% \mathrm{~K}_{2} \mathrm{CO}_{3}$ promoted catalyst (Calverley, 1991)

A

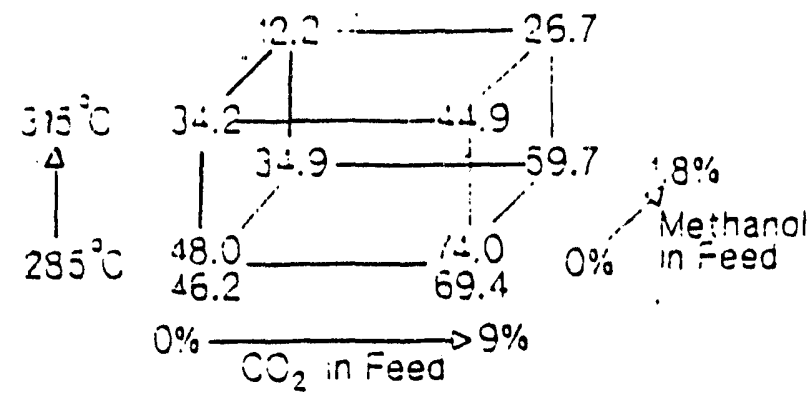

3

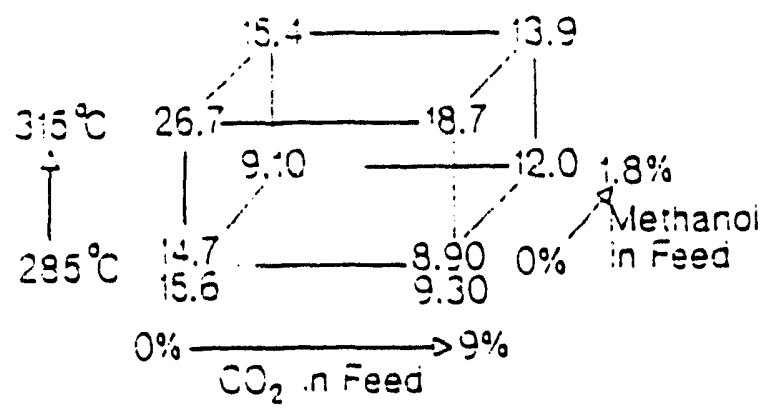

Figure 15. Space-time vields of higher alcohols at conditions of interest in the present study (yields in $\mathrm{mmol} / \mathrm{h} / \mathrm{gram}$ of calalyst, $\left(\mathrm{CO}+\mathrm{CO}_{2}\right) / \mathrm{H}_{2}=2 / 1$, space velocity $=20000 \mathrm{~h}^{-1}$, $\mathrm{P}=10 \mathrm{MPa}$ ). (A) $0.5 \% \mathrm{~K}_{2} \mathrm{CO}_{3}$ promoted catalyst (B) $4.0 \% \mathrm{~K}_{2} \mathrm{CO}_{3}$ promoted catalyst (Calverley, 1991)

A

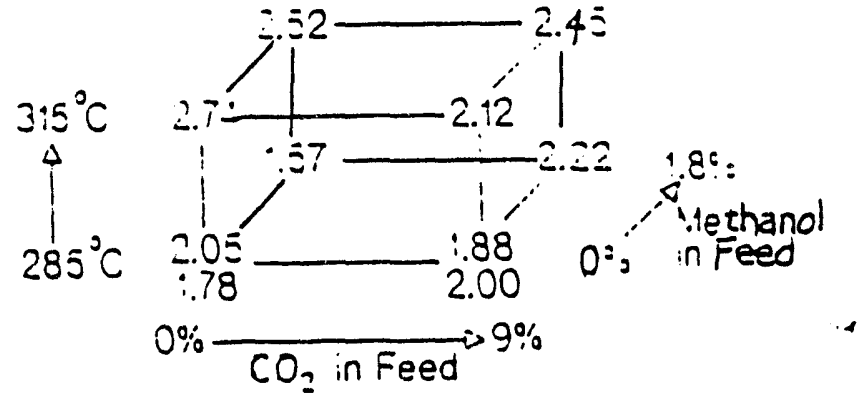

8

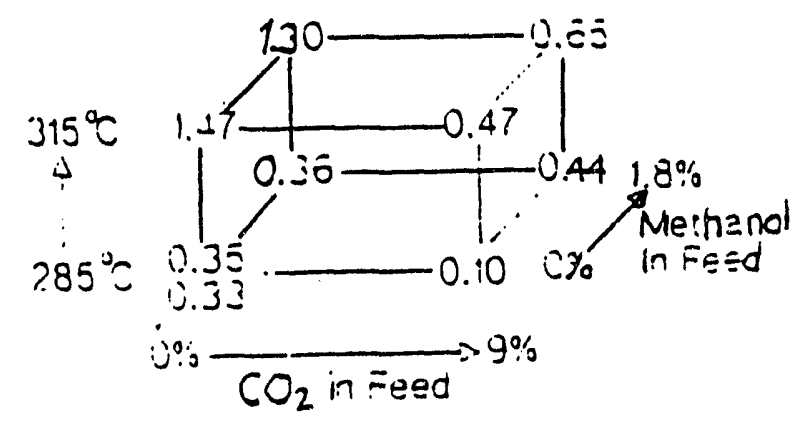


significant since no additional methanol can be formed under these conditions, giving rise to the concept of recycle, as mentioned before with the thermodynamic calculations. Howvever, since the product is primarily methanol, the recycle amounts would be high and possibly unpractical for the promoted $\mathrm{Cu} \mathrm{ZnO}$ catalysts. The water-gas shift equilibrium is heavily favored toward $\mathrm{CO}_{2}$, indicating that little water should be present in the product stream.

The mechanism for higher alcohol synthesis has been extensively studied by several researchers. (Nunan, 1988, 1989; Smith, 1990; Elliot, 1986, 1988, 1988, 1989) The primary technique used has been isotopic labeling of alcohols, followed by injection into the feed stream and subsequent determination in which products the label appears. After many studies, the current mechanisms can be summarized as follows:

- Methyl formate originates from the direct carbonylation of a methoxy species.

- The $C-C$ bond in ethanol is formed by coupling of $C_{1}$ surface intermediates related to methanol.

- Carbon chain growth to $C+$ oxygenates occurs by addition of oxygenated species at the $\beta$ carbon atom of the growing intermediate, both with classic aldol coupling and with aldol coupling with what is called "oxygen retention reversal" where a ketone is generated. This will be discussed in detail later with the modified $\mathrm{ZnCrO}$ methanol catalysts.

- This latter mode is specific to the presence of alkali and is responsible for the formation of ketones and for the higher productivity to propanol.

The $\mathrm{Cu} / \mathrm{ZnO}$ methanol catalysts have received considerable attention for the past 15 years, and higher alcohol synthesis for these catalysts probably have been fairly well optimized. Their major disadvantages are that the predominant alcohol product is methanol and that these catalysts typically deactivate rapidly above reactor temperatures of $250^{\circ} \mathrm{C}$, which does not allow for optimum operating temperatures for higher alcohol synthesis.

\section{Modified ZnCrO Methanol Catalysts for HAS}

Catalysts composed of $\mathrm{ZnCrO}$ were the original methanol synthesis catalysts and were characterized by relatively high operating temperatures $\left(250\right.$ to $400^{\circ} \mathrm{C}$ ) and pressures $(1500$ to 7000 
psig). (Anderson, 1952) These catalysts dominated methanol synthesis until the advent of the lower pressure, lower temperature $\mathrm{Cu} / \mathrm{ZnO}$ methanol catalysts in the early 1970's, as discussed previously. The $\mathrm{ZnCrO}$ catalysts did produce some higher alcohols as byproducts, so this catalyst was a logical place to start for HAS. For higher alcohol synthesis, Morgan and co-ivorkers (1932) tested the effect of alkali promotion on $\mathrm{MnO}-\mathrm{C}_{2} \mathrm{O}_{3}$ catalysts which increased the 2-methy-1propanol (iso-butanol) selectivity, but methanol was still the dominant product. DuPont utilized an alkali-promoted Mn-Cr-O catalyst in the 1940's to produce a mixture of methanol and higher alcohols, but the $\mathrm{H}_{2} / \mathrm{CO}$ ratios were about $12 / 1$ and as much water was produced as alcohols. (Forzatti, 1991) Natta, et.al. (1957) discussed higher alcohol synthesis from the ZnCrO catalysts using alkali oxide or carbonate promoters, again yielding primarily methanol and iso-butanol.

After reneived interest in HAS, the focus for modified $\mathrm{Zn}-\mathrm{Cr}-\mathrm{O}$ and $\mathrm{MIn}-\mathrm{Cr}-\mathrm{O}$ has been on cantalyst structure and composition, partly to find the active sites for alcohol formation and party to encourage higher alcohol selectivity and productivity. Starting from the base constituents of these catalysts, Tronconi, et.al. (1987) investigated the performance of pure $\mathrm{Zn}, \mathrm{Mn}$, and $\mathrm{Cr}$ oxides, and compared the results with a $\mathrm{K}$ promoted $\mathrm{ZnO} / \mathrm{Cr}_{2} \mathrm{O}_{3}$ calalyst. The pure oxide catalysts were prepared by precipitation from metal nitrate solutions, the metal phases were identified by X-ray powder diffraction, and the catalyst alkali content by atomic absorption spectrometry. These catalyst properties along with their surface areas are shown in Table 4 . Note the high surface area of the $\alpha-\mathrm{Cr}_{2} \mathrm{O}_{3}$, and also note that the $\mathrm{ZnCrKO}$ commercial catalyst appears to be a combination of $\mathrm{ZnO}$ metal phase and a $\mathrm{ZnC}_{2} \mathrm{O}_{4}$ spinel like phase. 


\section{TABLE 4}

(Tronconi, 1987)

Physico-Chemical Properties of the Catalysts after Activity Runs

$\begin{array}{ccccc}\text { Sample } & \begin{array}{c}\text { Identified } \\ \text { Phases }\end{array} & \begin{array}{c}\text { Surface Area } \\ \mathrm{m}^{2} / \mathrm{g}\end{array} & \begin{array}{c}\% \mathrm{Na} \\ \text { by wt. }\end{array} & \begin{array}{c}\% \mathrm{~K} \\ \text { by wt. }\end{array} \\ \mathrm{ZnO} & \mathrm{ZnO} & 11.5 & \begin{array}{c}<0.01 \\ (27 \mathrm{ppm})\end{array} & \begin{array}{c}<0.01 \\ (12 \mathrm{ppm})\end{array} \\ \mathrm{MnO} & \mathrm{MnO} & 17.6 & <0.01 & <0.01 \\ \mathrm{Cr}_{2} \mathrm{O}_{3} & \mathrm{MnCO}_{3} & & (60 \mathrm{ppm}) & (18 \mathrm{ppm}) \\ \mathrm{ZnCrKO}_{\mathrm{r}} & \alpha-\mathrm{Cr}_{2} \mathrm{O}_{3} & 92.2 & 0.09 & 0.03 \\ & \mathrm{ZnCr}_{2} \mathrm{O}_{4} & 42 & \text { n.a. } & 3.0 \\ & \mathrm{ZnO} & & & \end{array}$

Table 5 lists the results from catalyst testing with $\mathrm{CO}$ and $\mathrm{H}_{2}$ in a $\mathrm{Cu}$ lined, tubular, fixed-bed reactor. Several observations can be made from this data:

- The $\mathrm{CO}$ conversion is approximately the same for the pure oxides, but the $\mathrm{ZnCrKO}_{x}$ catidyst $\mathrm{CO}$ conversion is almost double the pure oxides.

- The pure oxide catalysts demonstrate reasonable methanol productivity relative to the $\mathrm{ZnCrKO}$. catalyst. Methane productivities for the pure oxides are higher than for the $\mathrm{ZnCrKO}_{x}$ catalyst.

- The $\mathrm{C}_{2+}$ oxygenates and $\mathrm{C}_{2}$ hydrocarbons productivity for the pure oxides are much lower than the $\mathrm{ZnCrKO} \mathrm{s}_{\mathrm{x}}$ catalyst. Howvever, the average carbon number $\left(\mathrm{N}_{\mathrm{c}}\right)$ for $\mathrm{ZnO}, \mathrm{MnO}$ and $\mathrm{ZnCrKO}_{x}$ catalysts are similar. Though the $\mathrm{ZnO}$ and $\mathrm{MnO}$ are not productive HAS catalysts, the carbon chain growth mechanism is apparently active and may not depend on alkali promoters. 


\section{TABLE 5}

(Tronconi, 1987)

Results of Activity Runs

Reaction Conditions: $\mathrm{T}=405^{\circ} \mathrm{C}, \mathrm{P}=85 \mathrm{~atm}, \mathrm{H}_{2} / \mathrm{CO}=1 / 1$, GHSV $=8000 \mathrm{~h}^{-1}$. Catalyst Loads: $\mathrm{ZnO}=5.5 \mathrm{~g}, \mathrm{MnO}=8.8 \mathrm{~g}, \mathrm{Cr}_{2} \mathrm{O}_{3}=4.0 \mathrm{~g}, \mathrm{ZnCrKO}_{\mathrm{x}}=11.4 \mathrm{~g}$

\begin{tabular}{|c|c|c|c|c|c|c|c|}
\hline \multirow[t]{2}{*}{ Sample } & \multirow{2}{*}{$\begin{array}{l}\approx \mathrm{CO} \\
\text { conversion }\end{array}$} & \multicolumn{4}{|c|}{ Productivities/g $1^{-1} \mathrm{~h}^{-1}$} & \multicolumn{2}{|c|}{ Average $\mathrm{N}_{c}$} \\
\hline & & $\mathrm{CH}_{3} \mathrm{OH}$ & $\mathrm{CH}_{4}$ & $c_{2}+0 x y g$ & $\mathrm{C}_{2}$ +hydr. & $C_{2}+0 \times y 9$ & $C_{2}$ thydr. \\
\hline $2 n o$ & 3.9 & 50.8 & 21.3 & 6.0 & 8.5 & 3.5 & 2.7 \\
\hline Mno & 3.5 & 47.6 & 17.6 & 10.2 & 9.7 & 4.2 & 2.8 \\
\hline $\mathrm{Cr}_{2} \mathrm{O}_{3}$ & $4: 6$ & 71.5 & 19.0 & 4.2 & 17.2 & 2.7 & 2.6 \\
\hline $2 n \operatorname{cor}^{2} 0_{x}$ & 10.7 & 71.9 & 11.9 & 128 & 32.6 & 4.1 & $3.0=$ \\
\hline
\end{tabular}


When the data in Table 5 are reported in a different form as weight based product selectivities, then the catalyst performance is clear. (Table 6) Note that the selectivities are almost identical for the oxygenates over the pure oxide catalysts, while the $\mathrm{ZnCrKO}_{\mathrm{x}}$ catalyst displays a greater oxygenate selectivity. When these values are narrowed to include only higher oxygenates, then the difference is evident. Apparently the combination of the $\mathrm{Zn}-\mathrm{Cr}-\mathrm{K}$ dramatically improves the $\mathrm{C}_{2}+$ selectivity. Since $\mathrm{Zn}$ and $\mathrm{Cr}$ alone do not appear to be good HAS catalysts as shown earlier, then either the $\mathrm{Zn}-\mathrm{Cr}$ combination or the $\mathrm{K}$. promoter are the instigators for increased HAS productivities. This will be discussed in detail later.

\section{TARLE 6}

(Tronconi, 1987)

$\begin{array}{ccc}\text { Catalyst Selectivities for Lethanol and Higher Alcohol Synthesis } \\ \text { Catalyst } & \begin{array}{c}\text { Total Oxygenate } \\ \text { Selectivitya }\end{array} & \begin{array}{c}\mathrm{C}_{2}+\text { Oxygenate } \\ \text { Selectivity }\end{array} \\ \mathrm{ZnO} & 66 \% & 41 \% \\ \mathrm{MnO} & 68 \% & 51 \% \\ \mathrm{Cr}_{2} \mathrm{O}_{3} & 67 \% & 20 \% \\ \mathrm{ZnCrKO}_{x} & 82 \% & 80 \%\end{array}$

${ }^{2}$ Selectivity $=100 \times \frac{\text { Total Oxvgenate Productivitv }}{\text { Total Oxygenate }+ \text { Total Hydrocarbon Productivity }}$ bSelectivity $=100 \times \frac{C_{\underline{t}}+\text { Oxvgenate Productivitv }}{C_{\underline{\underline{\underline{p}}}}+\text { Oxygênate }+C_{\underline{\underline{2}}}+\text { Hydrocarbon Productivity }}$

Although not shown in the tabies above, Tronconi, et.al. reported that large quantiues of $\mathrm{CO}_{2}$ were generated Irom al! of the catalysts; responsible for almost half of the CO converted. This and the absence of water in the product stream indicate high water-gas-shift activity for the catalysts, which can be of great benefit for higher alcohol synthesis, especially when low $\mathrm{H}_{2} / \mathrm{CO}$ ratios are used. 
When the $\mathrm{MnO}$ and $\mathrm{ZnCrKO}_{\mathrm{x}}$ product distributions are plotted on a Schulz-Flory graph, as done in Figures 16 and 17, the non-conformities of the oxygenates are clear. Note the large concentration of $\mathrm{C}_{4}$ oxygenates for both catalysts. The hydrocarbons also deviate significantly from a S-F distribution, with $\mathrm{C}_{4}$ products also in greater concentration than expected, but not as gr at as the oxygenates. The mechanisms explaining these deviations will be discussed later.

As discussed earlier, the pure $\mathrm{ZnO}$ and $\mathrm{MnO}$ catalysts do not make good HAS catalysts, but a combination of $\mathrm{Zn}$ or $\mathrm{Mn}$ with $\mathrm{Cr}$ oxides and an alkali promoter will allow HAS to occur. Therefore, determining the catalyst structure which encourages higher alcohol formation is critical for HAS catalyst design. Di Conco, et.al. (1984) examined different levels of $\mathrm{Z} n \mathrm{Cr}$ atomic ratios to determine the effect of $\mathrm{Cr}$ oxides on the structure. From X-ray diffraction powder data on samples prepared by precipitation from metal solutions, it was concluded that the metal phases present in the catalyst depended highly on $\mathrm{Zn} / \mathrm{Cr}$ atomic racio. First, catalyst samples with $\mathrm{Zn} / \mathrm{Cr}$ ratio $\leq 1.0$ had only a spinel-like phase, i.e. the general form of $\mathrm{ZnCr}_{2} \mathrm{O}_{4}$ For samples with $\mathrm{Zn} / \mathrm{Cr}$ ratios exceeding 1.0 , both a spinel-like microcrystalline phase and a crystalline $\mathrm{ZnO}$ phase were present. However, for both cases, the $\mathrm{Zn}$ present in the spinel phase, $\mathrm{ZnC}_{2} \mathrm{O}_{4}$, and/or the $\mathrm{ZnO}$ phase did not account for all of the $\mathrm{Zn}$ present in the catalyst $\mathrm{Di}$ Conco, et.al. believed that the "missing" $\mathrm{Zn}$ was present in the spinel phase, and hence the entire phase composition could be expressed in the form $\mathrm{Zn}_{\mathrm{x}} \mathrm{C}_{2 / 3(1-\mathrm{x})} \mathrm{O}$. Further analysis indicated that the amount of $\mathrm{Zn}$ ions present in the spinel phase, represented by the value of $x$, were dependent on calcination temperatures as shown in Figure 18. The possibility of excess $\mathrm{Zn}$ ions situated in either octahedral or tetrahedral sites in the spinel phase was supported by measurements of the lattice parameter a which ranged from 0.834 to $0.850 \mathrm{~nm}$, while that of pure $\mathrm{ZnCr}_{2} \mathrm{O}_{4}$ is only $0.8327 \mathrm{~nm}$.

Catalytic productivities of the $1 / 1$ and $3 / 1 \mathrm{Zn} / \mathrm{Cr}$ catalysts are shown in Table 7 . Note that the $1 / 1 \mathrm{Zn} / \mathrm{Cr}$ ratio demonstrates the higher alcohol productivity for both methanol and higher alcohols. Also note, however, that $\mathrm{CO}_{2}$ was present in the gas feed which discourages HAS over an active water gas shift catalyst, which these are, but does not affect methanol synthesis. So their productivity results may not represent the HAS capability of these catalysts. 
Figure 16. Product distribution over MnO catalyst. (Tronconi, 1987)

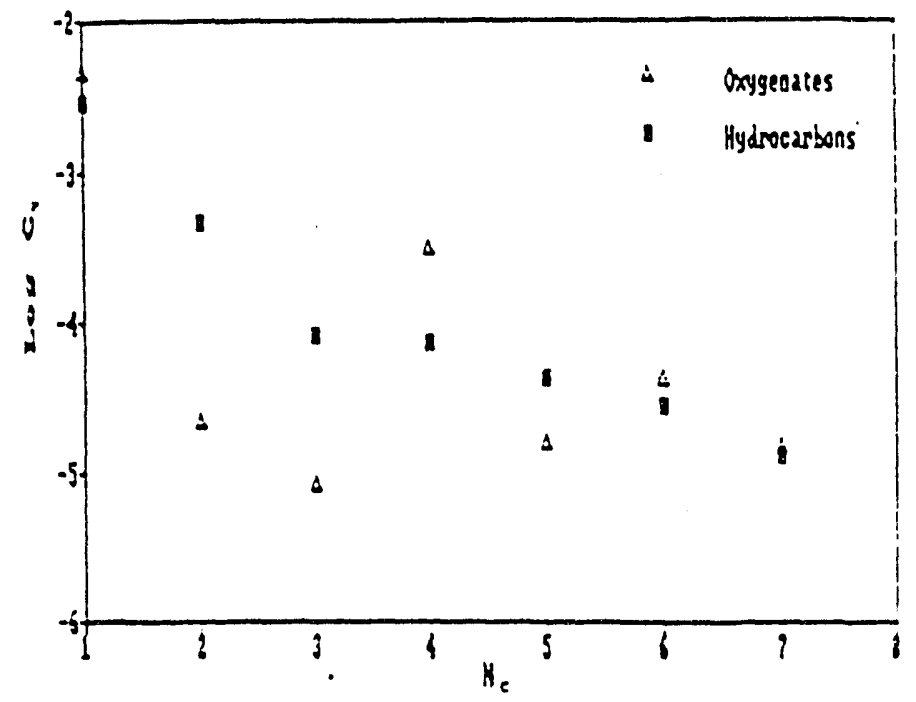

Figure 17. Product distribution over $\mathrm{ZnCrKO}_{x}$. (Tronconi, 1987)

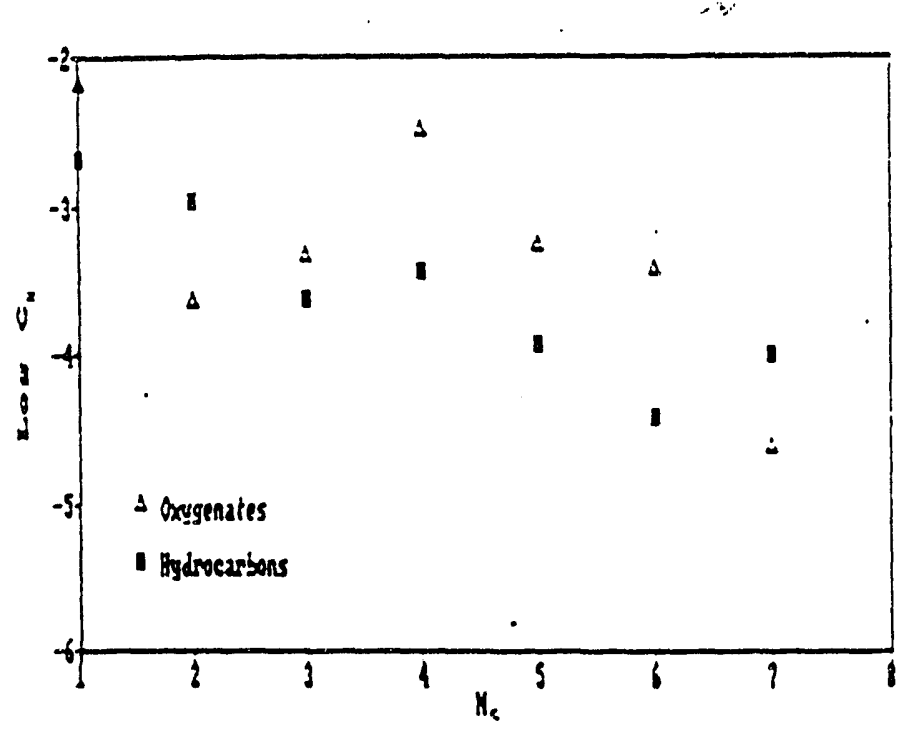


Figure 18. $\mathrm{X}$ values of the formula $\mathrm{Zn}_{\mathrm{x}} \mathrm{Cr}_{2 / 3(1-x)} \mathrm{O}$ for different calcination temperatures.

(Di Conca, 1984)

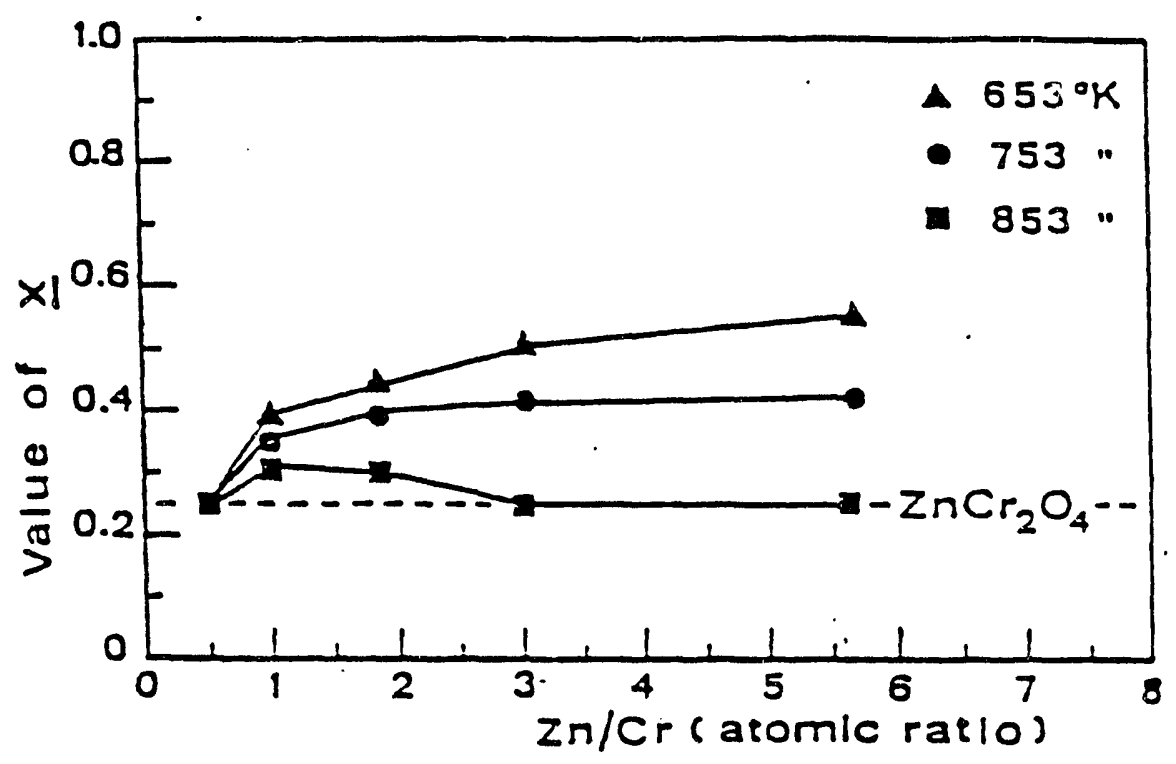

TABLE 7

(Di Conca, 1984)

Catalytic Data for the $\mathrm{Zn} / \mathrm{Cr}=3$ and $\mathrm{Zr} / \mathrm{Cr}=1$ Catalysts

$\mathrm{P}=8.0 \mathrm{MPa}$, Reaction Time $=8 \mathrm{~h}, \mathrm{GHSV}=8000-9000 \mathrm{~h}^{-1}, \mathrm{H}_{2} / \mathrm{CO} / \mathrm{CO}_{2}=62.1 / 32.5 / 5.4$

\begin{tabular}{|c|c|c|c|c|c|c|c|}
\hline \multirow{3}{*}{$\begin{array}{l}Z \mathrm{Z} / \mathrm{Cr} \\
\text { (at. ratio) } \\
50: 50\end{array}$} & \multirow{3}{*}{$\begin{array}{c}K \% \\
(w / w) \\
--\end{array}$} & \multirow{3}{*}{\multicolumn{2}{|c|}{$\begin{array}{l}\text { React. temp. } \\
\left({ }^{\circ} \mathrm{K}\right) \\
623 \quad \because\end{array}$}} & \multicolumn{4}{|c|}{ Productivity $\left(\mathrm{g} \mathrm{h}^{-1} \mathrm{~kg}_{\text {catalyst }}^{-1}\right)$} \\
\hline & & & & $\mathrm{CH}_{4}$ & $\mathrm{CH}_{3} \mathrm{OH}$ & H.A. & H.M.W. \\
\hline & & & & 4.6 & 392.6 & 10.9 & 3.6 \\
\hline$"$ & 3 & $"$ & & 0 & 130.0 & 4.2 & 1.2 \\
\hline $75: 25$ & -- & $"$ & & 0 & 188.4 & 0.6 & 1.0 \\
\hline$"$ & 3 & $"$ & & 0 & 108.3 & 6.7 & 1.0 \\
\hline $50: 50$ & -- & 673 & & 7.2 & 194.4 & 17.1 & 1.5 \\
\hline$"$ & 3 & $"$ & & 14.0 & 150.0 & 28.0 & 2.0 \\
\hline $75: 25$ & -- & $"$ & & 3.4 & 59.1 & 1.7 & 0.2 \\
\hline$"$ & 3 & $"$ & & 1.6 & 55.3 & 18.9 & 2.1 \\
\hline
\end{tabular}

H.A. = higher alcohols; H.M.H. = other higher molecular weight compounds. 
Based on these results and the catalyst structures, Di Conco, et.al. postulated that the spinel phase was the active species in the hydrogenation of $\mathrm{CO}$ to methanol. They further speculated that the reason for this effect is the presence of the excess $\mathrm{Zn}$ ions in the spinel like phase. Further work by Riva, et.al. (1987) supported these findings.

Cristiani, et.al. (1989) also studied the $\mathrm{Zn}-\mathrm{Cr}-\mathrm{O}$ catalyst structure for $\mathrm{Zn} / \mathrm{Cr}$ atomic ratio = 1 , and deduced an altemate structure. Based on similar results to those reported earlier, Cristiani, et.al. proposes a catalyst that has a shell rich in $\mathrm{ZnCrO}_{4}$ and a core of $\mathrm{ZnCr}_{2} \mathrm{O}_{4}$ and $\mathrm{ZnO}$, however, they do admit that their experimental data can be explained by the other structure.

Extensive catalyst structural studies were also done on the unpromoted $\mathrm{Mn}-\mathrm{Cr}-\mathrm{O}$ catalysts, - varying the $\mathrm{Mn} / \mathrm{Cr}$ ratios and the activation environments. (Cristiani, et.al., 1990) After examining catalysts activated in air, hydrogen, and nitrogen, the only catalyst usable for HAS was that activated under nitrogen.at 400 to $\$ 00^{\circ} \mathrm{C}$. The samples contain no free oxides of $\mathrm{Cr}$ and $\mathrm{Mn}$, and their surface areas were typically in excess of $100 \mathrm{~m}^{2} / \mathrm{g}$. These catalysts were subsequently tested for catalytic activity in a fixed-bed, Cu-lined, tubular reactor, The results are shown in Table 8. Also, a $\mathrm{K}$ promoted commercial $\mathrm{ZnCrO}_{x}$ catalyst, as well as a $\mathrm{Cs}$ promoted $\mathrm{MnCrO}_{\mathrm{x}}$ catalysts were examined for comparison purposes. The manufacturer of the commercial catalyst was not listed in the article.

\section{TABLE 8}

(Cristiani, 1990)

Results of Catalytic Activity Tests for $\mathrm{MnCrO}$ Samples with Different Mn/Cr Ratios

\begin{tabular}{|c|c|c|c|c|c|c|}
\hline \multirow[t]{2}{*}{$\mathrm{Mn} / \mathrm{Cr}$} & \multicolumn{6}{|c|}{ Productivity $\left(g / l_{\text {cat }} \cdot h\right)$} \\
\hline & $\mathrm{CH}_{3} \mathrm{OH}$ & $\mathrm{C}_{2+}$ oxyg. & $\mathrm{CH}_{4}$ & $\mathrm{C}_{2+\text { hydroc. }}$ & $\mathrm{CO}_{2}$ & Ethers \\
\hline 0.5 & 38.5 & 13.1 & 27.0 & 1.5 .9 & 213 & Si.j \\
\hline 1.0 & 152 & 19.9 & 12.1 & 12.0 & 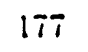 & 65.5 \\
\hline 5.0 & 127 & 22.1 & 14.6 & 13.0 & $12 T$ & 11.4 \\
\hline $1.0\left(+10.5 \% \mathrm{Cs}_{2} \mathrm{O}\right)$ & 85.7 & 132 & 7.8 & 20.2 & 422 & 0.2 \\
\hline $\mathrm{ZnCrO}_{2}\left(+3 \% \mathrm{~K}_{2} \mathrm{O}\right)(3)$ & 71.8 & 128 & 11.9 & 32.6 & 4.5 .3 & 5.0 \\
\hline
\end{tabular}


Several observations can be made from these results:

- The productivity toward $\mathrm{C}_{2+}$ oxygenates is greater than methanol productivity for the $\mathrm{Cs}$ promoted $\mathrm{MnCrO}$ and the $\mathrm{K}$ promoted $\mathrm{ZnCrO}_{x}$ catalysts.

- $\mathrm{Mn} / \mathrm{Cr}$ ratios $>0.5$ are required for high methanol synthesis activity

- Since $\mathrm{CO}_{2}$ formation is high, all of these catalysts are excellent water-gas-shift catalysts.

- Although the non-promoted catalysts gave lower productivities of higher alcohols, the higher alcohols are nevertheless formed. The alkali promoter does not appear to be required for chain growth. It probably speeds the growth steps.

- Increasing $\mathrm{Mn} / \mathrm{Cr}$ ratios depress the formation of ethers and methane, although alkali promoters are apparently much more effective.

Tronconi, et.al. (1989) investigated the effects of both $\mathrm{K}$ and Cs promoters on $\mathrm{MnCrO}$ and $\mathrm{ZnCrO}$ catalysts. First, the alkali promoters on the $\mathrm{MnCrO}$ improve higher alcohol selectivity with respect to all other products, as shown in Figures 19 and 20. Tronconi, et.al. reported that similar results were obtained with the $\mathrm{ZnCrO}$ catalyst, but no data was listed. The higher alcohol selectivity appears to pass through a maximum for the $\mathrm{K}$ promoted cataiyst around $3 \mathrm{wt} \% \mathrm{~K}_{2} \mathrm{O}$, but no maximum is observed for the Cs promoted catalyst up to 10 wt $\%$ Cs loading. If the selectivity data is plotted versus alkali/Cr atomic ratio as shown in Figure 21, then a maximum at 0.5 is clear for the $\mathrm{K}$ promoter. But the Cs promoter concentrations tested were not sufficient to reach a 0.5 ratio, possibly explaining why a maximum in higher alcohol-selectivity was not reached for this catalyst.

Also note in Figures 19 \& 20 that ether selectivity drops dramatically with increasing alkali promoter content. Tronconi, et.al. proposed that the alkali promoters suppressed the acidcatalyzed dehydration of alcohols to ethers, explaining their decrease upon promoter addition despite the relative increase in alcohols. Tronconi, et.al. also proposed that the alkali speeded up the $C_{1}$ to $C_{2}$ chain growth step, giving rise to the higher selectivity toward $C_{2}+$ alcohols. The actual mechanism of this chain growth will be discussed later. 
Figure 19. Results of activity tests over $\mathrm{MnCrO}$ catalysts promoted with increasing amounts of potassium. Reaction conditions: $\mathrm{T}=405^{\circ} \mathrm{C}, \mathrm{P}=85 \mathrm{~atm}, \mathrm{H}_{2} / \mathrm{CO}$ ratio $=1 / 1$, GHSV $=$ $8000 \mathrm{~h}^{-1}$, and $\mathrm{CO}_{2}$ feed $=0$. (Tronconi, 1989)

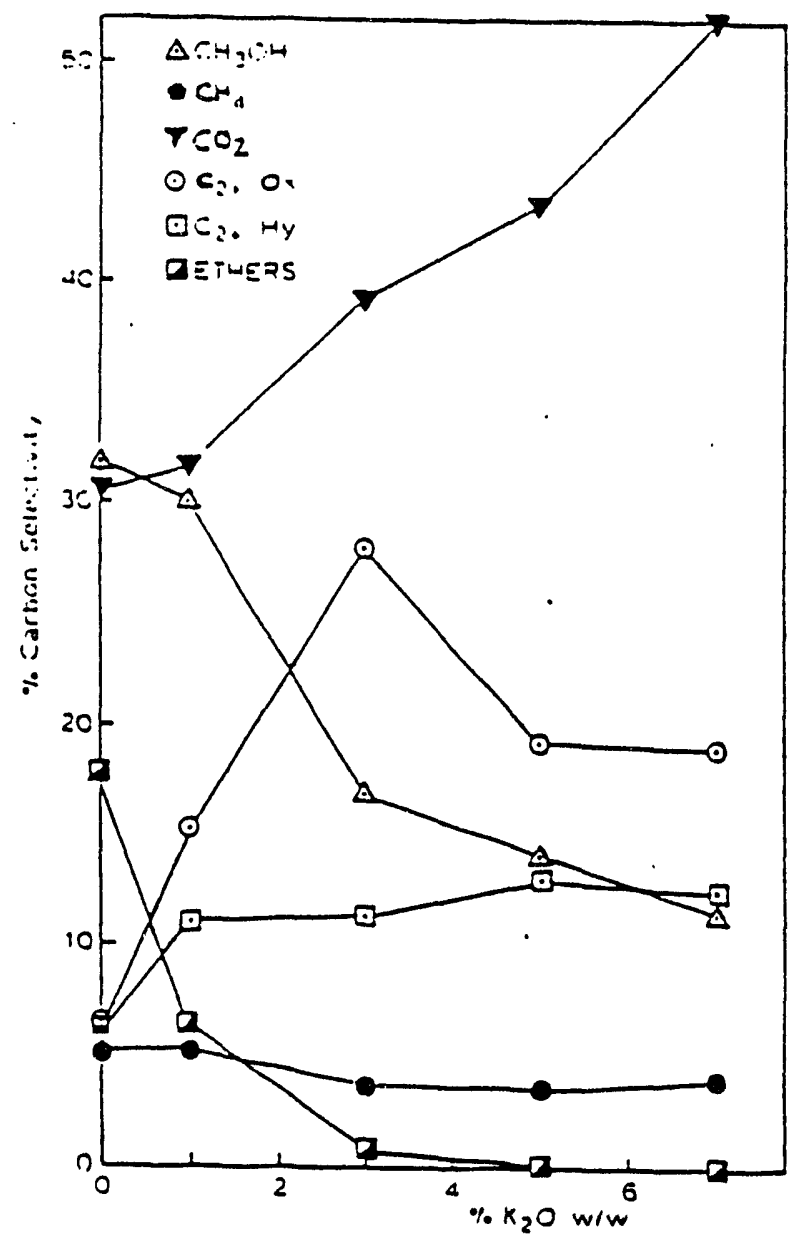


Figure 20. Results of activity tests over MnCrO catalysts promoted with increasing amounts of cesium. Reaction conditions: $\mathrm{T}=405^{\circ} \mathrm{C}, \mathrm{P}=85 \mathrm{~atm}, \mathrm{H}_{2} / \mathrm{CO}$ ratio $=1 / 1$, GHSV $=$ $8000 \mathrm{~h}^{-1}$, and $\mathrm{CO}_{2}$ feed $=0$. (Tronconi, 1989)

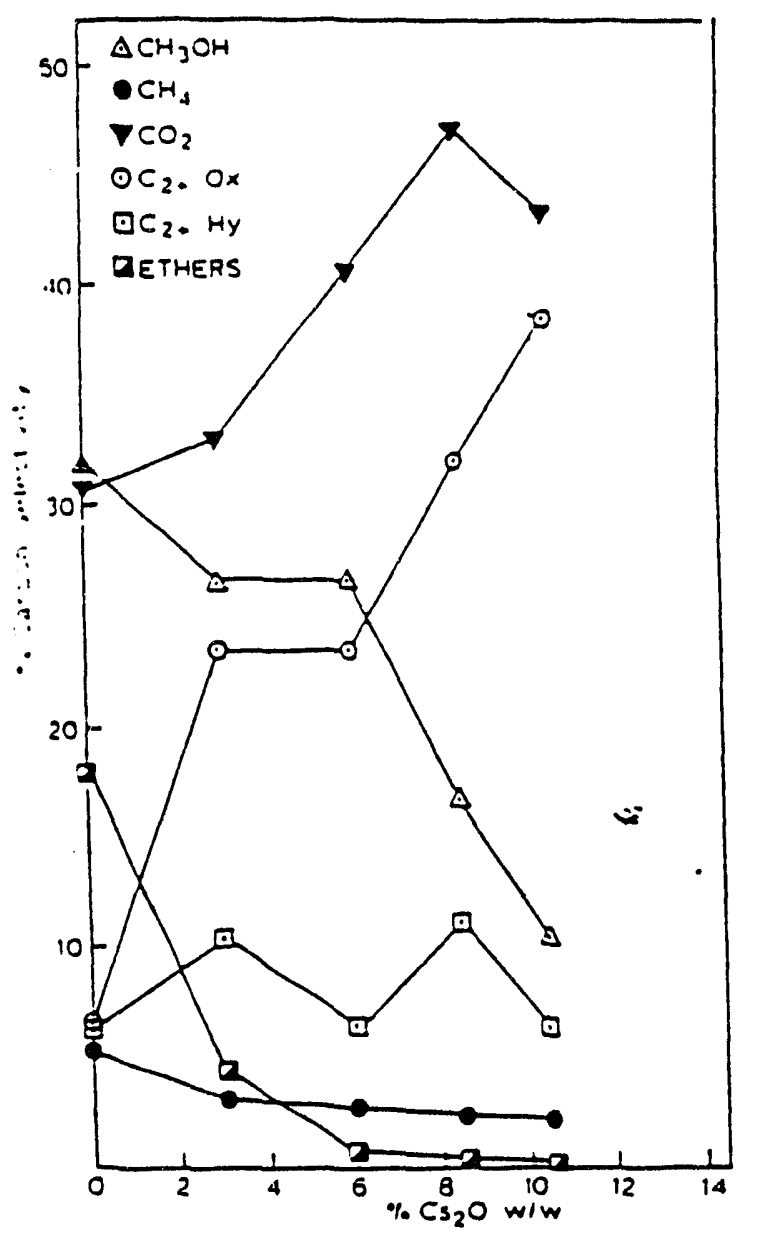


Figure 21. Correlation between carbon selectivity with respect to $C_{2}+$ oxygenates and XPS alkali metal-to-chromium ratio. $\mathrm{MnCrO}$ catalyst with reaction conditions: $\mathrm{T}=405^{\circ} \mathrm{C}, \mathrm{P}=85$ atm, $\mathrm{H}_{2} / \mathrm{CO}$ ratio $=1 / 1$, GHSV $=8000 \mathrm{~h}^{-1}$, and $\mathrm{CO}_{2}$ feed $=0$. (Tronconi, 1989)

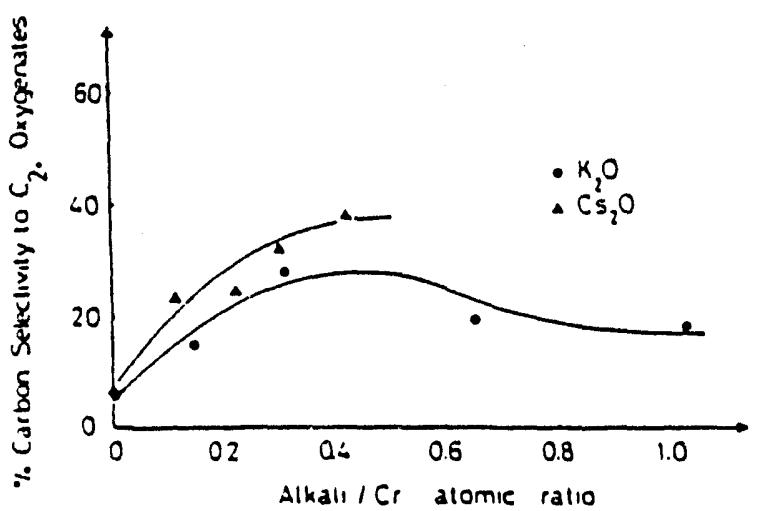


Alkali addition apparently decreases the catalyst surface area for the $\mathrm{ZnCrO}$ and the $\mathrm{MnCrO}$ catalysts, as shown in Table 9. The promoted catalyst surface area decreased as much as $70 \%$ relative to the unpromoted catalyst. Although this decrease should cause a decline in catalyst productivity, no productivity numbers were reported for comparison purposes.

\section{TABLE 9}

(Tronconi, 1989)

Effect of Alkali Metal Promotion on the Catalyst Surface Area, $A_{s}$, and on the Average Carbon Number of $\mathrm{C}_{2}$ Oxygenated Products, $\mathrm{N}_{\mathrm{Cox}}$, over $\mathrm{MnCrO}$ Catalysts

Reaction Conditions: $\mathrm{T}=405^{\circ} \mathrm{C}, \mathrm{P}=85 \mathrm{~atm}, \mathrm{GHSV}=8000 \mathrm{~h}^{-1}$,

$$
\mathrm{H}_{2} / \mathrm{CO} \text { feed ratio }=1 / 1, \mathrm{CO}_{2} \text { feed }=0
$$

\begin{tabular}{ccc}
$\begin{array}{c}\text { Alkali Metal } \\
\text { Loading }(\mathrm{w} / \mathrm{w})\end{array}$ & $\begin{array}{c}\mathrm{As}_{\mathrm{s}} \\
(\mathrm{m} / \mathrm{g})\end{array}$ & $\mathrm{N}_{\text {Cox }}$ \\
None & 170 & \\
$1 \% \mathrm{~K}_{2} \mathrm{O}$ & 138 & 4.3 \\
$3 \% \mathrm{~K}_{2} \mathrm{O}$ & 137 & 4.4 \\
$5 \% \mathrm{~K}_{2} \mathrm{O}$ & 106 & 4.5 \\
$7 \% \mathrm{~K}_{2} \mathrm{O}$ & 50 & 4.3 \\
$3 \% \mathrm{Cs}_{2} \mathrm{O}$ & 123 & 4.0 \\
$6 \% \mathrm{Cs}_{2} \mathrm{O}$ & 103 & 4.4 \\
$8.5 \% \mathrm{Cs}_{2} \mathrm{O}$ & 78 & 4.2 \\
$10.5 \% \mathrm{Cs}_{2} \mathrm{O}$ & 51 & 4.4 \\
\hline
\end{tabular}

Tronconi, et.al., also compared the average carbon number of the $\mathrm{C}_{2}+$ oxygenates for the promoted and unpromoted catalyst, also shown in Table 9. Note that the carbon number $\mathrm{N}_{\text {Cox }}$ does not change significantly upon alkali addition to the catalyst, indicating that the chain growth mechanism is operating over the unpromoted catalyst, and the alkali promoter simply encourages increased higher alcohol productivity and selectivity, but not longer chain growth. Note also that no significant difference exists in the carbon number between the $\mathrm{K}$ and $\mathrm{Cs}$ promoted catalysts.

The effects of temperature and pressure were investigated by Tronconi, et.al. (1989) over a $\mathrm{ZnCrO}$ catalyst promoted with $15 \mathrm{wt} \% \mathrm{CsO}_{2}$. Increasing pressure benefits $\mathrm{C}_{2+}$ oxygenates with 
respect to $\mathrm{C}_{2+}$ hydrocarbons, represented by their increasing ratio in Figure 22. Note that the ratios start above 10 and increase almost to 20, illustrating that higher hydrocarbons are not a significant portion of overall products produced. However, the relative amounts of methanol produced compared with higher oxygenates increases with ascending pressure, represented by the decreasing higher oxygenate/methanol ratio in Fig. 22. Also note that the $\mathrm{HA} / \mathrm{CH}_{3} \mathrm{OH}$ ratio starts at 1 , meaning the same amount of methanol is produced as higher alcohols, and decreases below 0.5. This is surprising since earlier data showed that $\mathrm{MnCrO}$ catalysts promoted with 12 wt \% Cs could produce at least a $4 / 1$ carbon atom ratio of higher oxygenates to methanol. Tronconi, et.al. do not clarify whether the ratios shown in Fig. 22 are weight or molar ratios, so no further comparisons can be made. Note, still, that the gas hourly space velocity (GHSV) for the data in Fig. 22 is $20,000 \mathrm{hr}^{-\mathrm{l}}$, but the GHSV for the previously reported data over the Cs promoted $\mathrm{MgCrO}$ catalyst is only $8000 \mathrm{hr}^{-1}$, again negating data comparison.

Increasing temperature encourages higher oxygenate formation versus methanol, represented by their increasing ratio in Figure 23. As discussed later, methanol formation approaches equilibrium under these operating conditions. Increasing temperarure depresses methanol formation under equilibrium conditions, so the decrease in methanol relative to higher alcohols is not surprising, since the higher alcohol formation is not under equilibrium constraints. A definite maximum is observed for the higher oxygenate to higher hydrocarbon ratio around $360^{\circ} \mathrm{C}$ for the $8000 \mathrm{hr}^{-1} \mathrm{GHSV}$ case, but the same type maximum occurs at $390^{\circ} \mathrm{C}$ for the $20000 \mathrm{hr}^{-1} \mathrm{GHSV}$ case. Also, note that decreasing GHSV apparently increases the HA/methanol ratio. Note that the temperatures investigated were all less than the $405^{\circ} \mathrm{C}$ listed for all other productivity data.

In both the pressure and temperature investigations, although some general trends are shown, the ratios presented were not defined as weight or molar, so no definite conclusions or comparisons can be made. Also, effects of temperature, pressure, and GHSV on productivity or activity data were not shown, but are necessary for a complete, accurate interpretation of the data presented. 
Figure 22. Effect of reaction pressure on the selectivity ratios $\mathrm{C}_{2}+$ oxygenates $(\mathrm{HA})$ to methanol and $\mathrm{C}_{2}+$ oxygenates to $\mathrm{C}_{2}+$ hydrocarbons $(\mathrm{HY})$. Reaction conditions: $\mathrm{T}=405^{\circ} \mathrm{C}$, $\mathrm{H}_{2} / \mathrm{CO}=1 / 1, \mathrm{GHSV}=20000 \mathrm{~h}^{-1}, \mathrm{CO}_{2}$ feed $=0$. (Tronconi, 1989)

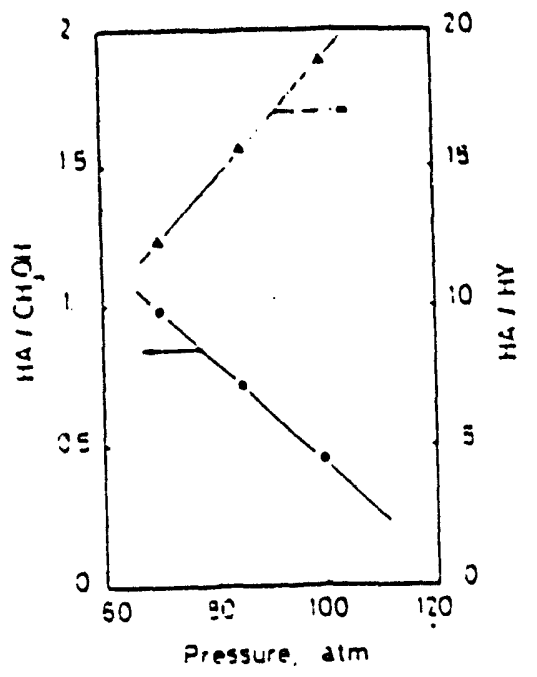


Figure 23. Effect of reaction temperature on the selectivity ratios of $\mathrm{C}_{2^{+}}$oxygenates (HA) to methanol and $\mathrm{C}_{2}+$ oxygenates to $\mathrm{C}_{2}$ hydrocarbons ( $\mathrm{HY}$ ). Reaction conditions: $\mathrm{P}=85$ atm, $\mathrm{H}_{2} / \mathrm{CO}=1 / 1, \mathrm{CO}_{2}$ feed $=0$. (Tronconi, 1989)

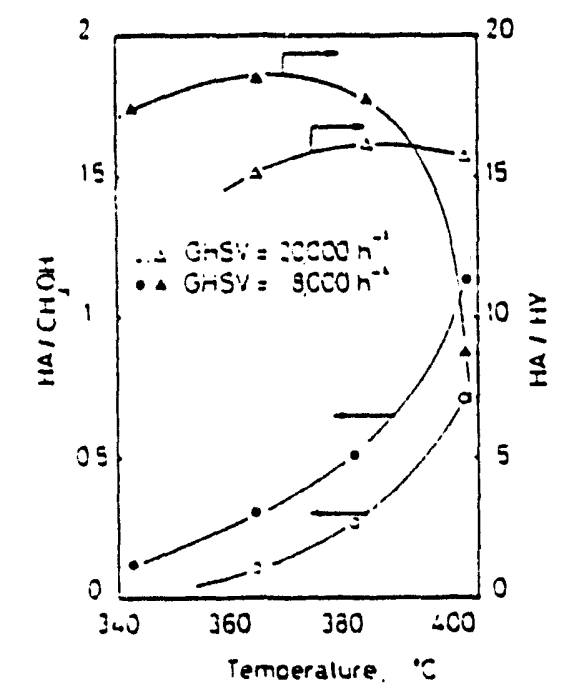


Under higher alcohol synthesis conditions, Tronconi, et.al. (1990) observed that several reactions approach chemical equilibrium. These reactions include: 1) methanol formation, 2) water-gas-shift, 3) methyl formate and possibly higher methyl esters formation, 4) hydrogenation of aldehydes to primary alcohols, 5) hydrogenation of ketones to secondary alcohols, and 6) ketonization reactions. The approach to equilibrium was determined by comparing the product of the partial pressures ratio $\mathrm{K}_{\mathrm{p} \text { }}$ determined experimentaliy for each reaction, and $\mathrm{K}_{\varphi}$, the ratio of the fugacity coefficients estimated by Soave-Redlich-Kivong equation of state, with the equilibrium constant $K_{\text {eq }}(T)$, calculated using thermochemical data. The data was gathered over a $15 \mathrm{wt} \%$ Cs promoted $\mathrm{ZnCr}$-oxide catalyst with a $1 / 1 \mathrm{Zn} / \mathrm{Cr}$ atomic ratio. The closest approach to equilibrium was achieved at $405^{\circ} \mathrm{C}, 8.6 \mathrm{MPa}$, GHSV $=8000 \mathrm{~h}^{-1}$, and $\mathrm{H}_{2} / \mathrm{CO} / \mathrm{CO}_{2}$ gas feed ratio of $1 / 1 / 0$. As a general rule, higher temperature and lower GHSV favor approach to equilibrium for the reactions listed above.

Although all the reactions listed are significant for HAS, the reactions which have the most impact are methanol formation, the water-gas-shift reaction and hydrogenation of aldehydes to primary alcohols. As explained in the thermodynamic studies, if methanol formation is at equilibrium, then methanol addition to the feed gas (simulated recycle) which surpasses the methanol produced does not affect the higher alcohol product distribution, essentially adding stoichiometric $2 / 1 \mathrm{H}_{2} / \mathrm{CO}$ feed. This also explains why HAS is favored at low $\mathrm{H}_{2} / \mathrm{CO}$ feed ratios and lower pressures where methanol formation is thermodynamically suppressed if the water-gasshift reaction is active.

Again, the thermodynamic calculations indicate that the water-gas-shift reaction plays an important role in oxygen rejection above $250^{\circ} \mathrm{C}$. In fact, Tronconi, et.al. (1990), report very little water is present in the HAS products, but a significant quantity of $\mathrm{CO}_{2}$ is present, indicating that the water-gas-shift is rapid, and by their calculations, close to equilibrium. Indeed, since water has been proposed as an inhibitor for HAS due to site competition with $\mathrm{C}_{1}$ oxygenated intermediates, the water gas shift is believed to be essential for water removal from the catalyst surface. (Tronconi, 1987) The only drawback is that $\mathrm{CO}_{2}$ competes with alcohol products for consumption 
of the available $\mathrm{CO}$.

The equilibrium between aldehydes and primary alcohols (i.e. the hydrogenation of aldehydes to primary alcohols) can be critical for alcohol chain growth. Alcohol chain growth is believed to occur by condensations of aldehydic intermediates over modified methanol catalysts. (Nunan, 1989; Elliot, 19.89; Lietti, 1989, 1990) Therefore, if the alcohol/aldehyde equilibrium suppresses aldehyde formation, then aldehydic intermediates might not form, retarding higher alcohol chain growth. Troncori, et.al. (1990) tested this theory by increasing the $\mathrm{H}_{2}$ partial pressure to drive the alcohol/aldehyde equilibrium toward the alcohoi side. The average carbon number of the $\mathrm{C}_{2}+$ oxygenates, $\mathrm{N}_{\mathrm{c}}$, decreased gradually with increasing $\mathrm{H}_{2}$ partial pressure, supforting the aldehydic chain growth theory, as shown in Figure 24.

The major catalytic functions for the $\mathrm{ZnCr}$ oxide catalyst have been studied in fair detail by Lietti, et.al. (1988, 1988, 1989,1990) using the temperat:--programmed surface reaction (TPSR) technique. Specifically, they studied the reactions of n-butanal, 1-butanol, n-butanoic acid, isobutanol, isobutanal, and isobutanoic acid over a commercial unpromoted $\mathrm{ZnCr}$ oxide catalyst with a $\mathrm{Zn} / \mathrm{Cr}$ atomic ratio of $3 / 1$, and the same catalyst promoted with 3 wt $\% \mathrm{~K}_{2} \mathrm{O}$, similar to $\mathrm{HAS}$ catalyst reported earlier. The data presented by Lietti, et.al. is detailed so a summary of their results and conclusions are listed below.

- Aldol condensation reactions occur over both promoted and unpromoted catalysts, consistent with the findings over the $\mathrm{C} / \mathrm{ZnO}$ catalysts. The reactions occur in two modes, the classic mode in which a primary alcohol is formed, but also in what is labeled an "oxygen retention reversal" (ORR) morie where a ketone is formed upon reaction of the two aldehydes. In the ORR mode, the aldol intermediate undergoes hydrogenation plus dehydration of the carbonyl group and retention of the anionic oxygen rather than the carbonyl oxygen, hence the name oxygen retention reversal. The ketone formed by ORR aldol condensation can subsequently be carboxylated to form both a linear and branched alcohol. These processes are shown in Figure 25 for clarification. The aldol condensations observed did not involve branched oxygenates, only linear oxygenutes. These reactions are believed to be the primary chain growth 
Figure 24. Effect of $\mathrm{H}_{2}$ partial pressure on the average carbon number of $\mathrm{C}_{2}+$ oxygenates.

Reaction conditions: $\mathrm{T}=405^{\circ} \mathrm{C}, \mathrm{P}=8.6 \mathrm{MPa}, \mathrm{GHSV}=8000 \mathrm{~h}^{-1}$, feed $\mathrm{CO}_{2}=0$. (Tronconi, 1990)

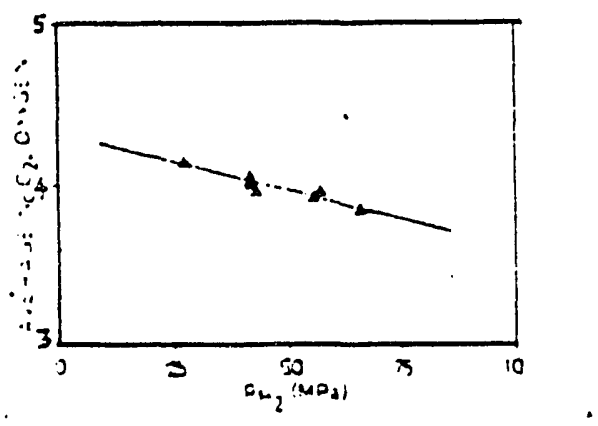


Figure 25. Reaction mechanisms for alcohol formation from aldol condensations. (A) "Classic" aldol condensation (B) Aldol condensation with "oxygen retention reversal"

(A)

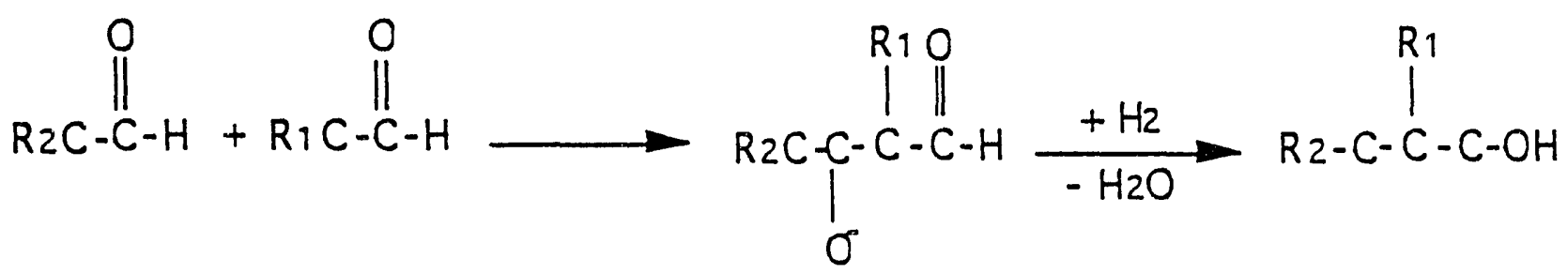

Aldol Intermediate

Alcohol Product

(B)<smiles>[R2]C(=O)[CH+][R4]C(=O)CC</smiles>

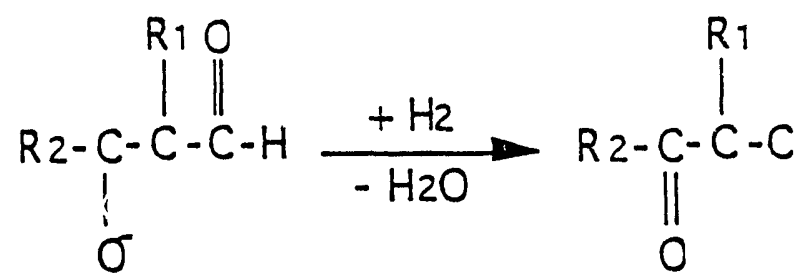

Aldol Intermediate

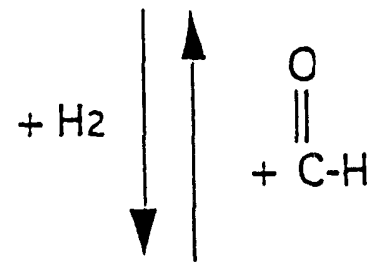

Alcohol Products<smiles>[R]C([R])=[C+][C-]C([R1])(O)O</smiles> 
mechanism for oxygenates, with branched oxygenate formation a terminal step since condensation can no longer occur. This does explain the abundance of branched products over these catalysts.

- Decarboxylation is quite active over the unpromoted $\mathrm{ZnCr}$ oxide catalyst, with olefins being generated from the decomposition of the adsorbed carboxylate species. The study also indicated that iso-carboxylate species are more stable toward decarboxylative decomposition than linear species. Decarboxylation is less active over the $\mathrm{K}$ promoted catalyst, so olefin formation decreases, and ketone carboxylation may increase to form alcohols, partly explaining the decrease in product selectivity toward olefins and hydrocarbons upon $\mathrm{K}$ or Cs promoter addition. Also, carboxylation of an adsorbed aldehyde has been proposed by Forzatti, et.al. (1991) as another route to alcohol chain growth, as shown in Figure 26. Again the decrease of decarboxylation activity upon alkali promoter addition encourages this mechanism.

- Both catalysts show hydrogenation and dehydrogenation activity, which is also evident in the thermodynamic studies discussed earlier, with equilibrium between aldehydes and primary alcohols and between ketones and secondary alcohols. However, equilibrium is not approached between olefins and their corresponding parafins, indicating these catalysts are not overly active hydrogenation catalysts.

- Dehydration is also evident over the $\mathrm{ZnCr}$ oxide catalyst, but is suppressed over the $\mathrm{K}$ promoted catalyst. Again, this can partly explain the decrease in hydrocarbon selectivity over the promoted $\mathrm{ZnCr}$ oxide catalysts versus the unpromoted ones. Also, this explains the decrease in ether productivity from unpromoted to promoted catalysts. 
Figure 26. Alcohol chain growth via carboxylation steps. (A) Normal mode (B) "Oxygen retention reversal" mode. (Tronconi, 1991)

(A)<smiles>[R4]C(=O)[13C]([13CH])=O</smiles>

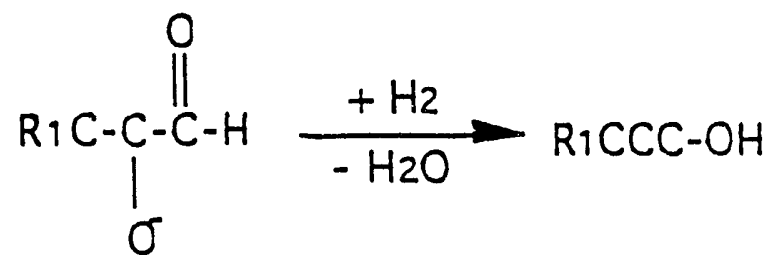

Aldol Intermediate Alcohol Product

(B)<smiles>[R]C(=O)[C+]=CCC</smiles><smiles>[R]O[C@H](C)C(=O)C([R])[O]</smiles>

Aldol Intermediate<smiles>CC(C)C=O</smiles>

$\mathrm{R} 1 \mathrm{CC}-\mathrm{OH}+\mathrm{CC}-\mathrm{OH}$

Alcohol Products 


\section{HAS Catalvsts Containing Molvbdenum}

Some of the most recent catalysts investigated for higher alcohol synthesis include the molybdenum-containing catalysts which can be divided into two groups based on catalyst structure. These groups are $\mathrm{SiO}_{2}$ supported Mo catalysts, and unsupported $\mathrm{Mo}_{2} \mathrm{C}$ and $\mathrm{MoS}_{2}$ catalysts. All of these catalysts form a mixture of hydrocarbons and oxygenates, both following the Schulz-Flory distribution with similar $\alpha$ values. The alcohols are mostly linear primary alcohols, consistent with alkyl chain growth mechanism similar to the Fischer-Tropsch catalysts.

\section{$\mathrm{SiO}_{2}$ supported Mo HAS Catalysts}

Silica-supported molybdenum catalysts have been investigated predominantly by Tatsumi, et.al. (1989). They have investigated and attempted to optimize for higher alcohol synthesis different aspects of catalyst preparation. These include effects of support, Mo precursor used for impregnation, and alkali addition including type of alkali salt used. First, effects of support were investigated using many different metal oxides and carbon black as supports. (Tatsumi, 1987) Among the unpromoted catalysts, the $\mathrm{MgO}$ supported catalyst has the highest alcohol selectivity, but apparently only methanol and ethanol were formed. $\mathrm{Upon} \mathrm{K}_{2} \mathrm{CO}_{3}$ addition, the $\mathrm{SiO}_{2}$ supported catalyst was the only one producing alcohols, but $\mathrm{CO}$ conversion decreased at least $50 \%$ from the unpromoted catalyst. Choosing silica supports as the best for Mo, Muramatsu, et.al.(1987) compared different silica gel supports for a $\mathrm{KCl}$ promoted $\mathrm{Mo}^{-} \mathrm{SiO}_{2}$ catalyst, finding that ID silica gel was the most alcohol selective and gave the highest alcohol space-time yield (STY). The ID silica gel has lowest surface area and higher average pore diameter of the three gels investigated. Murarnatsu theorized that since silica-supported Mo catalysts have moderate activity for alcohol dehydration, then if the pores are smaller, the odds increase that the alcohols would readsorb and dehydrate to hydrocarbons.

The Mo precursor $\left(\mathrm{NH}_{4}\right)_{6} \mathrm{Mo}_{1} \mathrm{O}_{24}$ was determined as the most selective and active for HAS of the precursors studied based on the results shown in Tables 10 and 11. Note the reported $\mathrm{CO}_{2}$ yields, indicating that this catalyst is probably an effective water-gas shift catalyst. Although not 
TABLE 10

(Tatsumi, 1986)

Steady-state Activities for $\mathrm{CO}$ Hydrogenation over $\mathrm{SiO}_{2}$ Supported Mo Catalystsa

\begin{tabular}{|c|c|c|c|c|c|c|c|c|c|c|}
\hline \multirow[b]{2}{*}{ K salt } & \multirow[b]{2}{*}{ Mo preciursor } & \multirow[b]{2}{*}{$\begin{array}{c}C O \\
\text { conversion } \\
\left(\begin{array}{c}0 \\
111\end{array}\right)\end{array}$} & \multirow[b]{2}{*}{$\begin{array}{l}\mathrm{CO}_{2} \\
\text { yield } \\
(\%)\end{array}$} & \multicolumn{7}{|c|}{ Selectivity (C atom \%) } \\
\hline & & & & $\mathrm{CH}_{4}$ & $\begin{array}{c}\mathrm{C}_{2} \text {. } \\
\text { hydro- } \\
\text { carbons }\end{array}$ & $\mathrm{MeOH}$ & $\mathrm{EtOH}$ & PrOH & $\begin{array}{c}\mathrm{C}_{4} \text {. } \\
\text { alcohols }\end{array}$ & $\begin{array}{l}\text { Other } \\
\text { oxygens }\end{array}$ \\
\hline Nune & $\left(\mathrm{NH}_{4}\right)_{6} \mathrm{MO}_{7} \mathrm{O}_{24}$ & 9.7 & 4.7 & 35.7 & 63.3 & 0.8 & 0 & 0 & 0 & 0 \\
\hline $\mathrm{KCl}$ & $\left\{\begin{array}{l}\left(\mathrm{NH}_{4}\right)_{6} \mathrm{MO}_{7} \mathrm{O}_{24} \\
\mathrm{H}_{3} \mathrm{PMO}_{12} \mathrm{O}_{40} \\
\mathrm{~N} 1 \mathrm{OO}_{2}(\mathrm{ac2c})_{2}{ }^{n}\end{array}\right.$ & $\begin{array}{l}5.6 \\
4.0 \\
8.9\end{array}$ & $\begin{array}{l}1.8 \\
1.8 \\
4.2\end{array}$ & $\begin{array}{l}18.9 \\
25.5 \\
32.4\end{array}$ & $\begin{array}{l}30.8 \\
35.0 \\
47.7\end{array}$ & $\begin{array}{r}17.7 \\
15.3 \\
7.4\end{array}$ & $\begin{array}{r}20.7 \\
15.6 \\
8.2\end{array}$ & $\begin{array}{l}7.0 \\
5.2 \\
2.5\end{array}$ & $\begin{array}{l}3.2 \\
1.5 \\
0.5\end{array}$ & $\begin{array}{l}1.7 \\
2.0 \\
1.4\end{array}$ \\
\hline $\mathrm{K}_{2} \mathrm{CO}_{3}$ & $\left\{\begin{array}{l}\left(\mathrm{NH}_{4}\right)_{4} \mathrm{MO}_{7} \mathrm{O}_{24} \\
\mathrm{H}_{3} \mathrm{PMO}_{1}: \mathrm{O}_{40}\end{array}\right.$ & $\begin{array}{l}6.3 \\
3.5\end{array}$ & $\begin{array}{l}2.9 \\
1.6\end{array}$ & $\begin{array}{l}21.1 \\
22.6\end{array}$ & $\begin{array}{l}47.3 \\
42.9\end{array}$ & $\begin{array}{r}10.9 \\
9.9\end{array}$ & $\begin{array}{l}13.3 \\
13.3\end{array}$ & $\begin{array}{l}5.3 \\
8.7\end{array}$ & $\begin{array}{l}2.1 \\
1.5\end{array}$ & $\begin{array}{l}2.5 \\
1.2\end{array}$ \\
\hline
\end{tabular}

- Conditions: $573 \mathrm{~K} .16 \mathrm{~kg} \mathrm{~cm}^{-2}, \mathrm{H}_{2} / \mathrm{CO}=1, W / F=10 \mathrm{~g}$ Cutalyst $\mathrm{h}^{-1} \mathrm{~mol}^{-1}, \mathrm{~K} / \mathrm{MO}=0.4$, and $\mathrm{Mo}=10 \mathrm{wt} \%$.

"Aciacit = acelylacetone.

\section{TABLE 11}

(Tatsumi, 1986)

O2 Adsorption Uptakes, Apparent Oxidation Number and

Initial and Steady-state Activity of Mo Catalysts supporte on $\mathrm{KCl}^{-\mathrm{SiO}_{2}{ }^{2}}$

\begin{tabular}{|c|c|c|c|c|c|c|c|c|c|}
\hline \multirow[b]{2}{*}{ Mo precursor } & \multirow{2}{*}{$\begin{array}{c}O_{2} \text { uplake" } \\
{[\text { [unol (g vialysa) }}\end{array}$} & \multirow{2}{*}{$\begin{array}{l}\text { CO TOl:e } \\
\left(10^{1} s \cdot 1\right)\end{array}$} & \multirow{2}{*}{$\begin{array}{l}\text { Apparent } \\
\text { oxidution } \\
\text { number }\end{array}$} & \multirow{2}{*}{$\begin{array}{c}\text { Initial CO } \\
\text { conversion } \\
(i,)\end{array}$} & \multicolumn{2}{|c|}{$\begin{array}{c}\text { Initial STY" } \\
{\left[g \mid k g \text { catalsstil } h^{-1}\right]}\end{array}$} & \multirow{2}{*}{$\begin{array}{c}\text { S.S. CO } \\
\text { coniersiun } \\
\left({ }^{\circ} .1\right)\end{array}$} & \multicolumn{2}{|c|}{$\begin{array}{l}\text { sisiti } \\
\text { silla. }\end{array}$} \\
\hline & & & & & Hydrocsroons & Alcohols & & Hỵuroc:urt:'ss & Hlan $\cdots$ \\
\hline$\left(\mathrm{N} I I_{4}\right)_{6} M_{11}, \mathrm{O}_{24}$ & 94.2 & 3.3 & 4.7 & 26 & 4.7 & 9.6 & 5.6 & $\because: !$ & $\because: 11$ \\
\hline $\mathrm{H}_{3} \mathrm{PMO}_{12} \mathrm{O}_{\text {an }}$ & 729 & 4.4 & 4.8 & 4.6 & $12+$ & 7.3 & +11 & $4 \vdots$ & 1.12 \\
\hline $\mathrm{MOO}_{2}(\mathrm{acac})_{2}{ }^{\prime}$ & 46.3 & 13.8 & 4.2 & 9.2 & 28.7 & 6.7 & $\$ . y$ & $\because \div 1$ & +4 \\
\hline
\end{tabular}

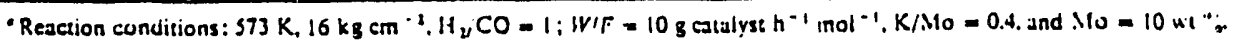

- $\mathrm{O}_{2}$ uptake measured at 1 YS K. currected fur support ndsorption.

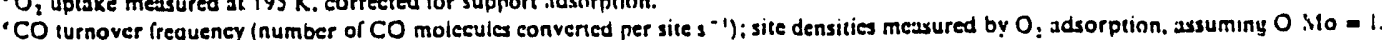

- Determined by oxygen titration.

- Space-time yieid.

seach = acetylacetune. 
shown in the table, Tatsumi reported that insignificant quantities of water were detected in the product stream, confirming the oxygen rejection via water-gas shift.

Also note in Table 10 how the alcohol space-time yields increase from initial to steady state conditions, indicating creation of alcohol active sites on the catalyst surface by $\mathrm{CO}$ and/or $\mathrm{H}_{2}$. This was confirmed by further investigations of Tatsumi, et.al. (1988) as shown in Figure 27. The alcohol space-time yield increased over time on stream, while both the hydrocarbon and $\mathrm{CO}_{2}$ STYs decreased. A freshly $\mathrm{H}_{2}$ reduced catalyst sample was then treated with $\mathrm{CO}$ at $523 \mathrm{~K}$ for 20 hours, and then tested on stream with $\mathrm{CO}$ and $\mathrm{H}_{2}$. The results, shown in Figure 28, indicate that the pretreated CO catalyst gave an alcohol STY with a greater initial value which then increased rapidly and subsequently leveled off only after 2 hours. These results, plus the data from the untreated sample, led Tatsumi to conclude that $\mathrm{CO}$ reduces $\mathrm{MoO}_{2}$ by the following reaction:

$$
\mathrm{MOO}_{2}+\mathrm{CO} \rightarrow \mathrm{MOO}_{2-x}+\mathrm{CO}_{2}
$$

and that these reduced sites, although not metallic Mlo, could encourage alcohol formation. Another possibility is the Boudouard reaction,

$$
\mathrm{nMO}+2 \mathrm{CO} \rightarrow-\mathrm{MO}_{\mathrm{n}} \mathrm{C}+\mathrm{CO}_{2}
$$

but Mo carbides are reported as active for methanation, but alcohol synthesis was enhanced by CO pretreatment, so this reaction was discounted.

Continuing with Mo catalyst effects on HAS, Tatsumi, et.al. (1987) tested several different alkali metal carbonate promoters and the selectivity for alcohol formation increased in the order $\mathrm{Li}$ $<\mathrm{Na}<\mathrm{K}<\mathrm{Rb}=\mathrm{Cs}$. This order is consistent with the electronegativity of each alkali, and also agrees with results from promoter tests on $\mathrm{Cu} / \mathrm{ZnO}$ catalysts (Vedage, 1985) and $\mathrm{ZnO} / \mathrm{Cr}_{2} \mathrm{O}_{3}$ (Natta, 1957). Muramatsu, et.al. (1987) and Tatsumi, et.al. (1988) subsequently determined the optimum $\mathrm{KCl}$ promoter concentration for a $20 \mathrm{wt} \% \mathrm{Mo}$ over silica (ID). Figure 29 reveals that the alcohol space-time yield (STY) reaches a maximum around $0.2 \mathrm{~K} / \mathrm{Mo}$ ratio (1.63 wt \% K), but notice how the ratio of $\mathrm{C}_{2}+$ alcohols to methanol doesn't level off until $0.4 \mathrm{~K} / \mathrm{Mo}$ ratio (3.25 wt \% $\mathrm{K}$ ) and that the ratio is greater than 2 . However, a dramatic decrease in overall catalyst STY is observed since the hydrocarbon STY rapidly decreases with $\mathrm{KCl}$ addition, and alcohol STY does 
Figure 27. Activity change with time on stream over $10 \mathrm{wt} \% \mathrm{Mo}-1.63 \mathrm{wt} \% \mathrm{~K}$ on $\mathrm{SiO}_{2}$ at $250^{\circ} \mathrm{C}, 1.6 \mathrm{MPa}, \mathrm{H}_{2} / \mathrm{CO}=1, \mathrm{~W} / \mathrm{F}=10 \mathrm{~g}$-cat $\bullet \mathrm{h} / \mathrm{mol}$. (Tatsumi, 1988)

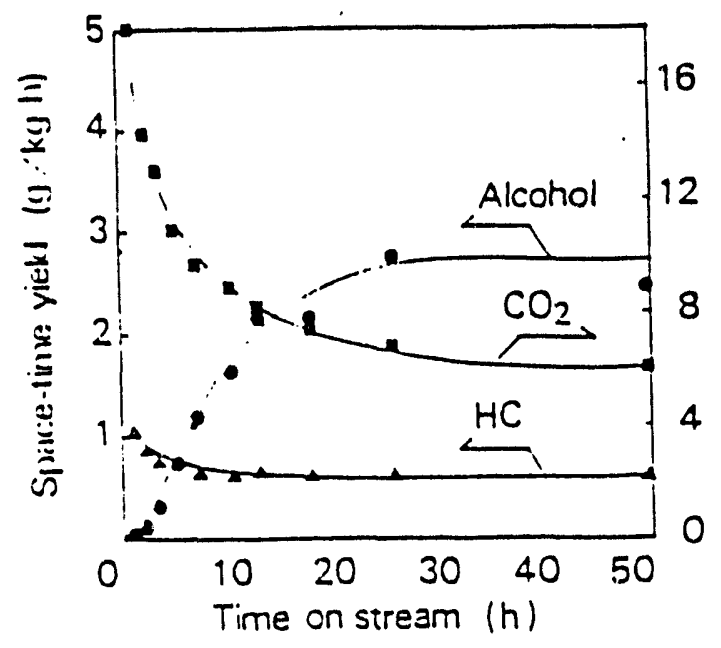

Figure 28. Change in alcohol production with time on stream over 5 wt \% Mo -0.81 wt \% $\mathrm{K}$ on $\mathrm{SiO}_{2}$ at $250^{\circ} \mathrm{C}, 1.6 \mathrm{MPa}, \mathrm{H}_{2} / \mathrm{CO}=1, \mathrm{~W} / \mathrm{F}=10 \mathrm{~g}$-cat $\bullet \mathrm{h} / \mathrm{mol}$. Effect of $\mathrm{CO}$ treatment. (Tatsumi, 1988)

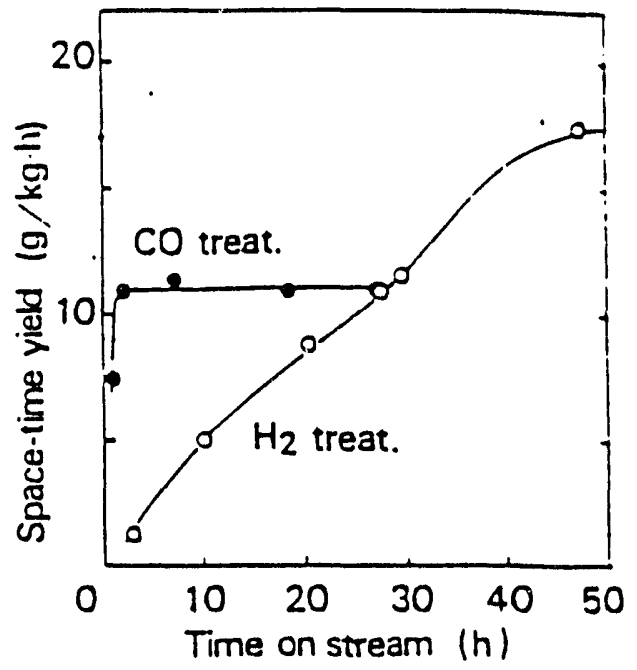


Figure 29. Effect of $\mathrm{K}$ content (K/Mo ratio) on space-time yields of alcohols (o) and hydrocarbons $(\bullet)$ and $\mathrm{C}_{2+} \mathrm{OH} / \mathrm{CH} 3 \mathrm{OH}$ ratio $(\Delta)$ over $20 \mathrm{wt} \% \mathrm{Mo}, \mathrm{KCl}, \mathrm{SiO}_{2}$ catalyst at W/F $=10 \mathrm{~g}$ catalyst $\cdot \mathrm{h} / \mathrm{mol}, 250^{\circ} \mathrm{C}$, and $1.6 \mathrm{MPa}$. (Muramatsu, 1987 )

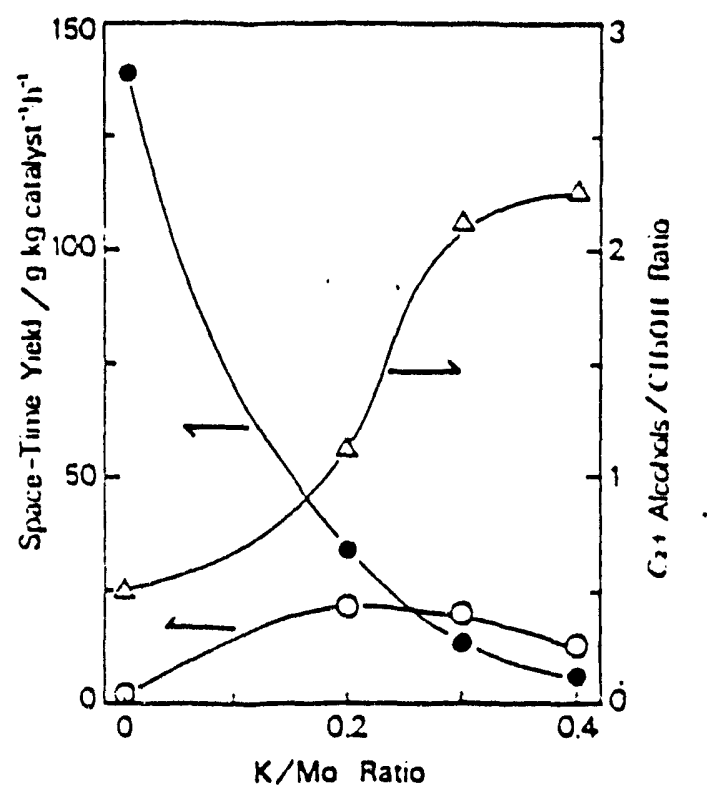


not compensate. So for HAS, relatively low catalyst activity is apparently a given for $\mathrm{Mo}_{\mathrm{SiO}}$ catalysts under these conditions. Figure 30 further illustrates these points, but now the selectivity of alcohol can be seen to increase from almost nothing to about 55 carbon atom \%. The results shown in the adjacent table indicate a possible explanation of the $\mathrm{K}$ promoting effect. Note that the oxygen uptakes of the catalyst decrease rapidly upon $\mathrm{K}$ addition, indicating reduced Mo dispersion on the surface, but it remains fairly constant with increasing $\mathrm{K}$ levels. This might explain some of the dramatic decrease in CO conversion and STY. Note also the X-ray diffraction (XRD) results. Apparently, the addition of $\mathrm{K}$ promoter increases the presence of $\mathrm{MoO}_{2}$ on the catalyst surface at the expense of metallic Mo. Therefore the addition of $\mathrm{K}$ apparently retards the reduction of surface Mo and also decreases the dispersion of Mo on the catalyst surface.

The effects of process variables were also investigated on the silica supported Mo catalysts. Muramatsu, et.al. (1987) reported effects of varying gas hourly space velocity (GHSV) over a $\mathrm{KCl}$ promoted silica supported Mo catalyst as shown in Figure 31 . As opposed to reporting GHSV, they used time factors which are ratios of the catalyst weight in the reactor over the hourly gas feed molar flow rate, essentially the inverse of the GHSV. The results indicate that alcohol selectivity increases with decreasing time factor (increasing GHSV) and the $\mathrm{C}_{2+}$ alcohol/methanol ratio remains essentially constant Note, however, that under these conditions, maximum alcohol selectivity is only about $50 \%$.

The effect of pressure on product selectivity is clearly shown for the same catalyst in Figure 32. Alcohol selectivity increases dramatically from about $50 \%$ to almost $70 \%$ when pressure is raised from 1.6 MPa (230 psi) to $5.1 \mathrm{MPa}$ (740 psi). Alcohol selectivity deteriorates, however, to $60 \%$ when pressure is increased further to $6.6 \mathrm{MPa}$ (960 psi). Apparently, residence time of the adsorbed species is critical for alcohol formation since the selectivity passes through a maximum as pressure increases. Increased residence time could lead to dehydration of the adsorbed alcohol intermediate. The catalyst activity also increases greatly upon increasing pressure as shown in Table 12. The space-time yield of alcohols jumps $483 \%$ to $420 \mathrm{~g} /[\mathrm{kg}$ catalyst $\bullet \mathrm{hr}]$. 
Figure 30. Effect of $\mathrm{K}$ content on activty of $20 \mathrm{wt} \% \mathrm{Mo} / \mathrm{SiO}_{2}$ catalyst at $250^{\circ} \mathrm{C}, 1.6 \mathrm{MPa}, \mathrm{H}_{2} / \mathrm{CO}$ $=1, \mathrm{~W} / \mathrm{F}=10 \mathrm{~g}$-catalyst $\bullet \mathrm{h} / \mathrm{mol}$. $\mathrm{O}_{2}$ uptake was measured at $195^{\circ} \mathrm{C}$. (Tatsumi, 1988)

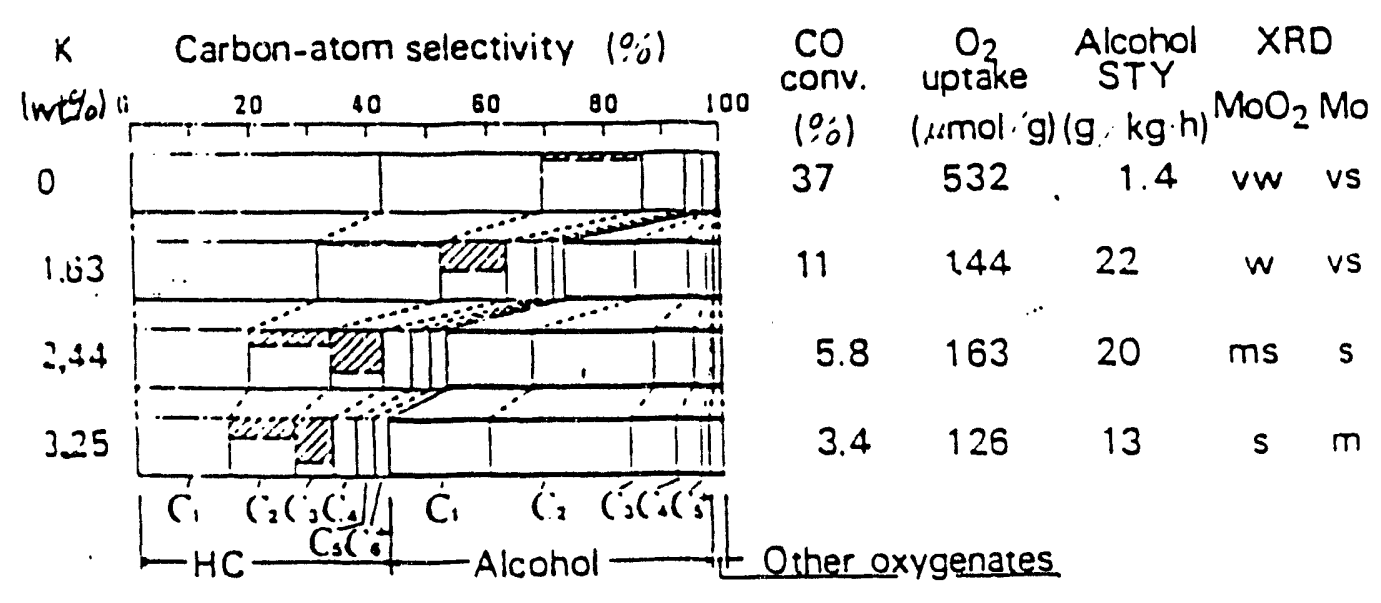


Figure 31. Effect of time factor on alcohol selectivity $(0)$ and $C_{2^{+}}$alcohols/methanol ratio $(\Delta)$ over 20 wt \% Mo, $1.63 \mathrm{wt} \% \mathrm{~K}, \mathrm{SiO}_{2}$ catalyst a $250^{\circ} \mathrm{C}$ and $1.6 \mathrm{MPa}$ (Muramatsu, 1987)

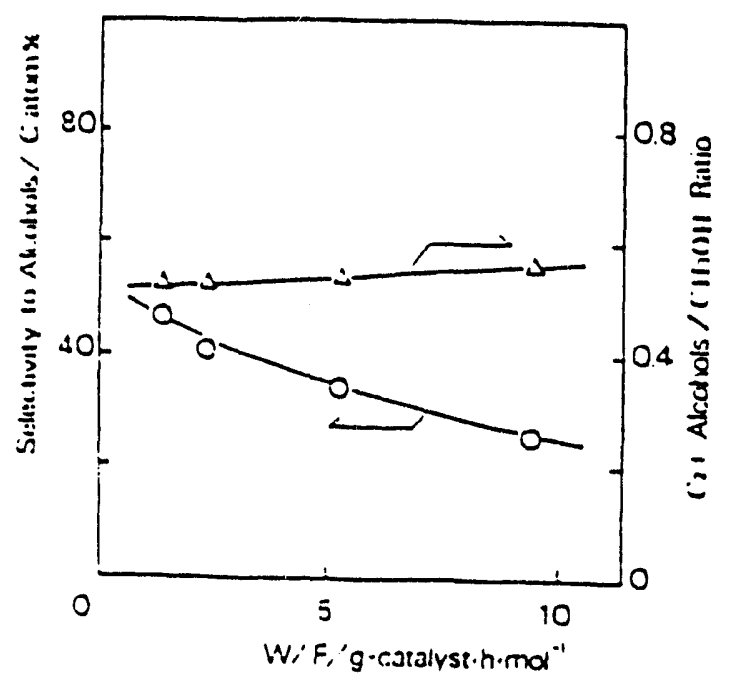


Figure 32. Effect of total pressure on product distribution over 20 wt $\% \mathrm{Mo}, 1.63$ wt $\% \mathrm{~K}, \mathrm{SiO}_{2}$ catalyst at $\mathrm{W} / \mathrm{F}=1.4 \mathrm{~g}$-catalyst $\bullet \mathrm{h} / \mathrm{mol}$ and $250^{\circ} \mathrm{C}$. (Muramatsu, 1987)

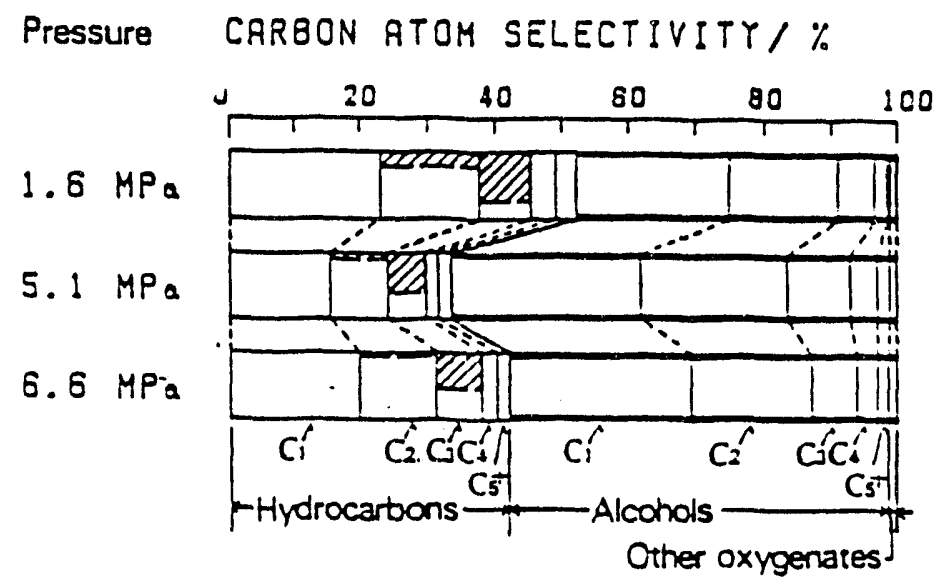

TABLE 12

(Muramatsu, 1987)

Effect of Total Pressure on Activity over 20 wt \% Mo, 1.63 wt \% K. SiO 2 Catalyst

Same Reaction Conditions as in Figure 31

\begin{tabular}{|c|c|c|c|c|}
\hline $\begin{array}{l}\text { Total } \\
\text { pressure }\end{array}$ & $\begin{array}{c}\text { CO } \\
\text { conversion }\end{array}$ & $\begin{array}{l}\mathrm{CO}_{3} \\
\text { yield }\end{array}$ & $\begin{array}{r}\text { Space-time } \\
\text { Hydrocarbon }\end{array}$ & $\begin{array}{l}\text { yield } \\
\text { Alcohol }\end{array}$ \\
\hline.$M P_{a}$ & $\%$ & $\%$ & $\mathrm{~g}(\mathrm{~kg}$-catalyse & $-1 h^{-1}$ \\
\hline 1.6 & 2.7 & 1.1 & 45 & 72 \\
\hline 5.0 & 10 & 3.1 & 124 & 420 \\
\hline 6.5 & 13 & 4.5 & 181 & +28 \\
\hline
\end{tabular}


The temperature effects on product selectivity and activity are shown in Figure 33 and Table 13 for the same $\mathrm{K}$ promoted $\mathrm{Mo} / \mathrm{SiO}_{2}$ cataly.t. Alcohol selectivity decreases with increasing temperature, however space-time yield increases with increasing temperature, but not as rapidly as the hydrocarbon STY, explaining the decrease in alcohol selectivity. None of the alcohol products listed appear to reach thermodynamic equilibrium considering the thermodynamic calculations discussed earlier. Note in Figure 33, how the ratio of $\mathrm{C}_{2+}$ alcohols to methanol increases with increasing temperature, but the ratio of $\mathrm{C}_{2}+$ hydrocarbons to methane remains relatively constant.

Although Muramatsu, et.al. demonstrated the general effects of temperature, pressure, and gas hourly space velocity on alcohol selectivity and productivity, they did not try to optimize the conditions for maximum yield of alcohols from the catalyst. A statistically designed set of experiments, which considers all of the process variables, would determine the most desirable set of operating parameters for higher alcohol production. The same is aiso true for $K$ addition and Mo loading. An optimum considering both of these factors was not reached since $20 \mathrm{wt} \% \mathrm{Mo}$ was the highest Mo loading considered.

To further understand the reaction paths for alcohol and hydrocarbon formation over the $\mathrm{MSO}_{\mathrm{SiO}}$ catalysts, Tatsumi, et.al. (1989) conducted a mechanistic study using addition of probe molecules, such as ethylene, propylene, methanol, etha sol, and acetaldehyde, to the $\mathrm{CO}-\mathrm{H}_{2}$ reactor feed. Both the $\mathrm{KCl}$ promoted and unpromoted $\mathrm{M}$ o/SiO, catalysts were tested. Their findings are summarized as follows:

- The main pathway for higher alcohol formation includes $\mathrm{CO}$ insertion into the alkyl-metal bond.

- The catalysts demonstrate poor methanol homologation activity.

- Aldol condensation is apna ently unimportant fo: cho:n growth.

- The formation of hydrocarbons via the dehydration of alcohols appears insignificant over the $\mathrm{K}^{\Gamma^{*}}$ promoted catalyst.

- $\mathrm{K}$ addition is believed to retard the hydrogenation of surface alkyls to form alkanes, and $\mathrm{K}$ increases the number of active sites for alcohol formation by slowing the reduction of Mo. 
Figure 33. Effect of temperature on product distribution over $10 \mathrm{wt} \% \mathrm{Mo}, 1.63 \mathrm{wt} \% \mathrm{~K}, \mathrm{SiO}_{2}$ catalyst at $\mathrm{W} / \mathrm{F}=10 \mathrm{~g}$-catalyst $\bullet \mathrm{h} / \mathrm{mol}$ and $1.6 \mathrm{MPa}$ (Muramatsu, 1987)

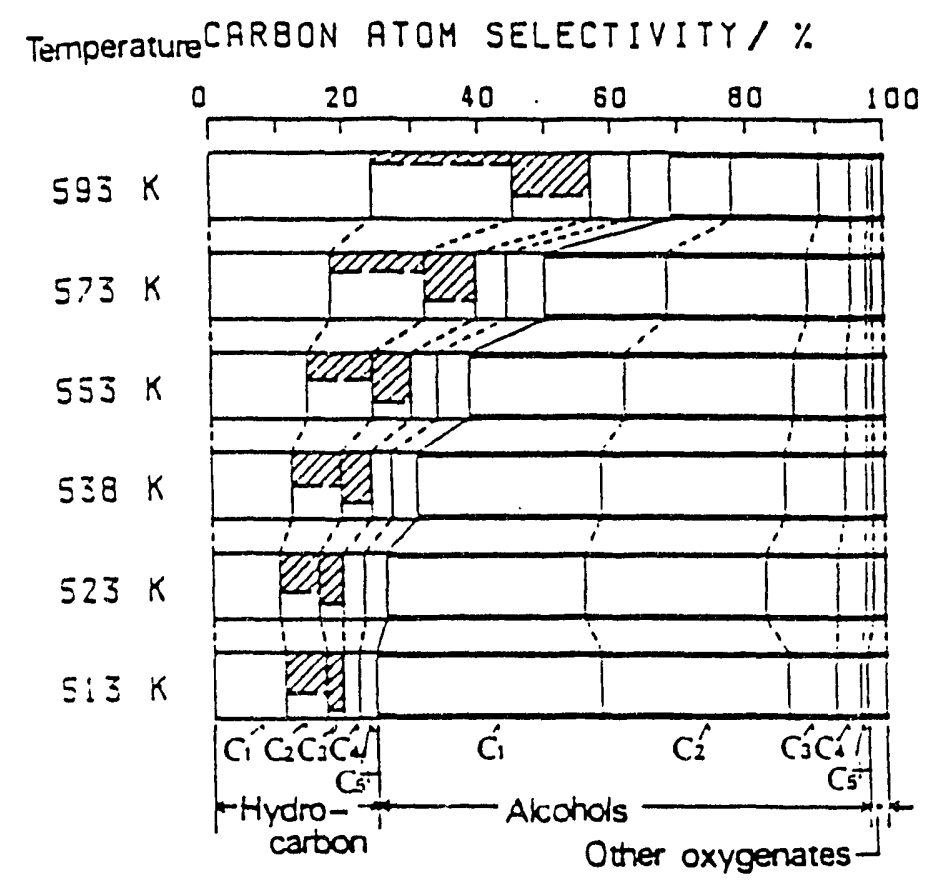

TABLE 13

(Muramatsu, 1987)

Effect of Total Temperature on Activity over $10 \mathrm{wt} \% \mathrm{Mo}, 1.63 \mathrm{wt} \% \mathrm{~K}, \mathrm{SiO}_{2}$ Catalyst Same Reaction Conditions as in Figure 32

\begin{tabular}{|c|c|c|c|c|}
\hline $\begin{array}{l}\text { Tempera- } \\
\text { lure }\end{array}$ & - $\underset{\text { conversion }}{\mathrm{CO}}$ & $\begin{array}{l}\mathrm{CO}_{2} \\
\text { yield }\end{array}$ & $\begin{array}{l}\text { Space-tin } \\
\text { Hydrocarbb }\end{array}$ & $\begin{array}{l}\text { yicid } \\
\text { Alcohol }\end{array}$ \\
\hline $\mathrm{K}$ & $\%$ & $\%$ & $\mathrm{~g}(\mathrm{~kg}$-catal & $-1 h^{-1}$ \\
\hline 593 & 7.3 & 3.2 & 22 & 16 \\
\hline 573 & 5.5 & 2.3 & 12 & 21 \\
\hline 553 & 2.0 & 0.67 & 4.0 & 11 \\
\hline 538 & 1.0 & 0.33 & 1.7 & 6.7 \\
\hline 523 & 0.52 & 0.15 & 0.74 & 3.6 \\
\hline 513 & 0.32 & 0.10 & 0.41 & 2.2 \\
\hline
\end{tabular}


The studies also indicate that although the alcohols formed are exclusively primary, some methyl branching does exist at the $\beta$ carbon (second carbon atom from the hydroxyl group). Tatsumi, et.al. never examined the $\mathrm{Mo} / \mathrm{SiO}_{2} \mathrm{CO}$ hydrogenation products with respect to the Schulz-Flory distribution, but over the promoted catalyst, the product distribution does not appear to strictly follow that pattern.

\section{$\mathrm{MoS}_{2}$ HAS Catalysts}

The research on $\mathrm{MOS}_{2}$ catalysts indicates several similarities between the $\mathrm{Mo} / \mathrm{SiO}_{2} \mathrm{HAS}$ catalysts and these catalysts. Youchang, et. al. (1986) found that alkali metal promotion of the base $\mathrm{MOS}_{2}$ catalysts enhanced higher alcohol selectivity over the unpromoted $\mathrm{MoS}_{2}$ catalyst. They prepared the $\mathrm{MOS}_{2}$ by thermally decomposing $\left(\mathrm{NH}_{4}\right)_{2} \mathrm{MlOS}_{4}$, and determined by XRD that the near surface region was actually MoS. Catalyst promotion was accomplished by alkali salt solution impregnation. $\mathrm{K}$ addition was found more effective than lia addition, in agreement with Tatsumi, et.al. (1987). Also, as expected, a maximum occurs in alcohol selectivity upon increasing $\mathrm{K}$ loading, as shown in Figure 34. The maximum occurs around $0.4 \mathrm{~g} \mathrm{~K}_{2} \mathrm{CO}_{3} / \mathrm{g}$ $\mathrm{MoS}_{2}$, equivalent to a $0.93 \mathrm{~K} / \mathrm{Mo}$ atom ratio. This number is much higher than Tatsumi, et.al. reported (0.2 $\mathrm{KM}$ Mo atom ratio), but they used a $20 \mathrm{wt} \%$ Mo catalyst, while the $\mathrm{MoS}_{2}$ catalyst is

about $60 \mathrm{wt} \% \mathrm{Mo}$, probably accounting for at least some the difference. Also note that maximum alcohol selectivity (carbon atom \%) is $60-65 \%$.

Youchang also examined the effects of pressure, varying both the $\mathrm{H}_{2}$ pressure and the total pressure. Figure 35 illustrates that increasing $\mathrm{H}_{2}$ pressure, which is essentially increasing the $\mathrm{H}_{2} / \mathrm{CO}$ ratio, increases the product selectivity for methanol above $80 \%$ at the expense of methane. Higher alcohol selectivity, however, drops slightly, hovering around 10\% The effect of total pressure is basically the same, with methanol selectivity approaching $80 \%$ at the expense of methane. Although not shown, again the higher alcohol selectivity remained almost constant, with a small decrease. Therefore, the whole effect of pressure appears to encourage only methanol selectivity at the expense of methane, with no effect on higher alcohol selectivity, a direct contrast 
Figure 34. The product distribution of the $\mathrm{MoS}_{2}$ catalyst as a function of $\mathrm{K}_{2} \mathrm{CO}_{3}$ loading. (Youchang, 1986)

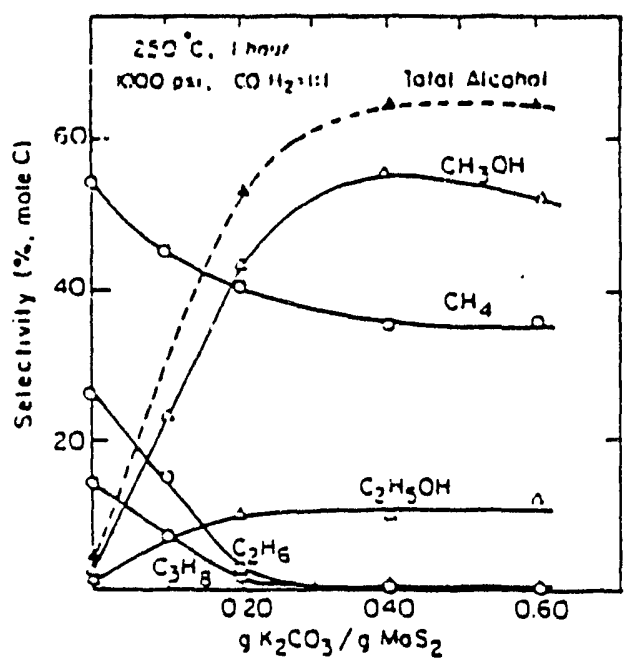


Figure 35. The $\mathrm{H}_{2}$ pressure dependence of the $\mathrm{K}_{2} \mathrm{CO} / \mathrm{MoS}_{2}$ catalyst's selectivity. (Youchang, 1986)

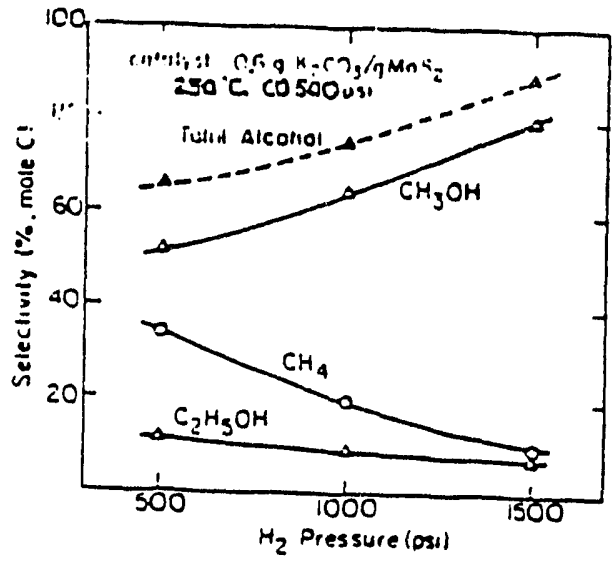


to the $\mathrm{Mo} / \mathrm{SiO}_{2}$ catalysts.

Murchison, et.al. (1988) investigated a carbon supported $\mathrm{MOS}_{2}$ catalyst promoted with $\mathrm{K}$ They reported alcohol selectivities of 80 - 90\% with a methanol/higher alcohol ratio of 70/30 and a catalyst productivity of $0.25 \mathrm{~kg} /[\mathrm{l} \mathrm{cat} \cdot \mathrm{h}]$ at $300^{\circ} \mathrm{C}$ and $13.8 \mathrm{MPa}(2000 \mathrm{psi})$. Addition $\mathrm{H}_{2} \mathrm{~S}$ in the feed increased the higher alcohol selectivity with respect to methanol, as shown in Figure 36. The weight $\%$ of $\mathrm{C}_{2}+$ oxygenates increased from about $30 \%$ to $70 \%$ of total products. Note, however, that Murchison does not reveal the levels of $\mathrm{H}_{2} \mathrm{~S}$ used to accomplish this. They did speculate that the $\mathrm{CO}$ and $\mathrm{H}_{2}$ could be desulfiding the Mo on the catalyst surface.

Further work by Murchison, et.al. revealed that carbon support $\mathrm{MoS}_{2}$ catalysts promoted with both potassium and Co would enhance the higher alcohol selectivity without adding $\mathrm{H}_{2} \mathrm{~S}$ in the feed as shown in Table 14.

\section{TABLE 14}

(Murchison, 1988)

Effect of Promoter Element on Alcohol Distribution (Weight \%)

Reaction Conditions: $\mathrm{T}=310-320^{\circ} \mathrm{C}, \mathrm{P}=10.3 \mathrm{MPa}, \mathrm{H}_{2} / \mathrm{CO}=1.1$

Catalyst Notes: 10 wt $\% \mathrm{~K}_{2} \mathrm{CO}_{3}$, Molar ratio of $\mathrm{Co} / \mathrm{Mo}=\mathrm{Ni} / \mathrm{Mo}=\mathrm{Fe} / \mathrm{Mo}=2$

$$
\mathrm{MoS}+\mathrm{MOS}_{2}=66 \mathrm{wt} \%
$$

$\begin{array}{lccc}\text { Alcohol } & \mathrm{CoS}_{\mathrm{MoS}} / \mathrm{K} & \mathrm{NiS}_{2} / \mathrm{MoS}_{2} / \mathrm{K} & \mathrm{FeS} / \mathrm{MOS}_{2} / \mathrm{K} \\ \mathrm{MeOH} & 26 & 25 & 13 \\ \text { EtOH } & 47 & 50 & 29 \\ \mathrm{PrOH} & 14 & 12 & 22 \\ \mathrm{BuOH} & 3.4 & 1.3 & 12 \\ \mathrm{C} 5 \mathrm{OH} & 0.4 & 1.4 & 7.5 \\ \text { Ester } & 3.7 & 4.1 & 2.7 \\ \text { Other } & 4.3 & 4.5 & 6.9 \\ \text { H2O } & 1.9 & 1.9 & 6.7 \\ \text { O2 Free Carbon \% } & & 80 & 72 \\ \text { Feed Conversion } & 37 & 33 & 24\end{array}$

Total CO2 Free Carbon \%

Selectivity to Alcohols

CO Feed Conversion

37

33 
Figure 36. Effect of $\mathrm{H}_{2} \mathrm{~S}$ on selectivity for alkalized Mo sulfides on carbon. (Murchison, 1988)

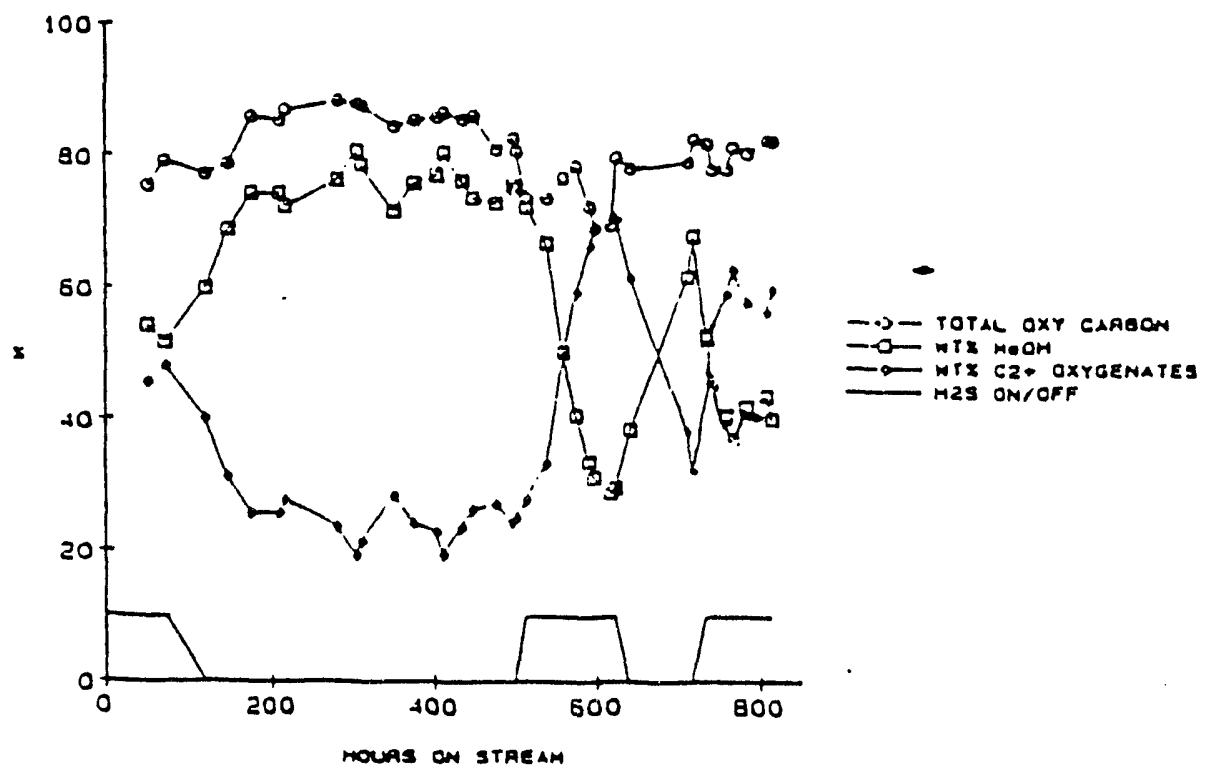


Observing that total alcohol selectivity decreases only slightly with increasing conversion, but weight \% methanol decreases rapidly with increasing conversion, Murchison, et.al. speculated that the Co promoter served as a methanol homologation catalyst. This was fairly well confirmed upon methanol addition to the feed, resulting in essentially no change of product distribution. (Table 15)

TABLE 15

(Murchison, 1988)

Comparison of Crude Alcohol Product from Syngas with/without co-Feed Methanol Reaction Conditions: $\mathrm{T}=290^{\circ} \mathrm{C}, \mathrm{P}=13.8 \mathrm{MPa}$

$\begin{array}{ccc} & \text { Case I } & \text { Case II } \\ \text { Added Methanol } & 0 \mathrm{~g} / \mathrm{hr} & 7 \mathrm{~g} / \mathrm{hr} \\ \text { Syngas Conversion } & 15.7 \mathrm{~g} / \mathrm{hr} & 20.5 \mathrm{~g} / \mathrm{hr} \\ \text { Recovered Liquid } & 7.2 \mathrm{~g} / \mathrm{hr} & 11.3 \mathrm{~g} / \mathrm{hr}\end{array}$

Liquid Analysis (Weight \%)

$\begin{array}{ccc}\text { Methanol } & 27.2 & 24.2 \\ \text { Ethanol } & 45.9 & 47.5 \\ \text { Propanol } & 13.8 & 13.4 \\ \text { iso-Butanol } & 1.1 & 1.2 \\ \text { n-Butanol } & 2.2 & 2.2 \\ \text { Methyl Acetate } & 1.0 & 1.3 \\ \text { Ethyl Acetate } & 1.5 & 2.2 \\ \text { Water } & 1.8 & 2.1 \\ \text { Other } & 5.5 & 5.9\end{array}$

No detailed mechanistic studies were found for $\mathrm{MOS}_{2}$ HAS catalysts, so further discussion is not warranted. 


\section{HAS Catalysts Containing Group VIII Metals}

The catalysts containing Group VIII metals can be further divided into subgroups based on their ability to dissociate $\mathrm{CO}$ to a surface carbide and oxygen. Catalysts containing $\mathrm{Ru}, \mathrm{Co}, \mathrm{Ni}$, and/or Fe can dissociate $\mathrm{CO}$ at elevated temperatures and are the classic Fischer-Tropsch catalysts, generating predominantly hydrocarbons, but they can be modified for HAS. Catalysts containing $\mathrm{Pd}, \mathrm{Pt}$, and $\mathrm{Ir}$ do not easily dissociate $\mathrm{CO}$, and generate primarily $\mathrm{C}_{1}$ oxygenated products. These have not been investigated in much detail, so further discussion is not warranted for this group. The final subgroup contains the promoted $R$ catalysts which are between the two groups already mentioned. All of these catalysts, similar to the Mo-containing catalysts, typically give a SchulzFlory distribution of both hydrocarbons and oxygenates, with some deviations around the $\mathrm{C}_{2}$ carbon number. The rhodium and cobalt-based catalysts particularly generate high selectivities to ethanol. The group VIII metal catalysts usually yield 40 to $60 \%$ carbon atom selectivity torvard oxygenates with somewhat less for higher alcohols.

\section{Ru, Co Containing HAS Catalysts}

One of the more famous Co containing HAS catalyst is that developed by Institut Français du Pétrole (IFP) based on a combination of $\mathrm{Co}, \mathrm{Cu}$ and $\mathrm{Cr}$ oxides. Courty, et.al. (1982) defined the effects of varying elemental compositions in this catalyst as summarized in Figure 37 . However, they determined that catalyst preparation procedures are critical for determining the final selectivity, but do not have as great an effect on activity. Also, alkali promotion is required for alcohol selectivity, since uncontrolled methanation occurs below $290^{\circ} \mathrm{C}$ over the unpromoted $\mathrm{Co} / \mathrm{Cu} / \mathrm{Cr}$ oxide catalyst. The best performing catalyst reported yielded about $0.2 \mathrm{~g} / \mathrm{g}$ catalyst/hour productivity with a 60 to $80 \%$ selectivity to $\mathrm{C}_{1}-\mathrm{C}_{6}$ alcohols and a $\mathrm{C}_{2}+\mathrm{OH} / \mathrm{C}_{1}+\mathrm{OH}$ ratio greater than $60 \%$. However, their patent claims greater than 95 weight \% alcohol selectivity, with higher alcohols accounting for 25 to 75 weight $\%$ of the total product. These higher numbers have yet to be reproduced by independent researchers. 
Figure 37. Selectivity as a function of composition in the temary system $\mathrm{CuO}-\mathrm{CoO}-\mathrm{Cr}_{2} \mathrm{O}_{3}$. (Courty, 1982)

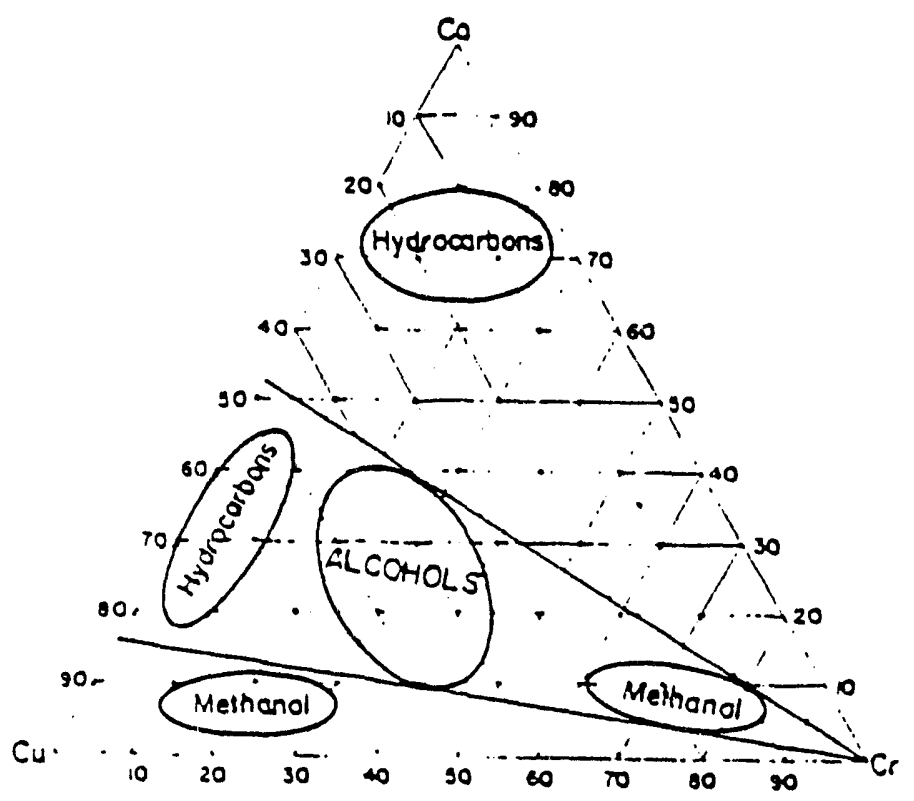


Further work by Sheffer and King (1988) indicated that special attention should be paid to catalyst calcination temperature for the $\mathrm{Cu} / \mathrm{Co} / \mathrm{Cr}$ oxide catalyst to provide the highest alcohol selectivities. Increasing calcination temperature decreased oxygenate selectivity, but hydrocarbon selectivity remained relatively unchanged. Also, to a lesser extent, the choice of metal salt precursors and the amount of potassium promoter effect the alcohol selectivities as well. Later, Sheffer, et.al. (1989) determined that the activated $\mathrm{Cu} / \mathrm{Co} / \mathrm{Cr}$ oxide catalyst consisted of copper metal and a cobalt chromium spinel. The oxygenate production correlated with copper dispersion in the catalyst, with poorer copper dispersion decreasing oxygenate formation. This explained the effect of calcination temperature since increasing temperature decreased copper dispersion. Also, if the cobalt sites are responsible for hydrocarbon formation, then this could explain why increasing calcination temperature had little effect of hydrocarbon selectivity.

Other combinations of Co HAS catalysts have been examined, like $\mathrm{Cu} / \mathrm{Co} / \mathrm{Zn}$ oxides on alumina, $\mathrm{Co}$ on $\mathrm{SiO}_{2}$ promoted with $\mathrm{Ru}$ and other alkaline earths, but these have not shown as great activity or selectivity toward higher alcohols as the $\mathrm{Cu} / \mathrm{Co} / \mathrm{Cr}$ combinations.

Ru-based catalysts are actually combinations of Ru and Mo. Chen (1986) studied a Ru/MoO2 catalyst promored with potassium carbonate and found that this catalyst gave a $98 \mathrm{~mol} \%$ selectivity to alcohols, with the alcohols following a classic Schulz-Flory distribution. The catalyst gave low productivity relative to other HAS catalysts, and it did not remain stable over time, with activity decreasing over $50 \%$ in only 24 hours.

Inoue, et.al. (1984, 1987, 1988) investigated Ru-Mo- $\mathrm{Na}_{2} \mathrm{O}$ supported on alumina HAS catalysts. Their findings show that this is a fairly active catalyst, but alcohol selectivity is only 39 carbon atom \% at best, with the remaining products primarily methane and other hydrocarbons. This catalyst did demonstrate water-gas shift activity, indicated by a high $\mathrm{CO}_{2}$ content in the product stream. Inoue, et.al. did propose a mechanism for alcohol formation, suggesting that alcohols formed on Ru sites influenced by Mo, whereas hydrocarbons formed on Ru sites isolated from Mo. 


\section{Rh Containing HAS Catalysts}

HAS catalysts containing rhodium have been extensively studied since, as mentioned earlier, $\mathrm{Rh}$ lies between the metals which easily dissociate $\mathrm{CO}$ and those which do not, and therefore can do both. Rh has great potential for combining the benefits, and possibly the disadvantages, of both types of catalysts. A variety of supports and promoters have been studied for Rh containing catalysts, and in general, selectivity for higher oxygenates is highly dependent upon support, promoter, and metal precursor chosen. For example, $\mathrm{Rh}$ supported on $\mathrm{Mg}(\mathrm{OH})_{2}$ is selective to methanol, on quartz to hydrocarbons, and on $\mathrm{V}_{2} \mathrm{O}_{3}$ to $\mathrm{C}_{2}$ oxygenates. (Nonneman, 1990) Much of the current research has focused on $\mathrm{Rh}$ supported on $\mathrm{SiO}_{2}$ and $\mathrm{Al}_{2} \mathrm{O}_{3}$ with different metal and alkali promoters. Howvever, many other combinations have also been examined, such as $\mathrm{LaRhO}_{3}$ monophasic catalysts (Watson, 1982; Gysling, 1987), Rh carbonyl clusters supported on $\mathrm{ZnO}$ and $\mathrm{MgO}$ (Ichikawa, 1978), and $\mathrm{L}_{2} \mathrm{O}_{3}$ promoted $\mathrm{Rh}$ on $\mathrm{TiO}_{2}$ catalysts (Bond, 1986), but these will not be discussed in further detail.

Wilson, et.al. (1981) examined $\mathrm{Rh}$ on $\mathrm{SiO}_{2}$ promoted with iron and manganese. They found that iron promotion (i.e., 35 atom \% Fe) doesn't change rate of syngas conversion, but produces primarily ethanol and methanol. However the $\mathrm{Mn}$ had an entirely different effect. With as little as 10 atom \% Mn promotion, an almost tenfold increase in syngas conversion rate is observed, but insignificant changes in selectivity are observed, so the catalyst produced primarily hydrocarbons. Therefore, a combination of $\mathrm{Mn}$ with some selectivity promoter might be useful for higher alcohol synthesis, but this was not pursued in the reviewed literature.

Effects of rare earth oxide supports were examined by Underwood and Bell (1986). The supports examined were $\mathrm{La}_{2} \mathrm{O}_{3}, \mathrm{Nd}_{2} \mathrm{O}_{3}$, and $\mathrm{Sm}_{2} \mathrm{O}_{3}$ and were compared with a $\mathrm{Rh}$ on $\mathrm{SiO}_{2}$ unpromoted catalyst. The Rh concentration and dispersion were very similar on all the catalysts. The rare earth supported catalysts demonstrated relatively high selectivity to methanol as compared with $\mathrm{Rh}$ on $\mathrm{SiO}_{2}$, as shown in Table 16. However, note that the selectivity to $\mathrm{C}_{2}$ oxygenates is abouth the same for all the catalysts, but the $C_{3}$ oxygenate selectivity increases over the rare earth supports. 
TABLE 16

(Underwood, 1986)

Distribution of Products Formed over $\mathrm{SiO}_{2}$ and Rare Earth Oxide Supported Rhodium

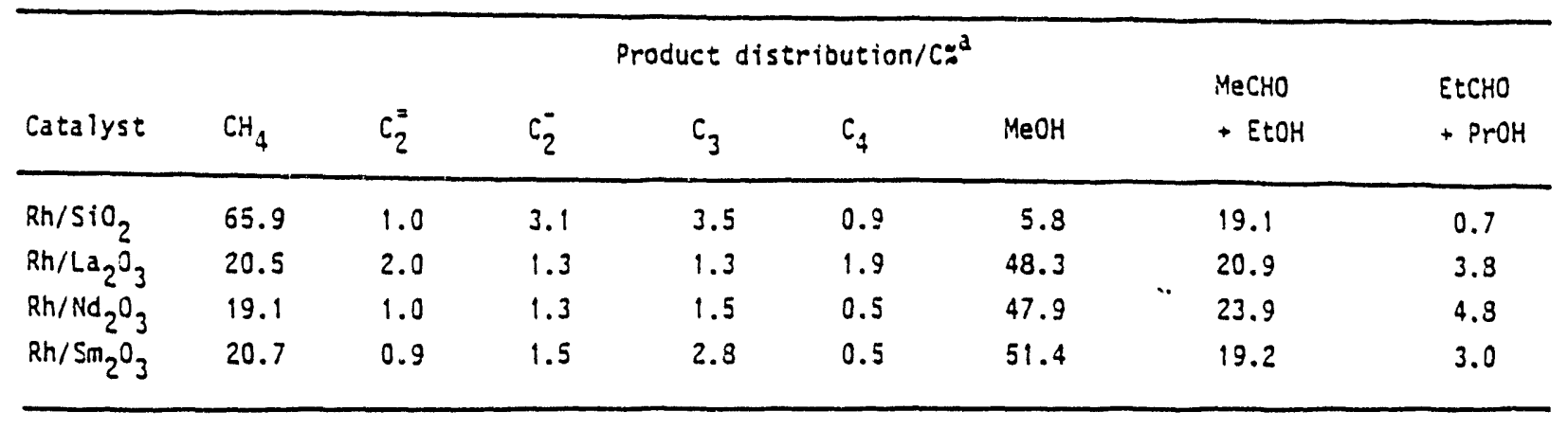

a Reaction conditions: $T=530 \mathrm{~K} ; P_{H_{2}}=8 \mathrm{~atm} ; P_{C O}=4 \mathrm{~atm} .$, co conversion $<0.1 \%$ 
Underwood and Bell did not proposed any explanations for increased methanol production. However, they did examine the relationship between acetaldehyde and ethanol, attributing ethanol production via hydrogenation of acetaldehyde over the rare earth oxide supported catalysts. This was confirmed by adding acetaldehyde in the reactor feed and examining the product distribution.

Yu-Hua, et.al. (1987) investigated the effects of rare earth oxides as promoters on Rh on silica catalysts. The results as shown in Table 17, indicate that the rare earth oxides as promoters, instead of supports, show high selectivity to ethanol formation. However, note that the second most predominant product is methane. Kiennemann, et.al. (1987) presented similar results with their Ce promoted $\mathrm{Rh}$ on $\mathrm{SiO}_{2}$ catalyst.

Both groups supported Undervood and Bell's proposition that acetaldehyde is a primary, product from the synthesis gas over these catalysts, and that the presence of the rare earth oxides is responsible for subsequent hydrogenation of some of the acetaldehyde to ethanol. They also found a large decrease in catalyst productivity upon addition of the rare earth metal, probably blocking the active sites for hydrocarbon formation. This was attributed to the suppression of the carbon monoxide dissociation. Both groups also proposed a similar mechanism for alcohol formation. Kiennemann, et.al., showed that CO can chemisorb in a bridge type fashion between the Rh and the Ce.

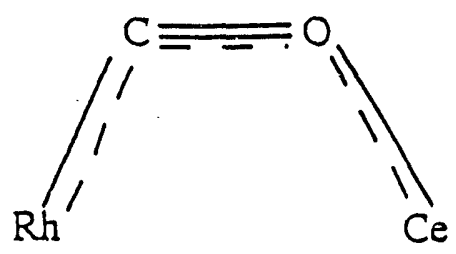

They proposed that formyl species are involved in both the formation of hydrocarbons and oxygenates. When the formyl species is adsorbed to a large rhodium group, a hydrocarbon is formed. Howeve:, when the formyl species is stabilized between a metal-support or promoter interface by interaction of the carbonyl oxygen with a Lewis-acid site of the support/promoter, then an oxygenate is likely to result. Yu-Hua, et.al., proposed a slightly different active site containing a CO bridge, where $\mathrm{M}$ may be a cation or an oxygen vacancy of the reduced rare earth oxide. 
TABLE 17

(Yu-Hua, 1987)

\section{Catalytic Properties of Rh-Rare Earth Oxide/SiO 2 in Syngas Reaction}

Resctun ecuntiti.r.s: $+9.1 \mathrm{~K} .1 \mathrm{~atm} . \mathrm{CO} / \mathrm{H}=11.59$

\begin{tabular}{|c|c|c|c|c|c|c|c|c|c|c|c|c|}
\hline \multirow[t]{3}{*}{ C3:aițst } & \multirow{3}{*}{ 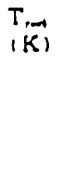 } & \multirow{3}{*}{$\begin{array}{l}\text { sil: } \\
\text { (h-1) }\end{array}$} & \multirow{3}{*}{$\begin{array}{l}\text { TOF } \\
(h \cdot 1)\end{array}$} & \multirow{3}{*}{ 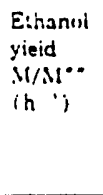 } & \multicolumn{7}{|c|}{ 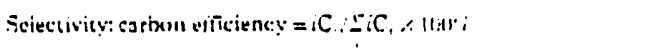 } & \multirow{2}{*}{-} \\
\hline & & & & & \multicolumn{3}{|l|}{ Oxyzenates } & \multicolumn{4}{|c|}{ Hydroxurinuts } & \\
\hline & & & & & Mechound & $\begin{array}{l}\text { Aces. } \\
\text { aldenide }\end{array}$ & E.thannat & $c_{1}$ & $c_{3}$ & $c_{1}$. & $c$ & $l_{3}$ \\
\hline \multirow{4}{*}{ 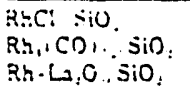 } & 53.3 & Eij & $(. .79$ & $+10^{\cdots}$ & 0.1 & - & 0.1 & 25 & -.0 & 33 & 3.3 & - \\
\hline & +123 & 52 & 1.1 & 0.30 & 0.1 & +.3 & $5+$ & 13 & 12 & 1.2 & - & - \\
\hline & 623 & $4(x)$ & 1.09 & 0.18 & S.t & 1.9 & 26.4 & $33 . .5$ & $9 . \dot{0}$ & 10.1 & 0.5 & 3.1 \\
\hline & 773 & $3 \div 0$ & 2.44 & 0.42 & 6.4 & 2.1 & $34 . i$ & 33.0 & n.t & 9.0 & 5.5 & J.: \\
\hline \multirow[t]{2}{*}{ 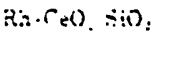 } & $(i) 3$ & $:(n)$ & 1.9 & 0.4 .7 & 3.0 & 11.9 & 4.0 & 29.5 & 7.0 & 3.0 & 4.7 & $1 . ;$ \\
\hline & - & 2100 & 2.4 & $0 . j \tilde{0}$ & $\because .0$ & $0 . \overline{1}$ & $4+4.3$ & 20.5 & 5.0 & 8.6 & 4.4 & 1.3 \\
\hline \multirow[t]{2}{*}{ Rh-P:..O., SiO: } & $\hat{n} \geq 3$ & 3110 & 1.1 & $0.2:$ & 3.9 & 2.3 & 45.6 & 24.7 & 3.4 & 8.0 & 6.1 & $2 \because$ \\
\hline & -:נs & 3100 & 3.0 & $0 . i 2$ & 2.4 & 11.8 & +7.7 & 32.1 & b.. & 6.0 & 2.2 & 1.: \\
\hline \multirow[t]{2}{*}{$\mathrm{Rh}-\mathrm{Nd}$ :O.isio } & 6.23 & 300 & 2.5 & 0.30 & $3 .:$ & 1.2 & 24.2 & 33.6 & 12.5 & 13.0 & 3.0 & 3.5 \\
\hline & נד & 290 & 2.1 & 0.31 & 6.4 & 2.0 & 29.4 & 32.4 & $9 . i$ & 10.2 & 6.3 & 3.: \\
\hline Rh-Sm.0., SiO, & 523 & 270 & +.1 & 0.48 & 1.0 & $r$ & $2: 3.4$ & 36.3 & 11.2 & 13.6 & 9.9 & 4.: \\
\hline
\end{tabular}

"Luading: thuditm 2.0 wt.Te. REO t.j ur. ̃र in all catalyses.

- Ethanol yreld $=\frac{\text { TOF } \times \text { seiectwity oi E:OH!? }}{\text { lGi }}$ 


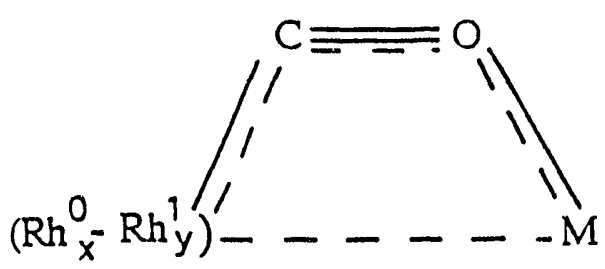

However, they supported Kiennemann's mechanism for alcohol formation.

The effect of alkali metal promoters was examined over $\mathrm{Rh} / \mathrm{SiO}_{2}$ catalysts by Kip, et.al. (1987). Basically, their results are consistent with the general effects of alkali metal promoters over the other HAS catalysts. The alkali decreases overall activity, but increases oxygenate selectivity, as shown in Table 18. However, the difference in alkali effect on $\mathrm{Rh}$ versus other HAS catalysts is that the increase in oxygenate selectivity is almost entirely due to increased methanol selectivity, not increased $\mathrm{C}_{2}+$ oxygenate selectivity. Note also that hydrogenation appears suppressed upon alkali addition, shown by the increase in $C_{4}=/ C_{4}$ ratio.

The last observation for the $R h$ based catalysts is that these catalysts do not demonstrate any water-gas shift activity since there is no $\mathrm{CO}_{2}$ present in the reported product streams. This is advantageous for carbon selectivity, since $\mathrm{CO}_{2}$ is not competing with hydrocarbon or oxygenate products for the feed carbon. However, if water generation from alcohol synthesis blocks active catalyst sites, although no one has reported this, then the lack of water-gas-shift could be detrimental. 
TABLE 18

(Kip, 1987)

\section{Hydrogenation of Carbon Monoxide over $1.5 \mathrm{wt} \% \mathrm{Rh} / \mathrm{Al}_{2} \mathrm{O}_{3}$ Catalysts Promoted with Alkali, Using an Alkali/Rh Ratio of 1.0}

In situ reduction at $723 \mathrm{~K}$. Reaction conditions: $328 \mathrm{~K}, 4.0 \mathrm{MPa}$. GHSV $=400 \mathrm{O}: \mathrm{I}^{\text {in }} \mathrm{h}$ '. $\mathrm{H} / \mathrm{CO}=3.0$.

\begin{tabular}{|c|c|c|c|c|c|}
\hline & $\mathrm{Rh} /$. & $\mathrm{Rh} / \mathrm{Li}$ & $\mathrm{Rh} / \mathrm{Na}_{\mathbf{a}}$ & $\mathrm{Rh} / \mathrm{K}$ & lhic, \\
\hline$(0) / R h^{*}$ & 1.85 & 1.60 & 1.52 & 1.47 & $1 .+1$ \\
\hline irt." & 4.1 & 3.3 & 2.7 & $2 !$ & 1.9 \\
\hline \multicolumn{6}{|l|}{ Siel. $(.9)^{r}$} \\
\hline $1 \because 1 ;$ & 59.5 & 54.8 & 51.0 & 49.9 & +2.8 \\
\hline$\because$ & 8.3 & 3.3 & 6.2 & 4.2 & 4.6 \\
\hline$\because \cap \mathrm{H}^{\prime}$ & 6.3 & 12.5 & 17.0 & 20.9 & 26.3 \\
\hline f:.11xy & 22.4 & 25.6 & 33.6 & 22.5 & 21.1 \\
\hline (ixuset." & 32.2 & 39.9 & +2.9 & 45.9 & $\$ S .1$ \\
\hline$\left({ }^{\circ}=\mathrm{C}_{1}\right.$ & 0.53 & 0.23 & 0.24 & 0.17 & 1.09 \\
\hline firrmation rategr & & & & \\
\hline$\therefore, O H$ & 0.25 & 0.41 & 0.46 & 0.ts & 0.51 \\
\hline i.nxy & 0.93 & 0.83 & 0.64 & 0.18 & 0.40 \\
\hline $1 . \mathrm{H}$ & 2.9 & 2.0 & 1.6 & 1.2 & 0.9 \\
\hline ("1) disen." & 3.4 & 2.4 & 2.0 & 1.4 & 1.2 \\
\hline ' $\cap$ non diswo.' & 0.76 & 0.87 & 0.69 & 0.72 & $1) . \overline{1}$ \\
\hline lishers" & 1.4 & 1.3 & 0.3 & 0.5 & 0.4 \\
\hline "lihỵdration" & 2.4 & 2.1 & 1.2 & 0.9 & 1.1 \\
\hline \multicolumn{6}{|c|}{ 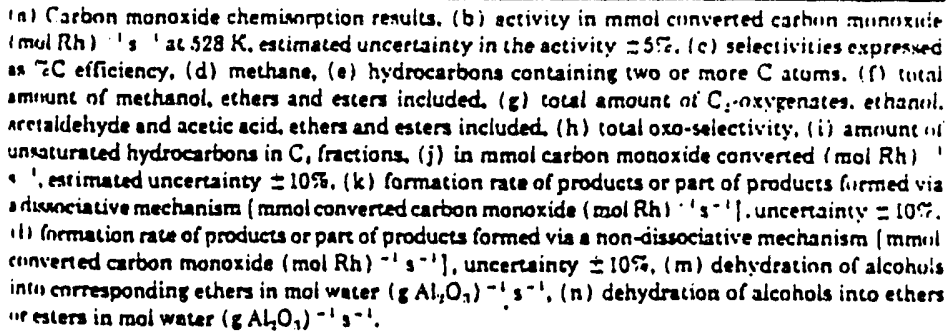 } \\
\hline
\end{tabular}




\section{HAS Catalvst Summary}

The preceding catalyst review was intended as a general overview of the higher alcohol synthesis catalysts currently under investigation. Álihough a direct comparison between catalysts is difficult due to differences in operating conditions, synthesis gas composition, reactor design, and even the manner in which data is reported, some general conclusions can be made.

- The modified methanol catalysts produce primarily methanol, $>50$ carbon atom \%, and isobutanol or 2-methyl-1-propanol. The alcohol product distribution does not follow the Schuiz-Flory distribution, and hydrocarbons are not a major product.

- The Mo based and the Group VIII metal HAS catalysts typically produce a Schulz-Flory distribution of both hydrocarbons and alcohols, with alcohol selectivity ranging from 30 to 60 carbon atom \%. The exception includes the Rh catalysts, which typically produce large amounts of ethanol. The remaining products are essentially hydrocarbons.

- The water-gas-shift reaction is rapid over the modified methanol catalysts, the Mo-based catalysts, and the copper-containing Co catalysts.

- The role of alkali metal promoters are similar over all the HAS catalysts, with the alkali promoting higher alcohol selectivity, but of ten decreasing catalyst productivity as well. The effectiveness of promoters generally followed the elemental electronegativity order with Cs being most effective and $\mathrm{Na}$ the least.

- None of the catalyst systems presented approach thermodynamic equilibrium for higher alcohol synthesis, indicating that there is plenty of room for improvement before thermodynamic constraints are encountered. 


\section{Novelty of Slurry Reactors}

Essentially all of the catalyst productivity and product selectivity data presented thus far were taken using fixed-bed reactors. However, for higher alcohol synthesis, these reactors are not necessarily the best suited for obtaining optimum catalyst performance. An alternative to the fixedbed reactor design is a stirred autoclave reactor or siurry reactor which has two major advantages over the fixed-bed. First, the stirred autoclave has superior heat transfer characteristics. In the stirred autoclave, the catalyst is suspended in a liquid medium and the reactant gas is sparged through this slunry mixture. The slurry is well agitated, so the reactor approaches ideal mixing, behaving as a continuous stirred tank reactor (CSTR). Since higher alcohol production from hydrogen and carbon monoxide is highly exothermic, heat transfer from the catalyst surface is critical to prevent localized "hot spots" which can lead to thermal deactivation of the catalyst and may lead to poor alcohol selectivity. To avoid this problem, fixed-bed reactors often must limit conversion of feed gas, or dilute the feed with an inert stream. However, the liquid medium in the stirred autoclave absorbs the heat generated by the reaction, and since the reactor is backmixed, the entire reactor approaches isothermal conditions at the desired reaction temperature. Therefore, higher conversions can be tolerated in the slurry reactor, allowing for higher "one pass" conversions, reducing costly recycle. Also, the suspended catalysts do not experience intense thermal deactivation despite the higher conversions.

Second, smaller particle sizes $(>50 \mathrm{~m})$ can be tolerated in a slurry reactor than in a fixed bed. The slurry liquid helps retain the catalyst in the reactcr, but if the catalyst does blow out, the catalyst will most likely entrain with any slurry that has also blown out of the reactor. The slurry with catalyst can easily be separated from the exit gases and recycled back to the reactor. Fixedbed reactors have no provision for catalyst recycle. If the catalyst attrits and leaves the reactor, it cannot be replaced. Therefore, fixed bed reactors require larger particle sizes (actual size depends on the gas flowrate) to prevent particle attrition. Also, as another plus for catalyst recycle in the slurry reactor, catalyst may be added and purged to maintain high activity in the reactor.

Due to this tolerance for small catalyst particles, catalyst pelletizing is not required for a slumy 
reactor, possibly yielding greater catalyst activity for the same catalyst weight. The slurry reactors are especially useful for small particle sizes, such as catalyst powders and Raney type catalysts. Roberts, et.al. (1985) have successfully used 1 to $10 \mu \mathrm{Cu} / \mathrm{ZnO}$ catalyst particles in a slurry reactor for methanol synthesis from $\mathrm{CO}$ and $\mathrm{H}_{2}$. This process, called LPMEOH ${ }^{\circledR}$ or Liquid Phase Methanol Process, has been demonstrated both on a laboratory scale with 0.3 to 2 liter stirred autoclaves, to a full process development unit manufacturing up to 13 tons/day of methanol using a slurry reactor design. (Studer, et.al., 1989) This work has demonstrated both the industrial and laboratory applicability of a slurty reactor system for alcohol synthesis from syngas.

Finally, a slurry reactor is ideal for laboratory kinetic studies since it approaches constant conditions, i.e. no temperature, pressure, or concentration gradients exist in the reactor. This design allows for direct measurement of a kinetic rate, unlike the fixed bed reactors which behave as plug-flow reactors which have pressure, temperature, and reactant concentration gradients. Each catalyst particle in a fixed bed does not experience the same reaction conditions which complicates the rate calculations.

Despite these advantages, a major challenge for the slurry reactor is to find a suitable liquid medium for the catalyst and reaction under consideration. The liquid must be inert and stable at reaction conditions. Air Products has successfully used a light mineral oil consisting of $100 \%$ paraffins for their liquid phase methanol process (LPMEOH ${ }^{\circledR}$ ) mentioned earlier.

The stirred autoclave reactor offers distinct advantages over the fixed bed reactor, fully utilizing catalyst performance with potentially higher per pass feed gas conversion and prolonged catalyst life due to lowered thermal deactivation. Also, use of catalyst powders and direct kinetic rate measurement in a slurry process benefits even the laboratory scale reactor systems. Therefore, for higher alcohol synthesis, a stirred autoclave reactor appears as a superior choice to fixed bed design.

Note: LPMEOH is a registered trademark of Chem Systems, Inc. 


\section{RESEARCH PROPOSAL}

\section{Overview}

Higher, i.e. $\mathrm{C}_{2}+$, alcohols are desired as gasoline additives, feedstocks for producing ethers and as alternative fuels for automobiles. In all cases, the backbone branching of an alcohol improves octane rating, which is essential for good engine performance. These types of branched, higher alcohols are the desired products for a process converting synthesis gas, a $\mathrm{CO}$ and $\mathrm{H}_{2}$ mixture, often generated from coal gasification. Based on this premise, promoted $\mathrm{ZnCr}$ oxide catalysts appear to be as one of the best avenues for further investigation. The reasons for this direction are:

- Branched butanols (2-methyl-1-propanol) are the primary $\mathrm{C}_{2}+$ products over these catalysts. The product distribution also does not obey a Schulz-Flory distribution, so methanol and ethanol are not necessarily the major alcohol products.

- Of all the HAS catalysts discussed, the $\mathrm{ZnCr}$ oxides are among the most selective for $\mathrm{C}_{2}+$ alcohols, not just $\mathrm{C}_{z}+$ oxygenates.

- $\mathrm{ZnCr}$ oxides are excellent water-gas-shift catalysts, with the reaction approaching equilibrium under HAS conditions. This can encourage product formation by eliminating competition for active sites between adsorbed water and $\mathrm{CO}$ or $\mathrm{H}_{2}$. However, $\mathrm{CO}_{2}$ is a large consumer of available carbon for alcohol synthesis, but this is offset if the feed gas consists of low $\mathrm{H}_{2} / \mathrm{CO}$ ratio.

- The $\mathrm{ZnCr}$ oxides are excellent candidates for methanol recycle, since under HAS conditions, the methanol synthesis approaches equilibrium. Therefore, no net formation of methanol can be achieved, yielding primarily $\mathrm{C}_{2}+$ products.

- The promoted $\mathrm{Cu} / \mathrm{ZnO}$ catalysts have been extensively investigated, and methanol remains the predominant product despite improvements. Also, $\mathrm{Cu} / \mathrm{ZnO}$ catalysts demonstrate relatively rapid deactivation at higher temperatures. 
- The $\mathrm{ZnCr}$ oxide catalysts have never been studied in a stirred autoclave system, which offers particular advantages since these catalysts operate at higher temperatures.

- The optimum levels of Cs promotion and the effect of operating variables, such as temperature, pressure, $\mathrm{CO} / \mathrm{H}_{2}$ ratio, and gas houriy space velority, have not been well defined in the literature.

Despite these reasons for further investigation, one of the biggest challenges is to find a high boiling liquid for autoclave operation since $\mathrm{HAS}$ for $\mathrm{ZnCr}$ oxides normally occurs from $350^{\circ} \mathrm{C}$ to $405^{\circ} \mathrm{C}$, well above the $275^{\circ} \mathrm{C}$ normal boiling point of the autoclave liquid from the Liquid Phase MeOH Process of Air Products. The liquid must also be inert under the reaction conditions under consideration. Air Products recommended using a 100\% parrafinic (alkane) mineral oil for any autoclave use, since unsaturated hydrocarbon oils were found to lower catalyst activity. Possibilities include two mineral oils from Penreco, a division of Penzoil, with normal boiling points above $425^{\circ} \mathrm{C}$.

An outline of the steps necessary to fully investigate the $\mathrm{ZnCr}$ oxide $\mathrm{HAS}$ catalysts are listed below. A detailed discussion of each phase follows in the Materials and Methods section.

- Construct stirred autoclave system with appropriate analytical system.

- Run a blank run with no catalyst in the stirred autoclave, but all other parameters normal.

- Test autoclave system with BASF $\mathrm{C} w \mathrm{ZnO}$ methanol catalysts, compare results with Air Products data on identical runs.

- Test probable suspension liquids for high temperature service in autoclave unit.

- Ensure reactor is a CSTR using tracer studies.

- Ensure that no mass transfer limitations exist in the reactor.

- Establish baseline with commercial ZnCrO methanol catalysts in a stirred autoclave.

- Determine effect of methanol recycle on product distribution.

Once this investigation is complete, a natural extension is to replace the $\mathrm{Cr}$ in the $\mathrm{ZnCr}$ oxide catalyst with Mo and W, both in the same elemental triad with $\mathrm{Cr}$. Mo has already been shown as an active $\mathrm{HAS}$ catalyst, both on $\mathrm{SiO}_{2}$ support and in the $\mathrm{MoS}_{2}$ form. The $\mathrm{Zn}$ encourages chain 
growth as shown earlier by Tronconi, et.al. (1987). Combining these two could encourage activity, and hopefully selectivity, especially if a promoter is added. Another catalyst, investigated by Tronconi, et.al. (1989) and Cristiani (1990), which demonstrates relatively high activity and selectivity for $\mathrm{C}_{2^{+}}$alcohols is a $\mathrm{MnCrO}$ catalyst. This is not available commercially, so catalyst synthesis would be required.

The three catalyst combinations, $\mathrm{ZnMo}, \mathrm{ZnW}$, and $\mathrm{MnCr}$ oxides will be tested in the stirred autoclave system. However, if none of the three indicate any comparable activity and/or selectivity toward higher alcohols as compared with other HAS catalysts, then an investigation of the effects of $\mathrm{Cs}$ promotion on the $\mathrm{ZnCr}$ oxide methanol catalysts will be executed. A continuing research plan is shown as a logic flow diagram in Figure 38 for clarification, with detailed discussion following in the Materials and Methods section. 
Figure 38. Continuing research plan with $\mathrm{ZnMo}, \mathrm{ZnW}$, and $\mathrm{MnCr}$ oxide catalysts and with alternite path.

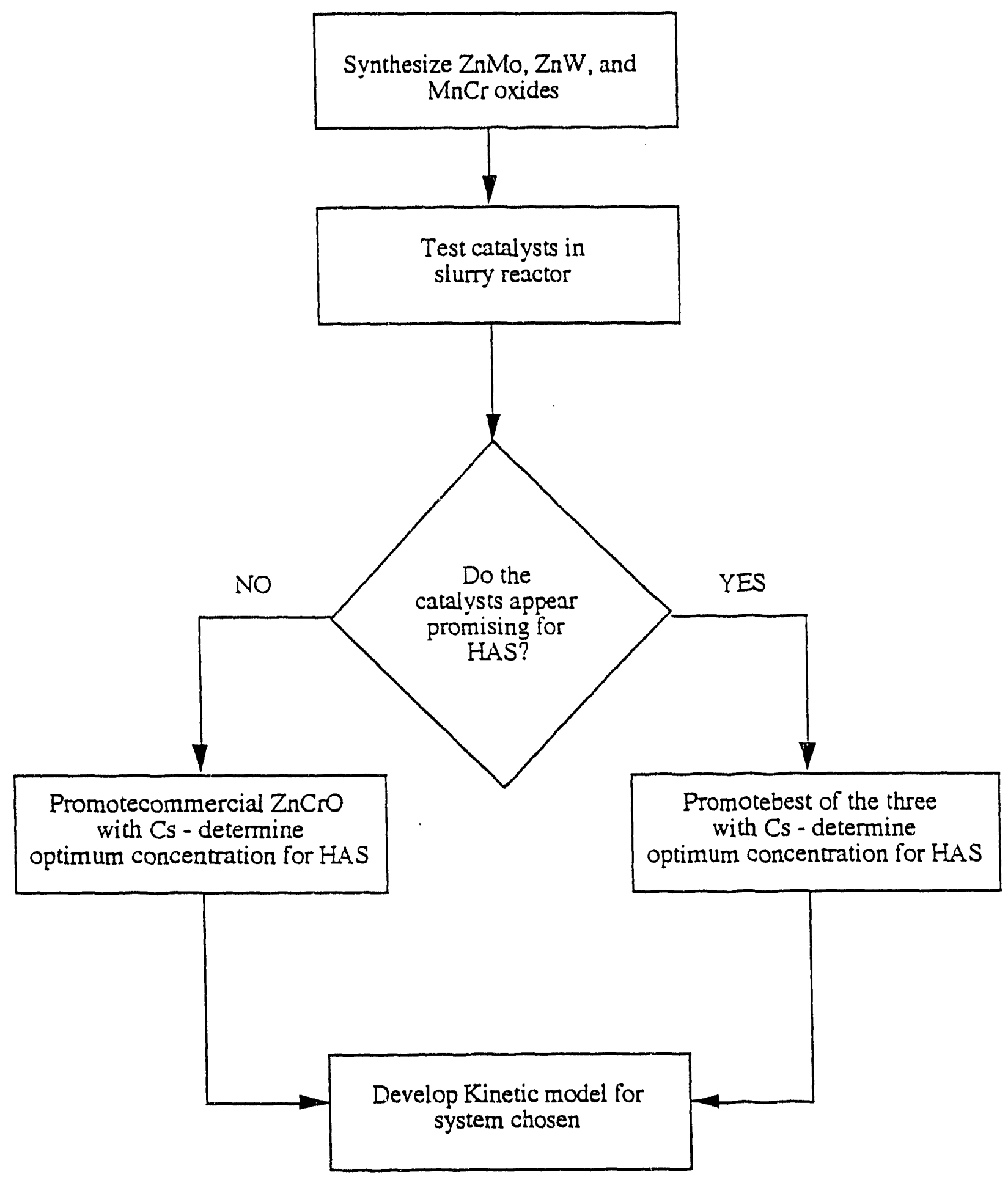




\section{Materials and Methods}

\section{Stirred Autoclave System}

A simplified diagram of the stirred autoclave system is shown in Figure 39. Basically the system is designed to deliver synthesis gas composed of $\mathrm{CO}, \mathrm{H}_{2}$ and $\mathrm{CO}_{2}$ in the desired ratio, flowrates, and pressure to the stirred autoclave reactor. In the reactor, the synthesis gas is mixed with the suspended catalyst powder in the liquid mineral oil medium, and a reaction occurs. The products, including unreacted $\mathrm{CO}$ and $\mathrm{H}_{2}$, flow out of the reactor to the analytical system for analysis via gas chromatography. A mass balance can be performed via flow measurement with the wet test meter combined with the results from the gas chromatograph. This system is rated to 5000 psig maximum pressure and $450^{\circ} \mathrm{C}$ maximum temperature. Therefore, all components are constructed of 316 stainless steel. The entire process is enclosed in a "walk-in" hood where the hood is a small ventilated room. The air changeover rate is approximately one per minute, or 60 per hour, well above most hood standards. The process design is similar to those used at Air Products for methanol and mixed alcohols research, and also to that used by Huff and Satterfield (1982) in Fischer-Tropsch synthesis work. The discussion that follows gives an indepth description of the process.

The components of synthesis gas, $\mathrm{CO}, \mathrm{H}_{2}$ and $\mathrm{CO}_{2}$, if desired, are fed from a gas cylirder storage house adjacent to, but outside Riddick Hall to minimize possible exposure to toxic $\mathrm{CO}$ and flammable $\mathrm{H}_{2}$ gas. The $\mathrm{CO}$ and $\mathrm{CO}_{2}$ gases pass through traps containing activated carbon to trap moisture and hydrocarbon impurities. The CO subsequently passes through a carbonyl trap which contains alumina pellets heated to a minimum of $300^{\circ} \mathrm{C}$. Any iron or nickel carbonyls should decompose on the alumina surface, leaving behind pure nickel or iron. This trap is placed before the synthesis gas is made, since iron and nickel are excellent methanation catalysts in the presence of $\mathrm{CO}$ and $\mathrm{H}_{2}$. The gas ratios and flows are controlled by Brooks $5850 \mathrm{E}$ Mass flow controllers, so that the proper sy/nthesis gas is created. The synthesis gas mixture is compressed to reactor pressure with a Haskel air-driven gas compressor, after which the gases pass into the reactor. 


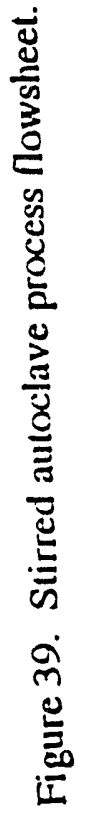
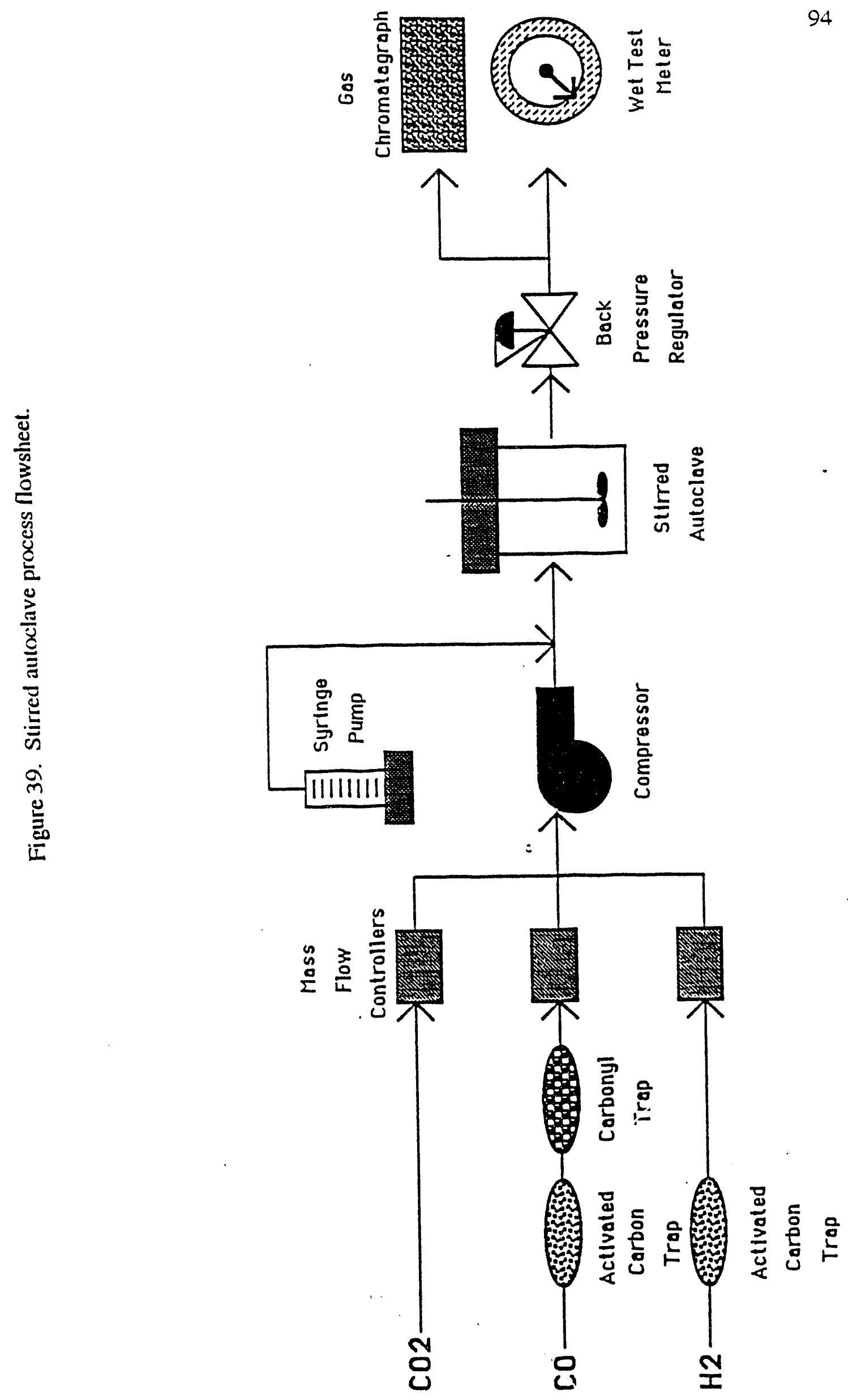
The heart of this process is the stirred autoclave reactor, manufactured by Autoclave Engineers. The reactor, as shown in Figure 40, has a $300 \mathrm{cc}$ capacity, with an internal cooling loop for water cooling in emergencies only. The reactor contains two baffles for optimum mixing, and the stirrer is an Dispersimax 6 bladed turbine type impeller by Autoclave Engineers for optimum mixing of gas and liquid. The stirring shaft is hollow, and has a hole above the liquid level to draw in gas while the agitator is in motion, and send the gas out through the impeller, again to maximize gas/liquid/catalyst contacting. Air Products' experience with the $300 \mathrm{cc}$ autoclave for methanol synthesis demonstrated the this impeller is adequate for catalyst dispersion and mixing.

The product gases leave the reactor through heat traced lines, to ensure no products condense before reaching the analytical system. The gases first pass through the gas/liquid separator, which should trap any mineral oil droplets that are carried out of the reactor. Beyond that, the gases flow through the back pressure regulator, which controls the reactor pressure. Then the gases are sent either to the gas chromatograph or the wet test meter for compositional or flow rate analysis. After both devices, the exiting vapors pass through a condensate trap to drain most of the condensing alcohol products and water. These are not heat traced to encourage condensation in the trap. The remaining gases vent into the hood exit duct. The condensates are collected for waste disposal through Life Safety.

This equipment has already been installed in Room 303 Riddick Hall, and all safety features have been tested. The process is currently in operation with the blank runs discussed later.

\section{Autoclave Analytical System}

The process gases can be sampled from three locations, the synthesis gas feed line to the compressor, the reactor feed line after the syringe pump injection, and the reactor exit stream. These gases are analyzed using a Perkin-Elmer Autosystem gas chromatograph with thermal conductivity (TCD) and flame ionization (FID) detectors with helium carrier gas used for each. The permanent gases, $\mathrm{CO}, \mathrm{CO}_{2}, \mathrm{H}_{2}, \mathrm{~N}_{2}$ and even $\mathrm{CH}_{4}$ are separated via a Molsieve $5 \mathrm{~A}$ capillary column which is connected to the TCD. The alcohols and hydrocarbons are separated with a 
Figure 40. Stirred autoclave reactor.

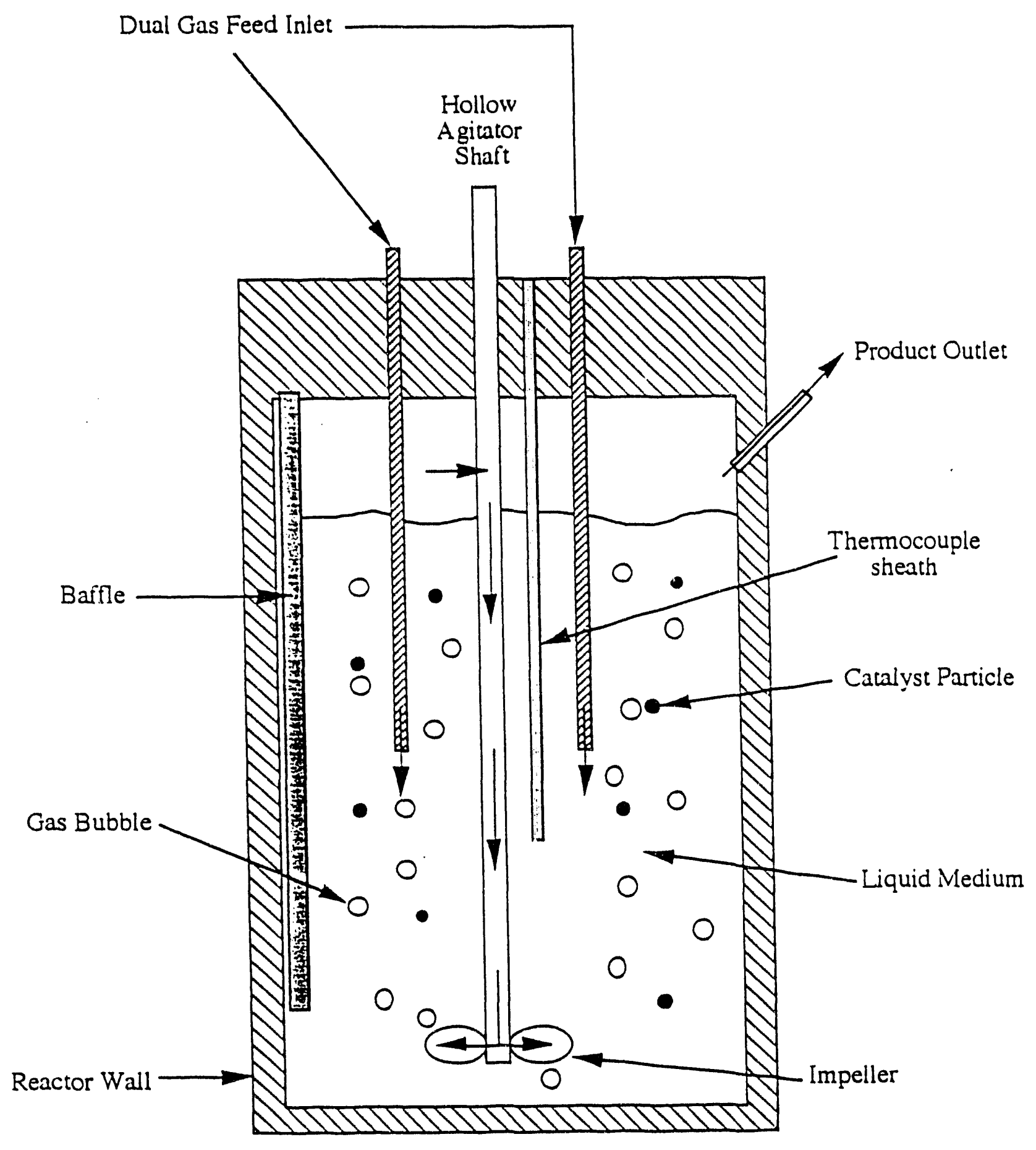


Poroplot Q capillary column which is connected to the FID. Water is measured by the TCD, but water saturates the Moisieve 5A, so the column is backflushed through another Poroplot Q column, also connected to the TCD. Process samples can be taken on-line with a gas sampling valve equipped with two $2 \mu \mathrm{L}$ sample loops.

The gas chromatographic data is recorded and stored by Turbochrom 3, a PE Nelson software package which runs on a IBM 386 personal computer or equivalent. The sof tware allows for automated sampling and identification of peaks and the sample composition, as long as standards have been stored in the software database.

The reactor gas exit flow can be measured with a Precision Scientific Wet Test Meter, which can measure up to 600 liters per hour. The meter is filled with mineral oil instead of water, since the reactor exit gas must be heated above $100^{\circ} \mathrm{C}$ to prevent water and other product condensation. Also, using mineral oil reduces the vapor pressure correction in the measured gas flowrate.

\section{Catalyst Characterization}

The following characterization procedures will be conducted on both freshly reduced catalysts, and on catalysts after an autoclave run is complete.

- BET surface area

- Pore volume measurement using $\mathrm{Hg}$ and He method

- Particle size distribution via electron micrographs

- Elemental analysis using atomic adsorption Hydrogen chemisorption to determine number of "active" sites is not applicable on the $\mathrm{Cu}$ or $\mathrm{Zn}$ systems. Duprez, et.al. (1990) used $\mathrm{N}_{2} \mathrm{O}$ decomposition for determining surface $\mathrm{Cu}$ sites assuming a stoichiometry of $1: 2$ for $\mathrm{N}_{2} \mathrm{O}: \mathrm{Cu}_{\text {s. }}$. No procedure was listed in the literature to determine the number of "active" sites for $\mathrm{ZnO}$ or $\mathrm{ZnCr}$ oxide catalysts. Other catalyst characterization methods that have been reported in the literature for the $\mathrm{Zn}$ oxide systems and could occasionally be used for surface characterization:

- X-ray Diffraction (XRD) to determine the crystalline phases present on the catalyst surface 
- X-ray Photoelectron Spectroscopy (XPS) can determine surface composition

- Scanning electron microscope (SEM) for surface characteristics

\section{Blank Runs}

Blank runs are conducted occasionally to ensure that the process equipment shows no catalytic activity. The main product expected is methane, since nickel and iron are good methanation catalysts. The blank runs are executed with the system at the desired operating pressure, temperature, $\mathrm{CO} / \mathrm{H}_{2}$ feed ratio and flowrates. The autoclave reactor is not charged with catalyst, but the light mineral oil liquid is present in the reactor. These runs usually last about 48 hours after reaching steady-state conditions. Initial runs on the autoclave system indicate that no methane is being formed, so the equipment appears to be catalytically inert. However, some process changes have been made since these runs, so another blank run is needed.

\section{Process Verification}

As a "shakedown" of the stirred autoclave process, a series of catalytic runs with a commercial $\mathrm{Cu} / \mathrm{ZnO}$ methanol catalyst will be done and the results compared with those generated at Air Products under exactly the same operating conditions. These runs will test the accuracy of the operating procedures, the mass balance procedures, and the analytical procedures. The low pressure methanol catalyst which will be used is the BASF S3-86 Cu/ZnO/alumina catalyst. The elemental composition is not given for the catalyst, so elemental analysis is needed. The catalyst will be reduced in the slurry reactor as outlined in an Air Products patent (Brown, 1989). The reduction procedure is fairly complicated, so it is attached in Appendix A for review.

The conditions for the series of runs are listed in Tables 19 and 20. 
TABLE 19

Operating Conditions for BASF Methanol Catalyst Runs

$\begin{array}{ccccc}\text { Run \# } & \text { Feed Gas } & \begin{array}{c}\text { Pressure } \\ (\text { psig })\end{array} & \begin{array}{c}\text { Temperature } \\ \left({ }^{\circ} \mathrm{C}\right)\end{array} & \begin{array}{c}\text { GHSV } \\ (\text { sl } / \mathrm{kg} \text {-hr })\end{array} \\ 1 & \text { Texaco } & 750 & 250 & 5000 \\ 2 & \text { Texaco } & 750 & 250 & 10000 \\ 3 & \text { Shell } & 750 & 250 & 5000 \\ 4 & \text { Shell } & 850 & 300 & 5000 \\ 5 & \text { Texaco } & 2500 & 250 & 16500 \\ 6 & \text { Shell } & 2500 & 300 & 5000\end{array}$

TABLE 20

Composition of Synthesis Feed Gases

$\begin{array}{ccc}\text { Component } & \text { Shell } & \text { Texaco } \\ \mathrm{H}_{2} & 30 \% & 35 \% \\ \mathrm{CO} & 66 \% & 51 \% \\ \mathrm{CO}_{2} & 2 \% & 13 \% \\ \text { Inerts }\left(\mathrm{N}_{2}\right) & 2 \% & 1 \%\end{array}$

The first three runs are typical methanol synthesis runs, but run 4 is a mixed alcohols synthesis run. Air Products has extensive data on those four runs. Runs 5 and 6 test the high pressure capability of the autoclave system, but Air Products has no data for these experiments. These runs will help extend Air Products' model.

For all of these runs, the slurry medium will be Drakeol 10B from Penreco, a light mineral oil containing a mixture of about half paraffins and half naphthenes. Air Products has used this oil for most of its autoclave research work, including both laboratory and pilot scale processes. The initial boiling point for the oil at $1 \mathrm{~atm}$ is $267^{\circ} \mathrm{C}$, so for the $300^{\circ} \mathrm{C}$ runs, some of the lighter paraffins may vaporize, although the reactor pressure will be at 850 psig or above. Therefore, the oil will be allowed to stabilize (let the low boilers vaporize) before the run can begin. Also, to 
minimize mass transfer limitations, Air Products uses a stirrer speed of $1200 \mathrm{rpm}$, but this may not hold for this autoclave system. A study examining mass transfer limitations is necessary for the autoclave system to ensure intrinsic reaction kinetics.

\section{High Temperature Autoclave Liquid}

A higher boiling autoclave liquid than the Drakeol $10 \mathrm{~B}$ is required for testing the $\mathrm{ZnCr}$ oxide catalysts, since they run typically at $350^{\circ} \mathrm{C}$ to $420^{\circ} \mathrm{C}$. Strong possibilities are Drakeol 25 and Drakeol SF, mineral oils by Penreco with normal boiling points of $425^{\circ} \mathrm{C}$ and $450^{\circ} \mathrm{C}$ respectively. Penreco has agreed to provide boiling curves for these oils, which will give more detailed composition information. These oils will be tested in the autoclave system by charging the reactor with the oil, running a nitrogen purge at the reaction pressure (1000 to $1500 \mathrm{psig}$ ), and heating the reactor to $425^{\circ} \mathrm{C}$. If any of the oil vaporizes out of the reactor, and subsequently condenses in the gas/liquid separator after the reactor, this oil will be collected and analyzed for composition. If these oils are suitable, then no oil should vaporize and be collected, provided the reactor is not overfilled.

The mineral oil must also be chemically inert under reaction conditions. The most likely reaction for the mineral oil is hydrocracking to light hydrocarbons. The oil will be tested under operating conditions with catalyst in the reactor, but with only hydrogen in the feed stream. Since no $\mathrm{CO}$ is present, if hydrocarbons appear in the reactor exit stream, they could only be generated from the oil. If no hydrocarbons are detected during this test, then the oil will be assumed chemically inert. 


\section{Determining Intrinsic Kinetic Conditions}

Mass transfer in slurry reactor systems can be broken down into four basic resistances:

1. mass transfer from gas bubble to bulk liquid,

2. mass transfer from bulk liquid to catalyst surface, and

3. diffusion into a catalyst pore, and

4. intrinsic reaction kinetics

All of these must be considered when determining whether a reactor with a certain catalyst has any mass transfer limitations, i.e. ensuring that intrinsic kinetics exist in the system. A procedure for determining which of the basic resistances is rate limiting is discussed generally below. A detailed discussion is contained in Mass Transfer in Heterogeneous Cacalvsis, by Satterfield (1970).

1. Run a series of experiments with different catalyst loadings, holding all other variables constant. Plot $1 / R_{a}$ (apparent reaction rate in $\mathrm{mol} / \mathrm{vol} /$ time) vs. $1 / \mathrm{m}$ where $\mathrm{m}$ is catalyst loading. The intercept gives the resistance to gas absorption by the liquid phase and the slope gives the other combined resistances. From this, one can determine whether gas absorption is controlling.

2. If gas absorption appears to be a major resistance (large intercept), increase the agitator speed which increases bubble surface area by creating smaller bubbles, thereby increasing mass transfer.

3. If gas absorption is not controlling, first assume that mass tranisfer to the catalyst surface is controlling, so that the concentration of reactant on the surface is essentially zero. Then estimate the mass transfer coefficient using mass transfer correlation for suspended solid particles based on Stoke's Law. This requires the particle diameter, the viscosity of the liquid and the density of both the particle and the liquid. If this number is comparable to the slope of the $1 / \mathrm{Ra}$ vs. $1 / \mathrm{m}$ curve, then this is the controlling step. If not, then pore diffusion and reaction is controlling.

4. The effectiveness factor, $\eta$, which is the ratio of actual reaction rate to the rate observed if no mass transfer limitations exist, can be estimated from overall rate data, the particle size 
characteristics, and the effective diffusion coefficient. The effective diffusion coefficient can be estimated from empirical correlations. The rate data is obtained from the experimental runs, and the particle size characteristics are determined after the experimental runs. The effectiveness factor can then be determined. If $\eta$ is much less than one, major mass transfer limitations exist within the pore, but if $\eta$ approaches one, then mass transfer effects in the pore are negligible.

\section{Reactor Tracer Studies}

Reactor tracer studies must be conducted to ensure that the stirred autoclave behaves as a continuous stirred tank reactor (CSTR). The tracer will be introduced either as a step function or as a pulse input. The tracer concentration exiting the reactor will be recorded with respect to time. The profile of tracer concentration versus time will then be compared to the profile generated by an ideal CSTR reactor.

The actual instrumentation for this study will most likely be an online thermal conductivity detector (TCD) continuously monitoring all or part of the reactor exit stream. This arrangement allows any gas to be used as the tracer, as long as its thermal conductivity is significantly different from the base reactor feed. For example, if helium is selected as a reference stream for the TCD, then a constant flow of helium could be sent through the reactor, providing the baseline. Then

another gas, such as nitrogen or carbon monoxide, could be used as the tracer gas. TCD analysis would also be needed to characterize the inputs.

Another alternative is using radicactive argon as the tracer gas, and continuously monitoring the radiation levels in the reactor exit stream. This method is obviously not as desirable since radioactive elements are involved.

\section{ZnCrO Methanol Catalyst Baseline}

One or two commercial $\mathrm{ZnCr}$ oxide methanol catalysts will be tested in the autoclave system to establish a baseline of products and catalyst activity. These results will be compared with literature 
data obtained from fixed-bed reactors to determine any advantages of stirred autoclave reactor process. The catalyst will probably contain a $3 / 1 \mathrm{Zn}$ to $\mathrm{Cr}$ atomic ratio, meaning that both a $\mathrm{ZnCr}_{2} \mathrm{O}_{4}$ spinel phase and a pure $\mathrm{ZnO}$ phase will be present. The catalyst will be reduced per manufacturer's recommendation. The reaction conditions for the methanol synthesis will be $350^{\circ} \mathrm{C}$ and around 1500 psig with a $\mathrm{H}_{2} / \mathrm{CO}$ feed ratio of 0.5 to 2 .

\section{Recycle Tests}

Simulate methanol recycle so that no net formation of methanol is allowed, yielding only higher alcohols and other products. Liquid methanol will be injected into the reactor feed stream using an Isco high pressure syringe pump. The liquid/gas mixture will pass through a vaporizer, set at $200^{\circ} \mathrm{C}$, to ensure that all of the methanol is vaporized before entering the reactor. The products and material balance will be performed as usual, except that the liquid methanol injection rate must be included.

$\mathrm{ZnMo}, \mathrm{ZnW}$, and $\mathrm{MnCr}$ oxide Catalysts

After a baseline has been established with the $\mathrm{ZnCr}$ oxide methanol catalyst in the slurry reactor, the next step is to synthesize $\mathrm{ZnMo}$ and $\mathrm{ZnW}$ oxide catalysts, basically replacing the $\mathrm{Cr}$ with Mo and W since Mo has been shown as a potential HAS catalyst, although W has not been studied. These catalysts will be tested in the stirred autoclave system. The potential problem with these catalysts are the low surface areas for a pure ZnMo oxide and possibly for a $\mathrm{ZnW}$ oxide. As mentioned earlier, a $\mathrm{MnCr}$ oxide catalyst will also be synthesized and tested in the stirred autoclave. If the results for any of these catalysts are not encouraging, then the fallback investigation will be the study of $\mathrm{Cs}$ promotion on the $\mathrm{ZnCr}$ oxide methanol catalyst for higher alcohol synthesis. If the $\mathrm{MnCr}, \mathrm{ZnMo}$, or $\mathrm{ZnW}$ oxides appear promising, then the next logical step is promotion with Cs, since it has been shown as the most effective alkali promoter for $\mathrm{Cu} / \mathrm{ZnO}$ and $\mathrm{ZnCr}$ oxide catalysts to encourage HAS. A series of promotion tests would be conducted to determine oprimum Cs concentration. 


\section{Alternate Research - Cs Promotion on $\mathrm{ZnCrO}$ Catalysts}

The same commercial catalyst will then be promoted with Cs by incipient wet impregnation technique with a cesium formate $(\mathrm{Cs} \mathrm{COOH})$ solution. The final desired concentrations of $\mathrm{Cs}$ will range from 3 to 20 weight percent. These catalysts will subsequently be tested in the autoclave reactor for higher alcohol synthesis activity. Based on Tronconi's findings, the operating pressure will be lowered to only $1000 \mathrm{psig}$, and the temperature raised to $410^{\circ} \mathrm{C}$. The product distribution and catalyst productivity will be carefully measured to determine an optimum Cs concentration for HAS in this system.

\section{Kinetic Model}

A kinetic model, based upon the data gathered from the previous experiments with the autoclave system, and with the surface mechanisms proposed both in the literature, and those which come from this work, will be constructed to explain the product distribution and composition generated over the $\mathrm{ZnM}$ oxide and $\mathrm{ZnW}$ oxide catalysts. This model will likely draw heavily upon a kinetic model proposed by Smith, et.al. (1991) for a Cs promoted Cu/ZnO HAS catalyst. 


\section{BIBLIOGRAPHY}

Aspen Technology (1988). Aspen Plus Users Guide. Chapter 5.

Anderson, R. B., J. Feldman, et al. (1952). "Synthesis of Alcohols by Hydrogenation of Carbon Monoxide." Industrial and Engineering Chemistry 44(10): 2418-2424.

Bond, G. C. and D. G. Richards (1986). "Lanthanum Oxide Promoted Rhodium/Titania and Rhodium-Platinum/Titania Catalysts for Alcohol Formation from Synthesis Gas." Applied Catalysis 28: 303-319.

Brooks, K. (1992). "EPA's Clean Air Guidelines to Pump Up Gasoline Prices." Raleigh News \& Observer June 27.

Brown, W. R., R.B. Moore, and J. Klosek (1988). "Coproduction of Electricity and Methanol." Eighth EPRI Coal Gasification Contractors' Conference.

Brown, D. M., T. H. Hsiung, et.al. (1989). "In-situ Activation of $\mathrm{CuO} / \mathrm{ZnO} / \mathrm{Al}_{2} \mathrm{O}_{3}$ Catalysts in the Liquid Phase." U.S. Patent \# 4,801,574

Calverley, E. M. and R. B. Anderson (1987). "Synthesis of Higher Alcohols over Promoted Copper Catalysts." Journal of Catalysis 104: 43440.

Calverley, E. M. and K. J. Smith (1991). "Effects of carbon dioxide, methanol, and alkali promoter concentration on the higher alcohol synthesis over a copper/zinc oxide/chromium sesquioxide catalyst." J. Catal. 130(2): 616-26.

Chen, Y. W. (1986). "High alcohol synthesis from carbon monoxide and hydrogen on ruthenium catalysts." Can. J. Chem. Eng. 64(5): 875-8.

Courty, P., D. Durand, et al. (1982). "C1-C6 Alcohols from Synthesis Gas on Copper-Cobalt Catalysts." Journal of Molecular Catalysis 17: 241-254.

Cristiani, C., P. Forzatti, et al. (1989). "Structural Investigation on a Spinel-related $\mathrm{Zn} / \mathrm{Cr}=1$ Mixed-oxide System." J. Chem. Soc.,. Faraday Trans., I. 85(4): 895-906.

Cristiani, C., M. Bellotto, et al. (1990). "Synthesis of Alcohois from Carbon Oxides and Hydrogen - XVIII. Preparation Chemistry, Phase Transformations and Catalytic Behaviour of Unpromoted Mn-Cr-O Systems in the Synthesis of Alcohols from Carbon Monoxide and Hydrogen." Applied Catalysis 56: 253-269.

Di Conca, M., F. Trifiro, et al. (1984). "The Zinc-Chromium Oxide Potassium Promoted Catalysts for Methanol and Higher Alcohols Synthesis." 8th Int. Congr. Catal. 2: II-173 to II183.

Duprez, D., Z. Ferhat-Hamida, et al. (1990). "Surface Mobility and Reactivity of Oxygen Species on a Copper-Zinc Catalyst in Methanol Synthesis." Joumal of Catalysis 124: 1-11.

Elliott D. J. and F. Pennella (1986). "Effects of transition metals on copper/zinc oxide alcohol synthesis catalysts." J. Catal. 102(2): 464-6. 


\section{BIBLIOGRAPHY}

(continued)

Elliott, D. J. (1988). "Higher alcohol synthesis over cupric oxide/zunc oxide catalysts: relationship between methanol and higher alcohol syntheses." J. Catal. 111(2): 445-9.

Elliott, D. J. and F. Pennella (1988). "Mechanism of Ethanol Formation from Synthesis Gas over CuO/ZnO/A12O3." Journal of Catalysis 114: 90-99.

Elliott, D. J. and F. Pennella (1989). "The Formation of Ketones in the Presence of Carbon Monoxide over CuO/ZnO/A12O3." Journal of Catalysis 119: 359-367.

Forzatti, P., C. Cristiani, et al. (1988). "Synthesis of Alcohols from Carbon Oxides and Hydrogen - VII. Preparation, Activation, and Catalytic Behavior of a ZnMnCrK-Oxide Catalyst." Journal of Catalysis 111: 120-135.

Forzatti, P., E. Tronconi, et al. (1991). "Higher Alcohol Synthesis." Catal. Rev. - Sci. Eng. $33(1 \& 2): 109-168$.

Gysling, H. J., J. R. Monnier, et al. (1987). "Synthesis, Characterization, and Catalyti Activity of LaRhO3." Journal of Catalysis 103: 407-418.

Ichikawa, M. (1978). "Catalysis by Supported Metal Crystallites from Carbonyl Clusters. I. Catalytic Methanol Synthesis under Mild Conditions over Supported Rhodium, Platinum, and Iridium Crystallites Prepared from Rh, Pt, and Ir Carbonyl Cluster Compounds Deposited on $\mathrm{ZnO}$ and MgO." Bulletin of the Chemical Society of Japan 51(8): 2268-2272.

Inoue, M., T. Miyake, et al. (1984). "Alcohol synthesis from syngas on ruthenium-based composite catalysts." Appl. Catal. 11(1): 103-16.

Inoue, M., T. Miyake, et al. (1987). "Direct alcohol synthesis from syngas on rutheniummolybdenum- sodium/alumina catalysts: effects of physical properties of alumina supports." Appl. Catal. 29(2): 285-94.

Inoue, M., T. Miyake, et al. (1988). "Direct Synthesis of Alcohols from Syngas on Ru-Mio$\mathrm{Na2O}$ A12O3 Catalysts: Synergistic Effect of Ru and Mo." Journal of Molecular Catalysis 45: 111-126.

Kiennemann, A., R. Breault, et al. (1987). "Ethanol Promotion by the Addition of Cerium to Rhodium-Silica Catalysis.” J. Chem. Soc., Faraday Trars. I. 83: 2119-2128.

Kip, B. J., E. G. F. Hermans, et al. (1987). "Carbon Monoxide Hydrogenation over AlkaliPromoted Rh/A12O3, Rh/V2O3/SiO2 and Rh/ThO2/SiO2." Applied Catalysis 35: 141-152.

Kirk-Othmer (1981) Encyclopedia of Chemical Technology. John Wiley \& Sons. New York.

Lietti, L., E. Tronconi, et al. (1988). "TPSR Study of 1-Butanol over a Zn-Cr-O Catalyst." Journal of Molecular Catalysis 44: 201-206.

Lietti, L., D. Botta, et al. (1988). "Synthesis of Alcohols from Carbon Oxides and Hydrogen VIII. A Temperature-Programmed Reaction Study of n-Butanal on a Zn-Cr-O Catalyst." Journal of Catalysis 111: 360-373. 


\section{BIBLIOGRAPHY}

(continued)

Lietti, L., E. Tronconi, et al. (1989). "Synthesis of alcohols from carbon oxides and hydrogen. XIX. Surface properties of zinc oxide based catalysts and related mechanistic features of the higher alcohol synthesis by FT-IR spectroscopy and TPSR." J. Mol. Catal. 55(1-3): 43-54.

Lietti, L., P. Forzatti, et al. (1990). "Temperature-programmed reaction of C4 oxygenates on unpromoted and potassium-promoted zinc chromium oxide in relation to the mechanism of the higher alcohol synthesis." J. Catal. 12,6(2): 401-20.

Mawson, S., M. S. McCutchen, et.al. (1992). "The Thermodynamics of Higher Alcohol Synthesis." Accepted for publication by Energy \& Fuels.

Moore, R. B. , W.R. Brown, et.al. (1989). "Coproduction of Power and methanol via CGCC and LPMeOH." World Methanol Conference.

Morgan, G. T., D. V. N. Hardy, et al. (1932). "Transactions and Communications." Journal of the Society of Chemical Industry Jan. 8: 1T-TT.

Muramatsu, A., T. Tatsumi, et al. (1987). "Mixed alcohol synthesis from carbon monoxide and hydrogen by use of potassium chloride-promoted molybdenum/silica catalysts." Bull. Chem. Soc. Jpn. 60(9): 3157-61.

Murchison, C. B., M. M. Conway, et al. (1988). "Mlixed Alcohols from Syngas Over Moly Catalysts." Proc. 9th Int. Congr. on Catalysis 2: 626-633.

Natta, G., U. Colombo and I. Pasquon (1957). "Direct Catalytic Synthesis of Higher Alcohols from Carbon Monoxide and Hydrogen." in Catalysis V. Reinhold Publishing. New York.

Nonneman, L. E. Y., A. G. T. M. Bastein, et al. (1990). "Role of Impurities in the Enhancement of C2-oxygenates Activity - Supported Rhodium Catalysts." Applied Catalysis 62: 123-128.

Nunan, J. G., C. E. Bogdan, et al. (1988). "Methanol and $C_{2}$ Oxygenate Synthesis over Cesium Doped $\mathrm{Cu} / \mathrm{ZnO}$ And $\mathrm{Cu} / \mathrm{ZnO} / \mathrm{Al}_{2} \mathrm{O}_{3}$ Catalysts: A Study of Selectivity and ${ }^{13} \mathrm{C}$ Incorporation Pattems." Journal of Catalysis 113: 410-433.

Nunan, J. G., C. E. Bogdan, et al. (1989). "Higher Alcohol and Oxygenate Synthesis over Cesium-Doped Cu/ZnO Catalysts." Journal of Catalysis 116: 195-221.

Nunan, J. G., R. G. Herman, et al. (1989). "Higher Alcohol and Oxygenate Synthesis over $\mathrm{Cs} / \mathrm{Cu} / \mathrm{ZnO} / \mathrm{M} 2 \mathrm{O} 3(\mathrm{M}=\mathrm{Al}, \mathrm{Cr})$ Catalysts." Journal of Catalysis 116: 222-229.

Riva, A., F. Trifiro, et al. (1987). "The promoting role of chromium and potassium in catalysts for high-pressure and high-temperature methanol and higher-alcohol synthesis." J. Chem. Soc., Faraday Trans 83(7): 2213-25.

Roberts, G. W., N. K. Dicciani, and J. Klosek (1985). "The LPMeOH Process - An Efficient Route to Methanol from Coal." Conference on Coal Gasification and Synthetic Fuels for Power Generation. San Francisco, CA. April 14-18. 


\section{BIBLIOGRAPHY}

(continued)

Roberts, G. W., D. M. Brown, et al. (1991). "Thermal Deactivation of Methanol Synthesis Catalysts in a Slurry Reactor." Catalyst Deactivation 1991.351-358.

Satterfield, C. N. (1970). Mass Transfer in Heterogeneous Catalysis M.I.T. Press. Cambridge.

Sheffer, G. R. and T. S. King (1988). "Effect of Preparation Parameters on the Catalytic Nature of Potassium Promoted Cu-Cu-Cr Higher Alcohol Catalysts." Applied Catalysis 44: 153-164.

Sheffer, G. R., R. A. Jacobson, et al. (1989). "Chemical Nature of Alkali-Promoted CopperCobalt-Chromium Oxide Higher Alcohol Catalysts." Joumal of Catalysis 116: 95-107.

Smith, K. J. and R. B. Anderson (1983). "The higher alcohol synthesis over promoted copperizinc oxide catalysts." Can. J. Chem. Eng. 61(1): 40-5.

Snith, K. J., R. G. Herman, et al. (1990). "Kinetic modeling of higher alcohol synthesis over alkali-promoted copperizinc oxide and molybdenum sulfide catalysts." Chem. Eng. Sci. 45(8): $2639-46$.

Smith, K. J., C. W. Young, et al. (1991). "Development of a kinetic model for alcohol synthesis over a cesium-promoted copperizinc oxide catalyst." Ind. Eng. Chem. Res. 30(1): 61-71.

Studer, D. W., D. M. Brown, et.al. (1989). "Status of the Development of Methanol Synthesis by the LPMeOH Process." DOE Indirect Liquefaction Contractors' Review Meeting. Pittsburgh, PA. November 13-15.

Tatsumi, T., A. Muramatsu, et al. (1986). "Effects of molybdenum precursors on the activity of alkali-promoted molybdenum catalysts for alcohol synthesis from carbon monoxide-hydrogen." Polyhedron 5(1-2): 257-60.

Tatsumi, T., A. Muramatsu, et al. (1987). "Supported molybdenum catalysts for alcohol synthesis from carbon monoxide-hydrogen." Appl. Catal. 34(1-2): 77-88.

Tatsumi, T., A. Muramatsu, et al. (1988). "Active species and mechanism for mixed alcohol synthesis over silica-supported molybdenum catalysts." Stud. Surf. Sci. Catal. : 219-228.

Tatsumi, T., A. Muramatsu, et al. (1989). "Mechanistic study on the alcohol synthesis over molybdenum catalysts: addition of probe molecules to carbon monoxide-hydrogen." J. Catal. $115(2): 388-98$.

Tronconi, E. C. Cristiani, et al. (1987). "Synthesis of Alcohols from Carbon Oxides and Hydrogen - V. Catalytic Behaviour of Pure $\mathrm{Cr}, \mathrm{Zn}, \mathrm{Mn}$ Oxides Towards $\mathrm{CO} / \mathrm{H} 2$." Applied Catalysis 32: 285-292.

Tronconi, E, L. Lietti, et al. (1989). "Higher alcohol synthesis over alkali metal-promoted hightemperature methanol catalysts." Appl. Catal. 47(2): 317-33.

Tronconi, E., P. Forzatti, et al. (1990). "Investigation of the thermodynamic constraints in higher alcohol synthesis over cesium-promoted zinc-chromium-onde catalyst." J. Catal. 124(2): 376 90. 


\section{BIBLIOGRAPHY}

(continued)

Underwood, R. P. and A. 1. Bell (1986). "CO Hydrogenation over Rhodium supported on SiO2, L2203, Nd2O3 and Sm203." Applied Catalysis 21: 157-168.

Vedage, G. A., P. B. Himelfarb, et al. (1983). "Alkali-promoted copper-zinc oxide catalysts for low alcohol synthesis." ACS Symp. Ser. : 1261-1271.

Vedage, G. A., P. Himelfarb, et al. (1985). "Alkali-promoted copper/zinc oxide catalysts for low alcohol synthesis." ACS Symp. Series 279: 295-312.

Watson, P. R. and G. A. Somorjai (1982). "The Formation of Oxygen-Containing Organic Molecules by the Hydrogenation of Carbon Monoxide Using a Lanthanum Rhodate Catalyst." Journal of Catalysis 74: 282-295.

Wilson, T. P., P. H. Kasai, et al. (1981). "The State of Manganese Promoter in Rhodium-Silica Gel Catalysts." Journal of Catalysis 69: 193-2n1.

Youchang, X., B. M. Naasz, et al. (1986). "Alcohol Synthesis from CO and H2 over Molybdenum Sulfide. The Effect of Pressure and Promotion by Potassium Carbonate." Applied Catalysis 2.7: 233-241.

Yu-Hua, D., C. De-An, et al. (1987). "Promoter Action of Rare Earth Oxides in Rhodium/Silica Catalysts for the Conversion of Syngas to Ethanol." Applied Catalysis 35: 77-92. 
5) Mixed-technique $0.1 \% \mathrm{Mo} / 1 \% \mathrm{Rh} / \mathrm{Al}_{2} \mathrm{O}_{3}$ catalyst (Catalyst No. 5 in Table 1

Three grams of alumina, processed as described in Section 1 above, was used for the catalyst preparation. Rh was impregnated using a solution of $0.090 \mathrm{~g} \mathrm{Rh}\left(\mathrm{NO}_{3}\right)_{3}(34 \mathrm{wt} \% \mathrm{Rh}$ ) in $5 \mathrm{cc}$ distilled water and the incipient wetness technique. The catalyst was dried overnight at $100^{\circ} \mathrm{C}$, calcined at $500^{\circ} \mathrm{C}$ for $4 \mathrm{hr}$ in oxygen and evacuated at $500^{\circ} \mathrm{C}$ for $1 \mathrm{hr}$. It was then cooled to room temperature and heated again to $200^{\circ} \mathrm{C}$ in helium for $1 \mathrm{hr}$ and to $400^{\circ} \mathrm{C}$ in hydrogen for $1 \mathrm{hr}$. It was cooled to $50^{\circ} \mathrm{C}$, exposed to 0.078 $\mathrm{g} \mathrm{Mo}(\mathrm{CO})_{6}$ (i $\mathrm{i} \mathrm{cr}$ an intended Mo loading of $1 \mathrm{wt} . \%$ ) and heated at $30^{\circ} \mathrm{C}$ for 1 $\mathrm{hr}$. Helium was passed over the sample at $50^{\circ} \mathrm{C}$ for $1 \mathrm{hr}$. The catalyst was heated in $50 \mathrm{cc} / \mathrm{min} \mathrm{H} \in$ at $200^{\circ} \mathrm{C}$ for $1 \mathrm{hr}$ and at $400^{\circ} \mathrm{C}$ in $50 \mathrm{cc} / \mathrm{min} \mathrm{H}_{2}$ for 1 hr prior to reaction.

6) $1 \% \mathrm{~W} / 1 \% \mathrm{Rh} / \mathrm{Al}_{2} \mathrm{Q}_{3}$ catalyst (Catalyst No. 6 in Table 1)

This catalyst was prepared as described above except that $.06 \mathrm{gr}$. of $\mathrm{W}(\mathrm{CO})_{6}$ was used instead of $\mathrm{Mo}(\mathrm{CO})_{6}$. 
APPENDIX B

Catalyst Preparation Techniques

1) Salt-derived $1 \% \mathrm{Rh} / 3 \% \mathrm{Nb}^{-\mathrm{Al}_{2}} \mathrm{O}_{3}$ catalyst (Catalyst No. 2 in Table 1 )

A gamma alumina support with $100 \mathrm{~m}^{2} / \mathrm{g}$ surface area was obtained from Degussa. A thick paste of this material in water was prepared. The paste was dried overnight at $100^{\circ} \mathrm{C}$, ground and screened. The size range 0.0035 to 0.0098 was used for catalyst preparation. The screened powder was heated at $500^{\circ} \mathrm{C}$ in $\mathrm{O}_{2}$ for $4 \mathrm{hr}$ and in vacuum for $1 \mathrm{hr}$. Three grams of alumina were used ior the catalyst preparation. $\mathrm{Nb}$ was added to the $\mathrm{Al}_{2} \mathrm{O}_{3}$ using a solution of $0.647 \mathrm{~g} \mathrm{Nb}\left(\mathrm{HC}_{2} \mathrm{O}_{4}\right)_{7}(14.5 \mathrm{wt} \% \mathrm{Nb})$ in $5 \mathrm{cc}$ distilled water and the incipient wetness impregnation technique. The $\mathrm{Nb} / \mathrm{Al}_{2} \mathrm{O}_{3}$ catalyst was dried overnight at $100^{\circ} \mathrm{C}$, calcined at $500^{\circ} \mathrm{C}$ for $4 \mathrm{hr}$ in oxygen and evacuated at $500^{\circ} \mathrm{C}$ for $1 \mathrm{hr}$.

Rh was impregnated on $\mathrm{Nb} / \mathrm{Al}_{2} \mathrm{O}_{3}$ using a solution of $0.092 \mathrm{~g} \mathrm{Rh}\left(\mathrm{NO}_{3}\right)_{3}(34$ wt\% Rh) in $5 \mathrm{cc}$ distilled water and the incipient wetness technique. The $\mathrm{Rh} / \mathrm{Nb} / \mathrm{Al}_{2} \mathrm{O}_{3}$ catalyst was dried overnight at $100^{\circ} \mathrm{C}$, calcined at $500^{\circ} \mathrm{C}$ for 4 $\mathrm{hr}$ in oxygen and evacuated at $500^{\circ} \mathrm{C}$ for $1 \mathrm{hr}$.

2) Salt-derived $1 \% \mathrm{Rh} / \mathrm{Al}_{2} \mathrm{O}_{3}$ catalyst (Catalyst No. 1 in Table 1)

This catalyst was prepared as described above, except that the $\mathrm{Nb}$ addition step was omitted.

3) Cluster-derived $1 \% \mathrm{Rh} / 3 \% \mathrm{Nb} / \mathrm{Al}_{2} \mathrm{O}_{3}$ catalyst (Catalyst No. 4 in Table 1 )

$3 \% \mathrm{Nb} / \mathrm{Al}_{2} \mathrm{O}_{3}$ was prepared as described in Section 1 above. Hexane was dried by distilling it from a sodium-benzophenone mixture. Rh was added to $\mathrm{Nb} / \mathrm{Al}_{2} \mathrm{O}_{3}$ by stirring $0.057 \mathrm{~g} \mathrm{Rh}_{4}(\mathrm{CO})_{12}$ dissolved in $57 \mathrm{cc}$ dry hexane solution with $3.094 \mathrm{gr}$. Nb/Al $\mathrm{O}_{3}$ for $4 \mathrm{hr}$. The mixture was then fitered and the catalyst was washed with fresh dry hexane, dried under flowing nitrogen for 15 minutes and stored under nitrogen.

4) Cluster-derived $1 \% \mathrm{Rh} / \mathrm{Al}_{2} \mathrm{O}_{3}$ catalyst (Catalyst No. 3 in Table 1)

This catalyst was prepared as described in Section 3 above, except that the $\mathrm{Nb}$ addition step was omitted. 


\section{APPENDIX B \\ Catalyst Preparation Techniques}

1) Salt-derived $1 \% \mathrm{Rh} / 3 \% \mathrm{Nb} / \mathrm{Al}_{2} \mathrm{O}_{3}$ catalyst (Catalyst No. 2 in Table 1)

A gamma alumina support with $100 \mathrm{~m}^{2} / \mathrm{g}$ surface area was obtained from Degussa. A thick paste of this material in water was prepared. The paste was dried overright at $100^{\circ} \mathrm{C}$, ground and screened. The size range 0.0035 to 0.0098 was used for catalyst preparation. The screened powder was heated at $500^{\circ} \mathrm{C}$ in $\mathrm{O}_{2}$ for $4 \mathrm{hr}$ and in vacuum for $1 \mathrm{hr}$. Three grams of alumina were used for the catalyst preparation. $\mathrm{Nb}$ was added to the $\mathrm{Al}_{2} \mathrm{O}_{3}$ using a solution of $0.647 \mathrm{~g} \mathrm{Nb}\left(\mathrm{HC}_{2} \mathrm{O}_{4}\right)_{7}(14.5 \mathrm{wt} \% \mathrm{Nb})$ in $5 \mathrm{cc}$ distilled water and the incipient wetness impregnation technique. The $\mathrm{Nb} / \mathrm{Al}_{2} \mathrm{O}_{3}$ catalyst was dried overnight at $100^{\circ} \mathrm{C}$, calcined at $500^{\circ} \mathrm{C}$ for $4 \mathrm{hr}$ in oxygen and evacuated at $500^{\circ} \mathrm{C}$ for $1 \mathrm{hr}$.

Rh was impregnated on $\mathrm{Nb} / \mathrm{Al}_{2} \mathrm{O}_{3}$ using a solution of $0.092 \mathrm{~g} \mathrm{Rh}\left(\mathrm{NO}_{3}\right)_{3}$ (34 $w t \% \mathrm{Rh}$ ) in $5 \mathrm{cc}$ distilled water and the incipient wetness technique. The $\mathrm{Rh} / \mathrm{Nb} / \mathrm{Al}_{2} \mathrm{O}_{3}$ catalyst was dried overnight at $100^{\circ} \mathrm{C}$, calcined at $500^{\circ} \mathrm{C}$ for 4 $\mathrm{hr}$ in oxygen and evacuated at $500^{\circ} \mathrm{C}$ for $1 \mathrm{hr}$.

2) Salt-derived $1 \% \mathrm{Rh} / \mathrm{Al}_{2} \mathrm{O}_{3}$ catalyst (Catalyst No. 1 in Table 1 )

This catalyst was prepared as described above, except that the $\mathrm{Nb}$ addition step was omitted.

3) Cluster-derived $1 \% \mathrm{Rh} / 3 \% \mathrm{Nb} / \mathrm{Al}_{2} \mathrm{O}_{3}$ catalyst (Catalyst No. 4 in Table 1)

$3 \% \mathrm{Nb} / \mathrm{Al}_{2} \mathrm{O}_{3}$ was prepared as described in Section 1 above. Hexane was dried by distilling it from a sodium-benzophenone mixture. Rh was added to $\mathrm{Nb} / \mathrm{Al}_{2} \mathrm{O}_{3}$ by stirring $0.057 \mathrm{~g} \mathrm{Rh}_{4}(\mathrm{CO})_{12}$ dissolved in $57 \mathrm{cc}$ dry hexane solution with $3.094 \mathrm{gr}$. Nb/Al $2 \mathrm{O}_{3}$ for $4 \mathrm{hr}$. The mixture was then filtered and the catalyst was washed with fresh dry hexane, dried under flowing nitrogen for 15 minutes and stored under nitrogen. 
4) Cluster-derived $1 \% \mathrm{Rh} / \mathrm{Al}_{2} \mathrm{O}_{3}$ catalyst (Catalyst No. 3 in Table 1)

This catalyst was prepared as described in Section 3 above, except that the $\mathrm{Nb}$ addition step was omitted.

5) Mixed-technique $0.1 \% \mathrm{Mo} / 1 \% \mathrm{Rh} / \mathrm{Al}_{2} \mathrm{O}_{2}$ catalyst (Catalyst No. 5 in Table 1

Three grams of alumina, processed as described in Section 1 above, was used for the catalyst preparation. Rh was impregnated using a solution of $0.090 \mathrm{~g} \mathrm{Rh}\left(\mathrm{NO}_{3}\right)_{3}(34 \mathrm{wt} \% \mathrm{Rh}$ ) in $5 \mathrm{cc}$ distilled water and the incipient wetness technique. The catalyst was dried overnight at $100^{\circ} \mathrm{C}$, calcined at $500^{\circ} \mathrm{C}$ for $4 \mathrm{hr}$ in oxygen and evacuated at $500^{\circ} \mathrm{C}$ for $1 \mathrm{hr}$. It was then cooled to room temperature and heated again to $200^{\circ} \mathrm{C}$ in helium for $1 \mathrm{hr}$ and to $400^{\circ} \mathrm{C}$ in hydrogen for $1 \mathrm{hr}$. It was cooled to $50^{\circ} \mathrm{C}$, exposed to 0.078 $\mathrm{g} \mathrm{Mo}(\mathrm{CO})_{6}$ (for an intended Mo loading of $1 \mathrm{wt} . \%$ ) and heated at $30^{\circ} \mathrm{C}$ for 1 hr. Helium was passed over the sample at $50^{\circ} \mathrm{C}$ for $1 \mathrm{hr}$. The catalyst was reated in $50 \mathrm{cc} / \mathrm{min} \mathrm{He}$ at $200^{\circ} \mathrm{C}$ for $1 \mathrm{hr}$ and at $400^{\circ} \mathrm{C}$ in $50 \mathrm{cc} / \mathrm{min} \mathrm{H}_{2}$ for 1 hr prior to reaction.

6) $1 \% \mathrm{~W} / 1 \% \mathrm{Rh} / \mathrm{Al}_{2} \mathrm{O}_{3}$ catalyst (Catalyst No. 6 in Table 1)

This catalyst was prepared as described above except that $.06 \mathrm{gr}$. of $\mathrm{W}(\mathrm{CO})_{6}$ was used instead of $\mathrm{Mo}(\mathrm{CO})_{6}$. 

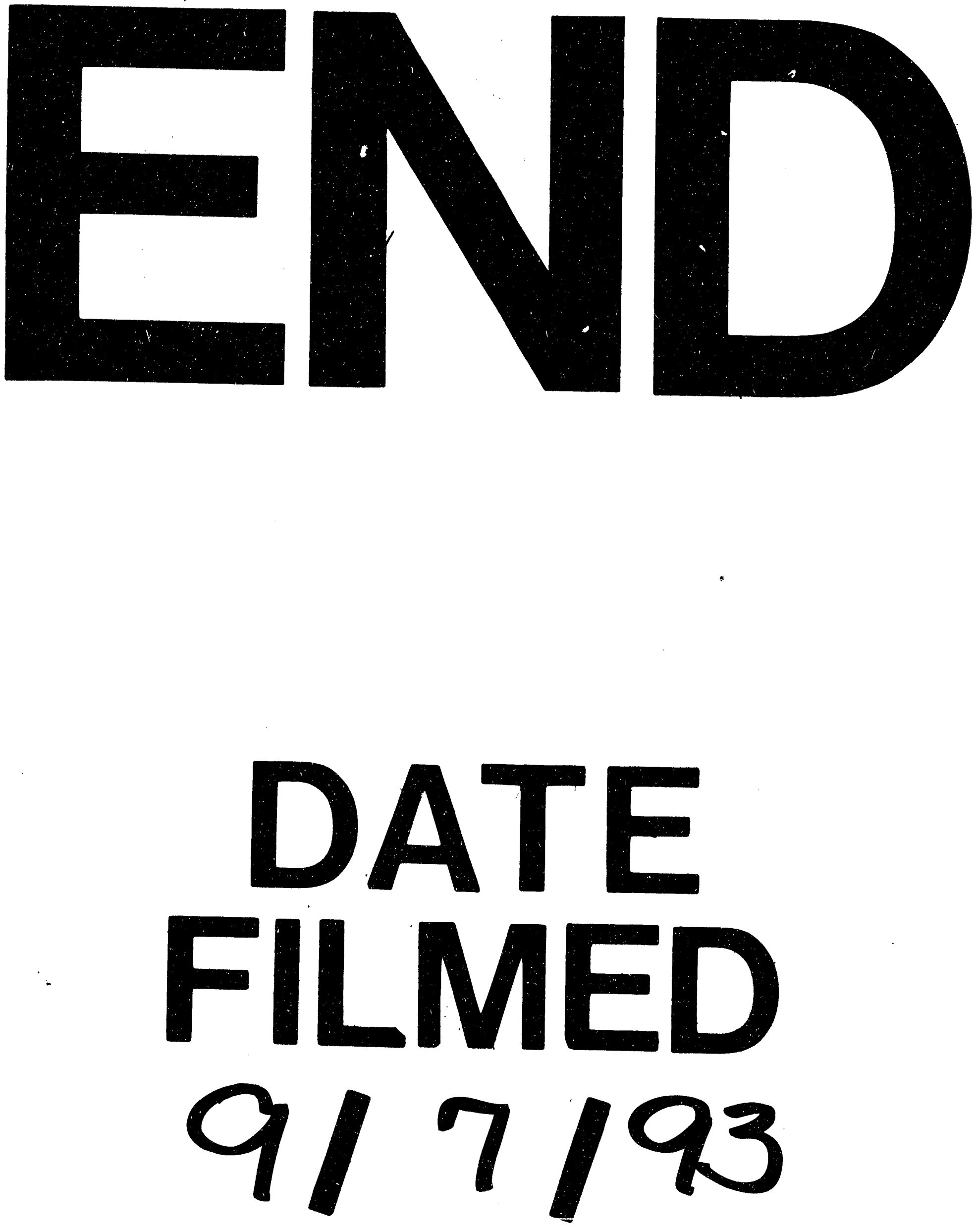
